

\section{DISCLAIMER}

This report was prepared as an account of work sponsored by an agency of the United States Government. Neither the United States Government nor any agency Thereof, nor any of their employees, makes any warranty, express or implied, or assumes any legal liability or responsibility for the accuracy, completeness, or usefulness of any information, apparatus, product, or process disclosed, or represents that its use would not infringe privately owned rights. Reference herein to any specific commercial product, process, or service by trade name, trademark, manufacturer, or otherwise does not necessarily constitute or imply its endorsement, recommendation, or favoring by the United States Government or any agency thereof. The views and opinions of authors expressed herein do not necessarily state or reflect those of the United States Government or any agency thereof. 


\section{DISCLAIMER}

Portions of this document may be illegible in electronic image products. Images are produced from the best available original document. 


\section{LEGAL NOTICE}

This report was prepared as an account of Government sponsored work. Neither the United States, nor the Commission, nor any person acting on behalf of the Commission:

A. Makes any warranty or representation, expressed or implied, with respect to the accuracy, completeness, or usefulness of the information contained in this report, or that the use of any information, apparatus, method, or process disclosed in this report may not infringe privately owned rights; or

B. Assumes any liabllities with respect to the use of, or for damages resulting from the use of any information, apparatus, method, or process disclosed in this report.

As used in the above, "person acting on behalf of the Commission" includes any employee or contractor of the Commisalon, or employee of such contractor, to the extent that such employee or contractor of the Commission, or employee of such contractor prepares, disseminates, or provides access to, any information pursuant to his employment or contract with the Commission, or his employment with such contractor.

Printed in USA. Price $\$ 3.00$. Available from the Clearinghouse for Federal Scientific and Technical Information, National Bureau of Standards

U. S. Department of Commerce, Springfield, Virginia 22151 
ANL-7099

Propulsion Systems and

Energy Conversion (TID-4500)

AEC Research and

Development Report

ARGONNE NATIONAL LABORATORY

CFIT PaICES

9700 South Cass Avenue

Argonne, Illinois 60439

Me $3.00 ; \mathrm{HN} 65$

STUDY OF REF LECTOR-BASED CONTROL OF

FAST NUCLEAR ROCKET REACTORS

by

K. K. Almenas

RELERSED ECE ARNOLNCEMENT

IN RUCLEST SCIENOE ABSTRACTS

Reactor Physics Division

Based on a thesis submitted to

Northwestern University

as partial fulfillment of the requirements for a

Master of Science degree

\section{LEGAL NOTICE}

This report was prepared as an account of Government sponsored
States, nor the Commission,

A. Makes any warranty or repry person acting on behalf of the work. Neither the United

racy, completeness, or usty or representation, expressed or of the Commission:

of any information, apparatus sess of the information contained in with respect to the accu

privately owned rights; or
B. Assumethod, or process disclosed in this report, or that the use

Be of Ansumes any liabilities with respect to thermation mot infringe

As used in the abovaratus, method, or process disclosed damages resulting from the ployee or contractor of the Corson acting on behalf of the commiss report.

such employee or contractor of the Con, or employee of such contracton" includes any em-

disseminates, or provides acces the Commission, or employee contractor, to the extent that

with the Commission, or hiccess to, any information pursuee of such contractor prepart that

May 1966

Whe commission, or his employment with such contractor.

Operated by The University of Chicago

under

Contract W-31-109-eng-38

with the

U. S. Atomic Energy Commission 
TABLE OF CONTENTS

Page

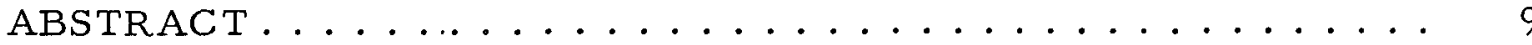

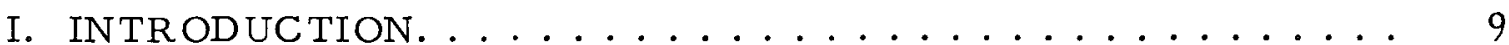

II. COMPARISON OF IDENTICAL REFLECTOR CONTROL-VANE

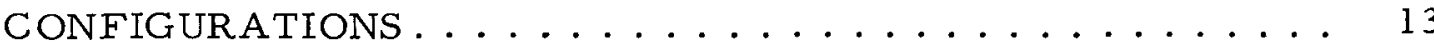

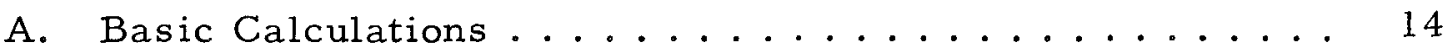

B. Energy-independent Control Parameters ......... 17

C. Energy Dependence of Parameters Determining Control

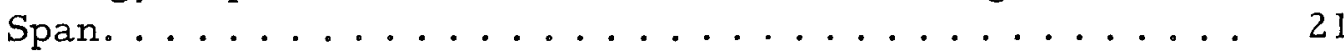

D. Correlation of Directly Calculable Control Parameters

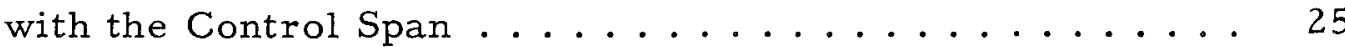

III. EVALUATION OF POISON-FREE REFLECTOR MATERIALS. . 30

A. Effect of Radial Reflector Volume on Conserved

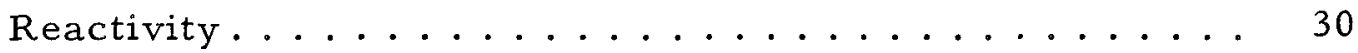

B. Effect of Radial Reflector Weight on Conserved

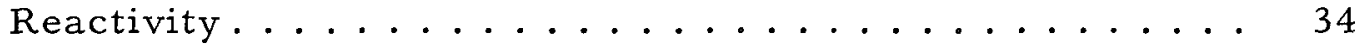

IV. OPTIMIZATION OF CONTROL MECHANISMS . . . . . . . 36

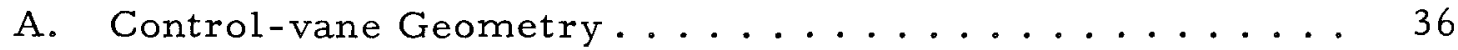

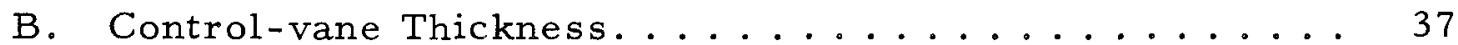

C. Control-vane Composition ............... 40

V. CONTROL-VANE HEATING . .............. 45

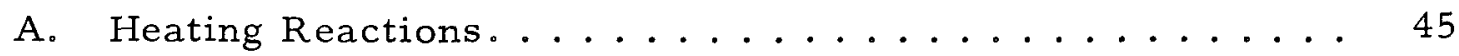

B. Influence of Heat-generation Rate on Vane Design . . . . . 45

C. Calculations of $(n, \alpha)$ Heating............... 49

D. Fast-neutron Heating ..................... 51

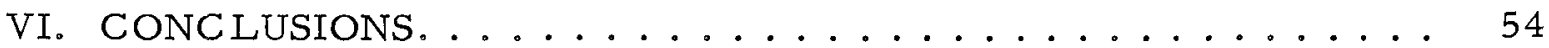

\section{APPENDICES}

A. Cross Sections Employed in Control Study and Correlation of Experimental and Calculated Results ..........

B. A FORTRAN Neutron-balance Code for the CDC-160A

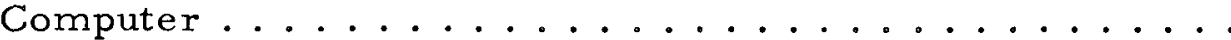


TABLE OF CONTENTS

$\underline{\text { Page }}$

C. A FORTRAN Code for Optimizing Control-vane Thickness Written for the CDC-160A Computer ...........

D. An Analytical Determination of Optimum Control-vane

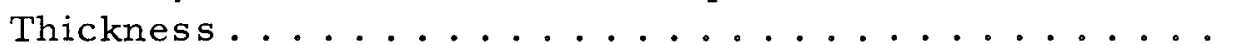

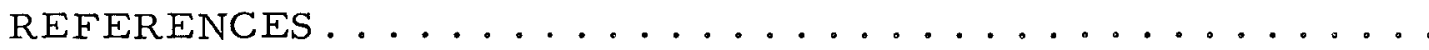




\section{LIST OF FIGURES}

No.

Title

Page

1. Control Span vs Change in Net Leakage ........... 26

2. Control Span vs Adjoint-flux-weighted Change in Net Leakage . 28

3. Control Span vs Neutron Absorption Fraction in Control Vane . 29

4. Critical Mass vs Reflector Thickness (of $\mathrm{Al}, \mathrm{Al}_{2} \mathrm{O}_{3}, \mathrm{Zr}$, and Depleted U) for a Constant-volume Core............

5. Critical Mass vs Reflector Thickness (of $\mathrm{Fe}, \mathrm{Ni}, \mathrm{Mo}$, and C) for a Constant-volume Core................

6. Critical Mass vs Radial Reflector Mass (for $\mathrm{Al}, \mathrm{Al}_{2} \mathrm{O}_{3}$, $\mathrm{Zr}$, and Depleted U) for a Constant-volume Core ........

7. Critical Mass vs Radial Reflector Mass (for Fe, Ni, Mo, and C) for a Constant-volume Core.............. 35

8. Schematic Representation of Control-vane Geometry . . . . 36

9. Reactivity Loss Produced by Control Vane at the OUT

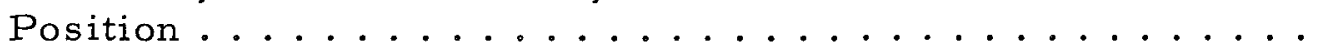

10. Control Span vs Control-vane Thickness for $\mathrm{Al}_{2} \mathrm{O}_{3}$-reflected

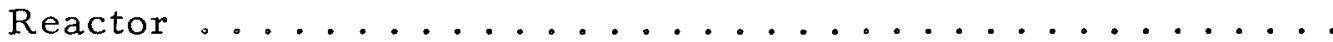

11. Control Span vs Control-vane Thickness for Aluminum-

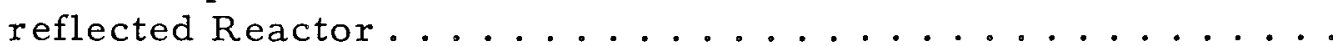

12. Control Span vs Control-vane Thickness for Nickel-reflected

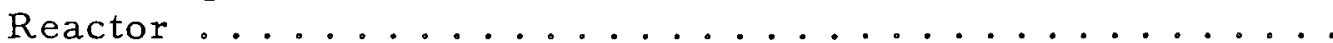

13. Control Span vs Control-vane Thickness for Beryllium-

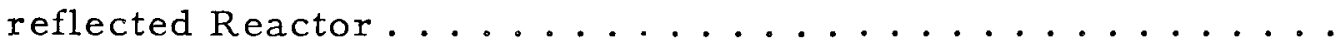

14. Control Span vs Control-vane Composition for $\mathrm{Al}_{2} \mathrm{O}_{3}$ -

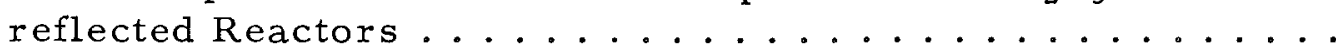

15. Control Span vs Control-vane Composition for Aluminum-

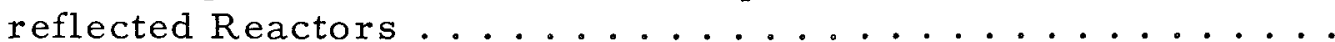

16. Control Span vs Control-vane Composition for Nickel-reflected

17. Relative Real and Adjoint Fluxes $4.2 \mathrm{~cm}$ from the CoreReflector Interface for $\mathrm{Al}$ and $\mathrm{Al}_{2} \mathrm{O}_{3}$ Reflectors .........

18. Relative Real and Adjoint Fluxes $4.2 \mathrm{~cm}$ from the CoreReflector Interface for $\mathrm{Ni}$ and $\mathrm{Fe}$ Reflectors . . . . . . . . . 42

19. Relative Real and Adjoint Fluxes $4.2 \mathrm{~cm}$ from the CoreReflector Interface for C Reflector.............. 


\section{LIST OF FIGURES}

No.

Title

$\underline{\text { Page }}$

20. Relative Real and Adjoint Fluxes in Aluminum Reflector $4.0 \mathrm{~cm}$ from Core-Reflector Interface . . . . . . . . . .

21. Relative Real and Adjoint Fluxes Inside Control Vane Located in $\mathrm{Al}_{2} \mathrm{O}_{3}$ and $\mathrm{Ni}$ Reflectors at the IN Position . . . . . 44

22. Power Distribution for 2-cm-thick Vane in Beryllium

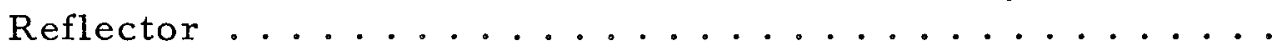

23. Power Distribution in Control Vanes of Beryllium Reflected

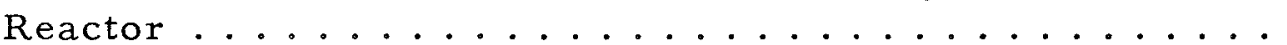

24. Power Distribution in Control Vanes of $\mathrm{Al}_{2} \mathrm{O}_{3}$-reflected

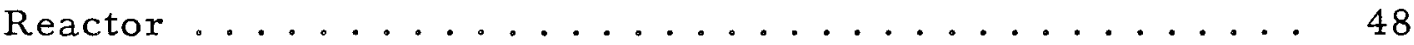

25. Fast-neutron Heating in Beryllium Reflector......... 52

A-1 Schematic Representation of EBR-II Boron Ring

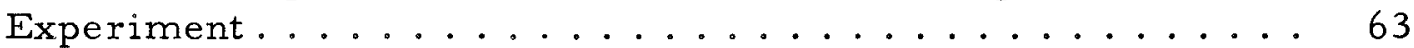

C-1 Diagram of Vane-optimization Code............ 74

D-1 Schematic Representation of Control Vane and Idealized Core Boundary....................... 80 


\section{LIST OF TAB LES}

No.

I. Energy-independent Control Parameters ......... 18

II. Leakage Neutrons for Five Reflector Compositions . . . . 21

III. Energy Distribution of Leakage Fraction into Boron-free

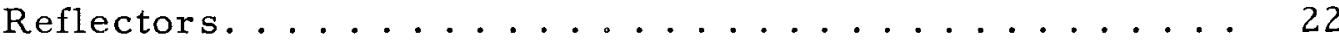

IV. Energy Distribution of the Increase in Leakage Produced by the Introduction of Boron-containing Control Vane

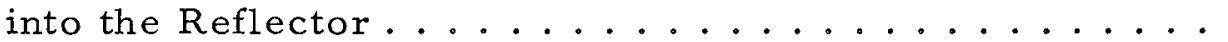

V. Energy Distribution of the Increase in Leakage Produced by the Introduction of $\mathrm{B}+\mathrm{H}$-containing Control Vane into

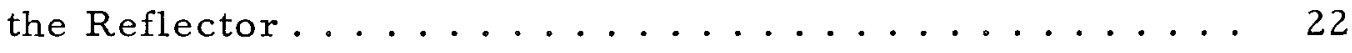

VI. Absorption Fraction in Boron Control Section ........ 23

VII. Absorption Fraction in $\mathrm{H}+\mathrm{B}$ Control Section . . . . . . 25

VIII. Critical Mass vs Radial Reflector Mass for a Constant-

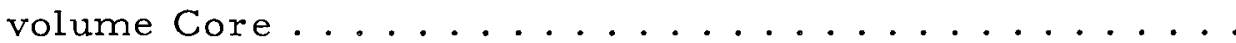

IX. Comparison of Poison Materials in Spectra of Various

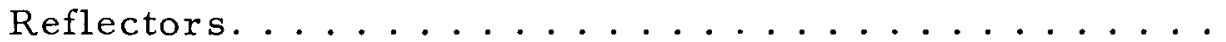

$\mathrm{X}$. Distribution of $(\mathrm{n}, \alpha)$ Reaction Rate in $1-\mathrm{cm}$ Control

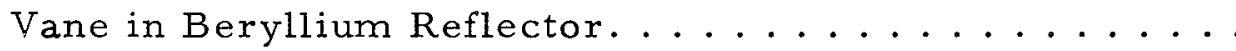

XI. Distribution of $(n, \alpha)$ Reaction Rate in 2-cm Control

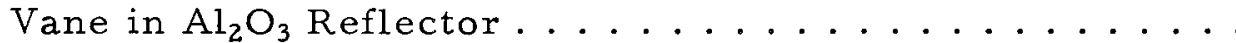

XII. Energy Transfer per Neutron Scattering and Absorption

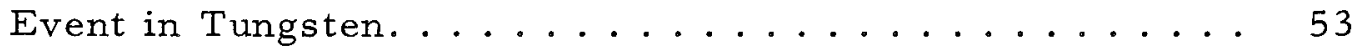

A-I. Cross Sections for Natural Tungsten ........... 57

A-II. Rhenium Cross Sections .............. 58

A-III. Averaged Rhenium Cross Sections $4.2 \mathrm{~cm}$ Inside Various

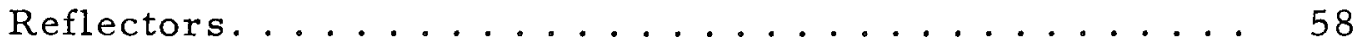

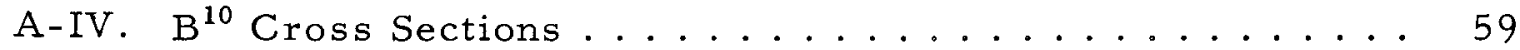

A-V. Averaged Cross Sections for Natural Boron $4.2 \mathrm{~cm}$ Inside Various Reflectors............... 59

A-VI. Fission-spectrum-averaged Cross Sections for Hydrogen . 61 A-VII. Several Measured and Calculated Properties of an Aluminum Reflector ................ 62

A-VIII. Reflector-located Boron Ring Problems . . . . . . . . 64 


\section{LIST OF TAB LES}

No.

Title

$\underline{\text { Page }}$

B-I. Test Problem for NEUTRON BALANCE Code . . . . . 66

B-II. Leakage Neutron Balances for $\mathrm{Al}_{2} \mathrm{O}_{3}$-reflected Reactor . . 67

B-III. Leakage Neutron Balances for Carbon-reflected Reactor. . 67

B-IV. Leakage Neutron Balances for Aluminum-reflected

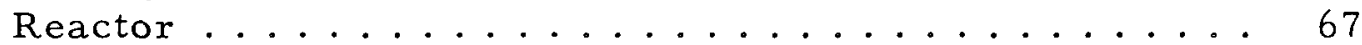

B-V. Leakage Neutron Balances for Iron-reflected Reactor. . . 68

B-VI. Leakage Neutron Balances for Nickel-reflected Reactor . . 68 


\title{
STUDY OF REFLECTOR-BASED CONTROL OF FAST NUCLEAR ROCKET REACTORS
}

by

K. K. Almenas

\begin{abstract}
A comparative evaluation of a variety of reflector and control materials suitable for use with fast-spectrum, highperformancecores was carried out. The evaluation focused primarily on the control potential of reflector-located control mechanisms, though factors such as weight, volume, and critical mass savings were also considered. It was determined that for most fast-spectrum core-reflector combinations a well-defined optimum control-vane design exists. The dependence of this optimum control span on control-vane thil kness and composition was explored in detail. Calculational methods for determining the optimum vane configuration and such ancillarybut important aspects as control-vane heating are presented.
\end{abstract}

\section{INTRODUCTION}

Because of the extremely high temperatures existing in nuclear rocket cores, it is advantageous to control these reactors with mechanisms located in the reflector. There environmental conditions can be kept tolerable for a wide range of control materials. However, the location of the control mechanism in the reflector can significantly reduce its neutronic effectiveness. The ability to control the reactor thus becomes important, and in some cases even limits, design considerations.

This study surveys and analyzes reflector-control problems as dictated by reactor physics considerations. It is recognized that in the design of a workable reflector-located control mechanism considerations other than those related to neutronics are important. For this reason the survey has been conducted on a general and broad plane. The objective was to map out neutronic limitations and possibilities of use of a wide range of reflector materials rather than to concentrate on the details of the neutronic problems of a special design.

Such a statement of purpose is expected and standard in any introduction, and makes one sorely wish that it could be followed by concise statements summarizing how said purpose was achieved. At the beginning 
of the study it was hoped it would be possible to isolate those specific nuclear properties of reflector and control materials that directly determine the control effectiveness and to present them in the form of a few, easily comparable parameters. The further objective then was to use these parameters in survey calculations for determining optimum reflector material and control-poison combinations. A considerable amount of effort was expended in search of this hoped-for simplicity, but without much success. Though the basic objectives of the study were achieved, the results are presented in a fairly detailed and involved manner.

These disappointed hopes are mentioned here because they do characterize a very important aspect of the problem and also because they illustrate the manner in which the results of the study may be used. This characteristic is that the problem of reflector control is inherently too complex to be reduced to a few universal parameters. A number of such parameters were tried, but invariably, as they approached simplicity, they became progressively more restrictive and eventually useless.

To illustrate: A common way of handling strongly self-shielded capture in a heterogeneous system is to reduce the capture distribution to a volume - and a surface-dependent term. This is unacceptable for the neutron capture inside a control vane because such surface and volume contributions will have very different magnitudes and importances when the control vane is in the IN and OUT positions. Further, correlations cannot be based on the simple total capture rate of neutrons, because the energy of the captured neutron has a very strong effect on the reactivity change produced by the capture. This energy dependence can change profoundly between the IN and OUT positions of the control vane and between various reflector materials.

This means that the presented analyses can be used for survey calculations and as an aid in choosing reflector and control materials which have a good potential of conforming to given design requirements; they should, however, be used with caution in evaluating the control worth of a specific design. Invariably the specific design will differ in some details from the calculational models used in this study, and the details can have a sufficiently perturbing influence on the control span to require an independent evaluation.

A definition of the major terms and the general scope is as follows:

By a "reflector-located control mechanism" we imply the use of rotating control drums which in part of their volume are loaded with neutron-absorbing materials.

The "control span" is the reactivity difference produced by rotating the control drums $180^{\circ}$. When the drum is in the IN position, the controlvane centerline faces the core; at the OUT position, it is at the furthest distance from the core. 
The study applies primarily to moderate-volume ( 300 liters), fast, tungsten-based reactors, although the relative comparisons of reflector and control materials apply to a large variety of general fast reactors.

The study is best introduced by considering each of its four sections separately.

In Section II the neutronic properties determining the control span of eight reflector materials is analyzed. The specifications of fast rocket reactor reflectors are presently not fixed. Therefore, the materials were chosen to cover a wide range of properties and are not to be considered as specific recommendations for nuclear rocket application. Truly moderating reflector materials (such as beryllium) do not fit in the framework of the study, since their use would require various reactor modifications. The materials range from carbon to materials having an equilibrium neutron spectrum similar to that of the core. The eight materials studied are depleted $\mathrm{U}, \mathrm{Al}, \mathrm{Al}_{2} \mathrm{O}_{3}, \mathrm{Fe}, \mathrm{Ni}, \mathrm{Zr}, \mathrm{Mo}$, and $\mathrm{C}$. In Section II completely identical configurations of reflector and control-vane materials are compared. Reflector thickness, porosity, and control-vane geometry and composition are kept constant. The energy dependence of the various neutronic parameters determining the control span are analyzed by detailed neutron bal ances. These parameters include leakage rates, capture reactions, and changes produced in core leakage by introducing the control vane.

In Section III the neutronic properties of the poison-free reflectors are analyzed. Parametric studies of reflector effectiveness with respect to changes in reflector weight and volume are made.

In Section IV the existence of optima with respect to the control span in some of the design parameters are explained. For three reflectors with different spectral characteristics the optimum vane thickness and vane composition were calculated. Correlations between the control span and other more directly calculable parameters are made.

In Section $V$ a separate, but very important, ancillary problem is considered: the $(n, \alpha)$ heating of the control vane produced by neutron capture by boron. Because of the high reaction cross section and the high boron atomic densities of the vane, the $(n, \alpha)$ heating rate can reach and even exceed core-heating rates. In addition, because of its strong dependence on the low-energy neutron flux, the $(n, \alpha)$ heating rate usually will have an extremely unequal spatial distribution. It is recommended that the $(n, \alpha)$ heating rate should be taken into account right at the start in control-vane design, since it could even influence the choice of reflector and control materials.

The data and analytical methods on which the study is based are given in four appendices. Two FORTRAN codes written especially for the study are also given. 
In conclusion, a word to the reader who will hopefully find the study most useful, that is to the reader actually engaged in some phase of reflector located control mechanism design. Sections III and IV and for those concerned with heat transfer design, Section $V$, have the most practical application. These sections were purposely written in a more general way. An effort was made not to overload them with details; most of the calculational specifics of these sections are described in the appendices. Section II is concerned directly with the basic neutronic differences of the reflector materials, and in order to express these resort was made to a large amount of detailed data. For a general understanding of the control neutronics a superficial reading of Section II should suffice. The details will be important if the study is extended to other reflector or control materials. 


\section{COMPARISON OF IDENTICAL REFLECTOR CONTROL-VANE CONFIGURATIONS}

The series of calculations on which this section is based had the purpose of classifying the chosen reflector materials according to their neutronic properties and determining the effect that said properties had on controllability. The objective was to evaluate the neutronic properties of the various reflector materials under as identical conditions as possible. Therefore, such parameters as reflector thickness and control-vane geometry and composition were kept identical in this series of calculations.

Throughout this study the term "reflector properties" will be used in many different ways. As the need arises, such reflector properties as neutron reflectivity, moderating power, absorptivity, and weight-volume relationships will be defined and used in comparing the reflector materials. Conclusions will be drawn from the comparisons and design recommendations made. It thus seems appropriate at this point to emphasize the primary source from which all of these "reflector properties" are obtained. This is, of course, the set of neutron cross sections of the various nuclides involved. In a very real sense, therefore, the calculations and resulting conclusions are only as valid as the basic data.

This is not a profound observation, but just because of its obviousness it is at times ignored. A direct corollary is that it is futile, and at times misleading, to derive relationships from the basic data which crowd the limits of accuracy of these data. The very important question thus exists--is the calculated effect real or is it just a calculational peculiarity inherent in the inaccuracy of basic data used? This question can be particularly relevant in calculations where the final answer is obtained as the difference of two separate computations which represent the subtraction of one uncertain cross section from another that is equally uncertain. The difference has a greater uncertainty associated with it than the basic cross sections.

Much of the experimental work which can be used for verifying the basic data and the calculations has been performed as a part of the Argonne ZPR- 9 critical program and is reported in Refs. 1 through 4. The experimental work there presented covers a range of fast assemblies with core compositions similar to that of the core used in these studies. The (until recently) unstudied tungsten diluent is present in most of these assemblies at various concentrations. Additional pertinent experimental work has been conducted in the Soviet Union. ${ }^{5-7}$ The experiments give a good basis for verifying various general types of reactor physics calculations. Thus, good estimates are available as to the degree of accuracy obtainable for the determinations of the critical mass, the neutron lifetime, or the reactivity worth of various materials located in the core. The adequacy of the calculated integral neutron spectrum is implied by the generally excellent agreement between calculated and measured values of the spatial distribution in 
the core of important reaction rates such as the fission in $\mathrm{U}^{235}$ or capture in boron. It is true that good information concerning the details of the neutron spectrum is still scarce. The data here are provided by some threshold reaction ratios, which in general can only give qualitative information on the neutron spectrum above several hundreds of kilovolts.

A quantitative presentation of the experimental data and of the important agreement between experiment and theory is outside the scope of this study. The general evaluation of this agreement is as follows:

All reactor core physics parameters of interest to this study can be calculated to a reasonable degree of accuracy. In cases where discrepancies do exist, the direction and magnitude of these discrepancies are usually adequately known. The presence of large amounts of tungsten in the core introduces less uncertainty than would, for example, the neutronically much more extensively studied $U^{238}$. The reasonably optimistic picture presented above applies most directly to reactor core parameters. Understandably enough, core properties have received the most experimental and analytical attention to date, with the consequence that neutronic properties of the reflectors have been somewhat neglected. The calculations performed for this report concern themselves mostly with neutron reactions occurring in various reflectors and with the neutronic properties of the reflectors themselves. Few experimental data are available ${ }^{4,7,8}$ to verify these calculations directly, and mostly the verification has to be based on the inference from core measurements. For this reason comprehensive quantitative estimates of the accuracy of presented results cannot be obtained. The available reflector-oriented experimental data and their correlation with calculated values are given in Appendix A. A qualitative evaluation of accuracy based on the available experimental data is as follows:

The conclusions about the relative merits of control and reflector materials have a high degree of validity. Except for cases where the relative merit indices approach to within $\sim 5 \%$ of each other, the conclusions can be regarded as quite definitive.

Absolute calculated values of control spans can be in error by as much as $30 \%$, although usually $10-20 \%$ is a better error estimate.

The cross sections employed in the calculations are given in Appendix A.

\section{A. Basic Calculations}

The choice of reflector materials was limited to elements which by themselves or in compounds would be suitable for reflecting a high-specificpower-density fast reactor and which would span a wide range of neutron spectra in the reflector. Purposely and after considerable deliberation 
elements which would be "too moderating" were excluded from consideration. Such materials are $\mathrm{H}$, Li, Be, and their compounds. This does not mean that these materials cannot be used as reflectors for fast reactors, but it certainly does imply that the use of these nuclides results in unique design problems.

For this study the strongly moderating reflectors were not included because they introduce a great analytical complexity as well as invalidate the basis on which the reflector materials are to be compared. As stated in the introduction, this basis is the use of the same core for all the reflectors. Theoretically, of course, this basis could be extended to the moderating reflectors also, but the results would be meaningless in practice. Take, for example, the comparison of identical beryllium- and nickelreflected cores. The control span achieved by the beryllium-reflected core would very well be twice as large as for the nickel-reflected core; however, the beryllium-reflected core would have a power spike of maybe a factor of 5 over average core power at the core-reflector interface. Clearly, even on paper, the simple beryllium-reflected core would be unacceptable.

The mean neutron energy for the moderating materials in the reflector is lower, by several orders of magnitude, than the mean neutron spectrum in the core. This means that, for a uniformly loaded core, there is a spectrum transition region at the core-reflector interface in which power spikes of up to 4 or even 10 times the average core power are produced. Such power spikes are, of course, completely unacceptable in the framework of current technology of design. Considerable design ingenuity would be required to eliminate them. Very extensive core-edge fuelconcentration grading or outright shielding of the core from the lowerenergy neutron spectrum would have to be built into the reactor in order to achieve a workable design. The very necessity of such design complications illustrates what may be a basic incompatibility of a fast-spectrum core and a truly moderating reflector. In a sense, the choice of a moderating reflector and the design steps required afterwards to make the corereflector combination workable are at complete cross purposes. Although those complications do not rule out the use of a moderating reflector, it is believed that the very achievement of a workable design will reduce the benefits for which the moderating reflector was originally chosen to such a degree that they will not compensate for the additional design complexity. For example, this proved to be the case for a particular design ${ }^{9}$ which evaluated the relative merits of a beryllium and an alumina reflector.

Based on a study of this "edge power spike" problem, it was determined that the most moderating thick reflector material that might be acceptable in practice is carbon. For a reflector thickness of $25 \mathrm{~cm}$ and a density of $70 \%$, the power spike produced at the edge of a carbon radial reflector approximately matches central core power. The other materials 
chosen for the study were depleted $\mathrm{U}, \mathrm{Al}, \mathrm{Ni}, \mathrm{Fe}, \mathrm{Mo}, \mathrm{Zr}$, and $\mathrm{Al}_{2} \mathrm{O}_{3} . \mathrm{All}$ of these are elements except the $\mathrm{Al}_{2} \mathrm{O}_{3}$, which was chosen to represent the promising class of oxides.

In the calculations a simplified model was used which was intended to approximate realistic rocket reactors. A tungsten-based, 300-liter core was chosen for evaluating the reflector materials. The core had a porosity of $40 \%$ and was fueled with highly enriched $\mathrm{UO}_{2}$.

The reflectors, $25 \mathrm{~cm}$ thick and with a porosity of $30 \%$, were assumed to be composed only of a single material. As shown in Section $B$, this combination of thickness and porosity approximately approaches an effectively infinite reflector for most materials. The choice of a reflector of close-to-infinite thickness is consistent with the purpose of this study. The objective is to focus upon the effect which the neutronic differences of the reflector materials have upon the achievable control span. One method of achieving this is to maximize the importance of these reflectors, i.e., make them close to infinite size. (Volume and weight considerations are, of course, very essential in the design of a practical reactor, and these considerations are taken up in Section III.)

The calculations were performed with the DSN code in spherical geometry and used the $\mathrm{S}_{4}$ angular approximation. The $\mathrm{S}_{4}$ approximation has been shown to be adequate for calculations for which the minimum region thicknesses are not below 0.5 of a mean transport length. All calculations performed in this series fell in this class. The cross-section set used is presented in Appendix A.

As compared to the cylindrical geometry of the actual rocket cores, where the control poison is located only in the radial reflector, the spherical model used in this calculational series overestimates the effect of the reflector. For this phase of the study such an overestimate is an advantage since it emphasizes the differences in the reflectors and in their control capability. In subsequent calculations the cylindrical model was employed.

It should be emphasized at this point that only one-dimensional calculations were used in the study. Whether in spherical or cylindrical geometry, the control region was represented by a continuous, concentric "poison curtain" region. For the comparative evaluations of this study, in which all of the materials considered are compared under identical conditions, such a method is valid. The translation of the presented control spans to the discrete control-vane configurations of an actual design must be done with great care. The practice employed in similar cases has been to reduce the calculated control span for the continuous curtain by the fraction of the solid angle spanned by the discrete control vanes. 
For all of the eight chosen reflector materials, 3 problems evaluating both the real and the adjoint fluxes were run:

1. A base problem with a poison-free reflector. In this series the reactivity computed by the base problem was taken to represent the reactivity with the control drums in the OUT condition. Both $\mathrm{k}_{\mathrm{eff}}$ and critical fuel concentration were calculated.

2. A problem incorporating a concentric, 2-cm-thick region in the reflector, $4 \mathrm{~cm}$ from the core-reflector interface. This region represented the control vanes with the drums in IN condition and contained $20 \mathrm{v} / \mathrm{o}$ of natural boron. The porosity of the region was $50 \%$; the balance consisted of the reflector material.

3. A problem identical to problem No. 2 except that one-half of the poison volume was occupied by hydrogen at the atomic density of water.

The calculational series thus provided data for two types of evaluations. Problems of type 1 allowed a comparison of the pure reflector materials: problems of type 2 and 3 evaluated the effect of 2 standard poison compositions. A quantity proportional to the control span is obtained from the difference in the calculated reactivities of type 1 and type 1 and 2 problems.

The multigroup output of both real and adjoint fluxes provided by the problems was used to obtain energy-dependent neutron balances for all reactor regions. The control span was found to be quite sensitive to the energy of the absorbed or reflected neutrons; thus a detailed energydependent analysis of all the neutronic reactions was necessary. A FORTRAN code was written especially for this purpose and is presented with some energy-dependent data in Appendix B. The more important results of the calculations are outlined in this section. The presentation is divided into three parts: 1. the overall energy-independent results; 2 . the energy dependency of the parameters determining the control span; 3. correlations between the control span and other more directly computable parameters.

\section{B. Energy-independent Control Parameters}

All of the presented results are based on multienergy-group calculations; thus the parameters involve reaction rates summed over neutron energy. Also of importance are the sums of the neutrons leaked into the reflector and the reactivity changes produced by this neutron leakage.

Several of the important energy-dependent control parameters are summarized in Table I. 
TABLE I. Energy-independent Control Parameters

\begin{tabular}{|c|c|c|c|c|c|}
\hline $\begin{array}{l}\text { Reflector } \\
\text { Composition }\end{array}$ & $\begin{array}{c}\text { Relative } \\
\text { Reflector }(\mathrm{a}) \\
\text { Worth }(\% \Delta \mathrm{k})\end{array}$ & $\begin{array}{c}\text { Control- } \\
\text { vane(b) } \\
\text { Composition }\end{array}$ & $\begin{array}{c}\text { Net Neutron }(\mathrm{c}) \\
\text { Leakage } \\
\text { Fraction }\end{array}$ & $\begin{array}{c}\text { Neutron } \\
\text { Fraction }(\mathrm{c}) \\
\text { Absorbed by B }\end{array}$ & $\begin{array}{c}\text { Control } \\
\text { Span } \\
(\% \Delta \mathrm{k})\end{array}$ \\
\hline Depleted U & 0 & $\begin{array}{c}B \\
B+H\end{array}$ & $\begin{array}{l}0.382 \\
0.384 \\
0386\end{array}$ & $\begin{array}{l}00462 \\
0.0359\end{array}$ & $\begin{array}{l}1.04 \\
1.22\end{array}$ \\
\hline $\mathrm{Al}$ & -5 & $\begin{array}{c}\mathrm{B} \\
\mathrm{B}+\mathrm{H}\end{array}$ & $\begin{array}{l}0.349 \\
0.352 \\
0.352\end{array}$ & $\begin{array}{l}0.0291 \\
0.0184\end{array}$ & $\begin{array}{l}0.52 \\
0.72\end{array}$ \\
\hline $\mathrm{Al}_{2} \mathrm{O}_{3}$ & +27 & $\begin{array}{c}\mathrm{B} \\
\mathrm{B}+\mathrm{H}\end{array}$ & $\begin{array}{l}0.276 \\
0.303 \\
0.298\end{array}$ & $\begin{array}{l}0.0693 \\
0.0526\end{array}$ & $\begin{array}{l}2.66 \\
2.40\end{array}$ \\
\hline $\mathrm{N}_{1}$ & +1.0 & $\begin{array}{c}\mathrm{B} \\
\mathrm{B}+\mathrm{H}\end{array}$ & $\begin{array}{l}0.302 \\
0.315 \\
0.315\end{array}$ & $\begin{array}{l}0.0462 \\
0.0392\end{array}$ & $\begin{array}{l}1.51 \\
1.71\end{array}$ \\
\hline $\mathrm{Fe}$ & -1.8 & $\begin{array}{c}\mathrm{B} \\
\mathrm{B}+\mathrm{H}\end{array}$ & $\begin{array}{l}0.324 \\
0.333 \\
0.331\end{array}$ & $\begin{array}{l}0.0389 \\
0.0308\end{array}$ & $\begin{array}{l}1.14 \\
1.17\end{array}$ \\
\hline Mo & +2.1 & $\begin{array}{c}B \\
B+H\end{array}$ & $\begin{array}{l}0.297 \\
0.306 \\
0.306\end{array}$ & $\begin{array}{l}0.0415 \\
0.0304\end{array}$ & $\begin{array}{l}1.19 \\
1.36\end{array}$ \\
\hline $\mathrm{C}$ & +0.67 & $\begin{array}{c}\mathrm{B} \\
\mathrm{B}+\mathrm{H}\end{array}$ & $\begin{array}{l}0.286 \\
0.321 \\
0.317\end{array}$ & $\begin{array}{l}0.0893 \\
0.0725\end{array}$ & $\begin{array}{l}3.45 \\
3.18\end{array}$ \\
\hline $\mathrm{Zr}$ & +0.83 & $\begin{array}{c}\mathrm{B} \\
\mathrm{B}+\mathrm{H}\end{array}$ & $\begin{array}{l}0.303 \\
0.316 \\
0.313\end{array}$ & $\begin{array}{l}0.0422 \\
00306\end{array}$ & $\begin{array}{l}1.57 \\
1.54\end{array}$ \\
\hline
\end{tabular}

(a) Relative worth with respect to a depleted-uranium reflector. Reflector thickness in all cases $25 \mathrm{~cm}$.

(b) 2 -cm-thick control vane located $4 \mathrm{~cm}$ from core-reflector interface. $20 \mathrm{v} / 0$ of control material, natural bor on and hydrogen at water density.

(c) Neutron fractions are given with respect to a total neutron source of 1 . The first number in the net-leakage column represents the leakage for the reference core (no poison).

(d) Reactivity difference between the control vane in IN and OUT positions.

The parameter having the most direct interest is the "control span," shown in the last column of Table I. For purposes of this series of calculations the control span is defined as the reactivity difference between equivalent boron-free and boron-containing problems.

The first observation about the control span is that it demonstrates a surprisingly large divergence among the eight reflectors studied. Thus, in terms of the control span, aluminum is by far the poorest reflector, 
whereas $\mathrm{Al}_{2} \mathrm{O}_{3}$ is almost at the top of the list. The difference amounts to a full factor of 5 for the control span produced by the control vane containing only boron and to about a factor of 3 for the control span produced by the vane containing boron plus a hydrogenous moderator. The existence of such a large difference between materials which at first glance do not seem to be so drastically different neutronically illustrates that a more detailed understanding of the controllability problem is required. The necessity for more precise information is illustrated further when the effect of the substitution of hydrogen for boron in a control vane located in the two reflectors is considered. As shown by the calculations, for the vane located in an aluminum reflector, a replacement of $50 \%$ of the boron with a hydrogenous material results in an increase in the calculated control span of $\sim 35 \%$. This very same process when performed for an identical vane located in an $\mathrm{Al}_{2} \mathrm{O}_{3}$ reflector produces a decrease of $\sim 10 \%$ in the control span. Similar observations can be made for the other reflector materials. The introduction of a hydrogenous moderator into a control vane will be analyzed in much more detail in subsequent sections.

The first column of Table I presents a "relative reflector worth" which is derived from the poison-free calculations and thus applies only to the reflector material. The reflector worth is defined as the relative reactivity worth of the reflector with the depleted-uranium reflector taken as a standard. The depleted-uranium reflector was chosen as a standard of comparison simply because most of the available critical data is of as semblies reflected by depleted uranium. It does not imply a recommendation of depleted uranium as a specially well-suited reflector material. Mathematically, this ratio is expressed as follows:

$$
\left[\begin{array}{c}
\text { Worth of } \\
\text { Reflector A }
\end{array}\right]=\frac{k_{\text {eff }(\operatorname{Refl~A})}-k_{\operatorname{eff}(\operatorname{Depl}-U \text { Refl })}}{k_{\text {eff }}(\text { Depl-U Refl })} .
$$

The table shows that this parameter exhibits an even wider variation for the eight reflectors under study than the control span. The neutronic difference between the aluminum and $\mathrm{Al}_{2} \mathrm{O}_{3}$ reflectors is especially pronounced. Thus, the values of calculated reflector worth show that the interchange of an aluminum with an $\mathrm{Al}_{2} \mathrm{O}_{3}$ reflector would result in a reactivity gain of $\sim 7 \% \Delta \rho$. This amounts to an $\sim 35 \%$ critical mass change for constant-fuel-concentration assemblies.

Variations in reflector worth are appreciable also for the other reflector materials. However, this variation is only approximately correlated with the control span. This can be seen in comparing the values of reflector worth and control span for the molybdenum and carbon reflectors. Carbon outranks molybdenum significantly in terms of the control span, but molybdenum has the higher reflector worth. The reason for the poor correlation is that for the fast-neutron-spectrum cores employed in the calculation the 
reflector worth is dependent mostly on the ability of the reflector to contain fast neutrons. The energy dependence of the control span, on the other hand, is influenced more heavily by the lower end of the neutron spectrum.

It is possible now to rank the reflectors according to the se two merit criteria. However, for design purposes such rankings would not be of much use. As is shown in the following sections, the "relative reflector worth," especially for reflectors thinner than $30 \mathrm{~cm}$, is strongly dependent on reflector thickness. Different reflector thicknesses would therefore produce a different merit scale of the reflector materials. In the same manner, the control span is very strongly dependent on the thickness and composition of the control vane. This dependence is quite distinct for each reflector material. For this reason, a comparison which is based on the same control vane for all reflectors does not give a true indication of the ultimate control span which can be achieved in a given reflector material.

It is, therefore, more appropriate to use these calculations to answer the question of why these large computed differences exist. Two of the parameters which might be expected to cause these differences and which most directly determine the control span and the relative reflector worth are also presented in Table I.

Column 3 shows the net neutron leakage into the various reflectors. The fast-neutron source in all of the reactors has been normalized to one. The net-leakage fraction therefore represents the percent (when multiplied by 100) of the neutrons leaked from the core minus the percent returned to the core by the reflector. (The normalization of the total source to one accounts for the abnormally large leakage fraction shown for the depleteduranium reflector, since in that case the fission source is not confined to the core.)

The net leakage into the boron-free reflector is inversely proportional to the reflector worth. Lower net leakages imply a larger fraction of neutrons returned to the core and thus higher reflector effectiveness. The difference between the leakages into the boron-containing reflector and into a boron-free reflector is approximately proportional to the reflector span. The increased leakage into the boron-containing reflectors is obtained by a reduction of the fraction of neutrons being returned to the core. The energy distribution of this very important reflected neutron fraction varies widely among the eight reflectors, and this variation accounts for the distinct individuality of the reflector materials.

The importance of the energy distribution of the neutron reactions which produce the above changes in neutron leakage is illustrated by the calculated values of Column 6, which shows the total fraction of neutrons captured by the boron poison of the control vane. (Normalization is again to one source neutron.) The important point to note is that the summation 
over energy for this reaction is not directly proportional to the control span. In some cases, in fact (i.e., for the $\mathrm{Al}$, Mo, and Ni reflectors), decreases in the absorption fraction produced by the substitution of hydrogenous material for $50 \%$ of the bor on resulted in actual and appreciable increases in the control span. Since the control span is a direct consequence of the reactivity decrease produced by neutron absorption in the control vane, this observation shows that the energy distribution of these absorbed neutrons plays a very large role.

\section{Energy Dependence of Parameters Determining Control Span}

Tables II-VI present the energy dependence of the parameters most directly determining the control span. Appendix B contains additional energy-dependent data for the individual reflectors and also presents the neutron-balance code with which the data shown in the tables were computed.

TABLE II. Leakage Neutrons for Five Reflector Compositions

\begin{tabular}{|c|c|c|c|c|c|c|}
\hline & $\begin{array}{c}\text { Energy-group } \\
\text { Lim1ts }\end{array}$ & $\mathrm{C}$ & $\mathrm{Al}_{2} \mathrm{O}_{3}$ & $\mathrm{~N}_{1}$ & $\mathrm{Fe}$ & $\mathrm{Al}$ \\
\hline Control Span $(\% \Delta \mathrm{k})$ & & 3.45 & 2.66 & 1.51 & 1.14 & 0.533 \\
\hline \multirow{5}{*}{$\begin{array}{l}\text { l) } \\
\text { Leakage fraction* } \\
\text { for reference (no } \\
\text { boron) core. }\end{array}$} & $10 \mathrm{MeV} \rightarrow 1.4 \mathrm{MeV}$ & 0.0813 & 0.0731 & 0.0746 & 0.0712 & 0.0636 \\
\hline & $1.4 \mathrm{MeV} \rightarrow 0.4 \mathrm{MeV}$ & 0.1718 & 0.1565 & 0.1236 & 0.1362 & 0.1476 \\
\hline & $0.4 \mathrm{MeV} \rightarrow 17 \mathrm{keV}$ & 0.1151 & 0.0977 & 0.1110 & 0.1230 & 0.1386 \\
\hline & $17 \mathrm{keV} \rightarrow$ thermal & -0.0820 & -0.0511 & -0.0067 & -0.0065 & -0.0009 \\
\hline & Total & 0.2862 & 0.2762 & 0.3025 & 0.3239 & 0.3489 \\
\hline \multirow{5}{*}{$\begin{array}{l}\text { 2) } \\
\text { Leakage fraction for } \\
\text { reactor with boron- } \\
\text { containing control } \\
\text { vane in IN position. }\end{array}$} & $10 \mathrm{MeV} \rightarrow 1.4 \mathrm{MeV}$ & 0.0719 & 0.0689 & 0.0727 & 0.0697 & 0.0633 \\
\hline & $1.4 \mathrm{MeV} \rightarrow 0.4 \mathrm{MeV}$ & 0.1640 & 0.1533 & 0.1278 & 0.1385 & 0.1488 \\
\hline & $0.4 \mathrm{MeV} \rightarrow 17 \mathrm{keV}$ & 0.1201 & 0.1071 & 0.1179 & 0.1285 & 0.1412 \\
\hline & $17 \mathrm{keV} \rightarrow$ thermal & -0.0353 & -0.0257 & -0.0037 & -0.0038 & -0.0008 \\
\hline & Total & 0.3207 & 0.3036 & 0.3147 & 0.3329 & 0.3525 \\
\hline \multirow{5}{*}{$\begin{array}{l}\text { (Leakage fraction) })_{1--} \\
\text { (Leakage fraction) }\end{array}$} & $10 \mathrm{MeV} \rightarrow 1.4 \mathrm{MeV}$ & 0.0094 & 0.0043 & 0.0019 & 0.0015 & 0.0003 \\
\hline & $1.4 \mathrm{MeV} \rightarrow 0.4 \mathrm{MeV}$ & 0.0078 & 0.0032 & -0.0042 & -0.0023 & -0.0013 \\
\hline & $0.4 \mathrm{MeV} \rightarrow 17 \mathrm{keV}$ & -0.0050 & -0.0093 & -0.0069 & -0.0056 & -0.0026 \\
\hline & $17 \mathrm{keV} \rightarrow$ thermal & -0.0468 & -0.0254 & -0.0030 & -0.0027 & -0.0001 \\
\hline & Total & -0.0346 & -0.0272 & -0.0121 & -0.0091 & -0.0037 \\
\hline \multirow{5}{*}{$\begin{array}{l}\text { Fraction of neutrons } \\
\text { absorbed in boron } \\
\text { containing control } \\
\text { vane. }\end{array}$} & $10 \mathrm{MeV} \rightarrow 1.4 \mathrm{MeV}$ & 0.0005 & 0.0006 & 0.0012 & 0.0004 & 0.0005 \\
\hline & $1.4 \mathrm{MeV} \rightarrow 0.4 \mathrm{MeV}$ & 0.0017 & 0.0018 & 0.0032 & 0.0029 & 0.0023 \\
\hline & $0.4 \mathrm{MeV} \rightarrow 17 \mathrm{keV}$ & 0.0235 & 0.0286 & 0.0271 & 0.0252 & 0.0213 \\
\hline & $17 \mathrm{keV} \rightarrow$ thermal & 0.0636 & 0.0383 & 0.0146 & 0.0105 & 0.0051 \\
\hline & Total & 0.0893 & 0.0693 & 0.0461 & 0.0389 & 0.0292 \\
\hline
\end{tabular}

*All neutron fractions are given with respect to a total neutron source of 1 .

The tables present the quantitative differences in the characteristic neutron spectra of the eight reflectors. These spectral differences change the energy distribution of the neutron reaction rates which in turn determine the variations of the control span. Unfortunately, the detail required for this purpose can literally succeed in obscuring it. For this reason the energy breakdown is presented in two steps. Table II presents an 
easily interpreted four-energy-group analysis, and the subsequent tables expand the energy division of Table II into 16 energy groups.

TABLE III Energy Distribution of Leakage Fraction into Boron-free Reflectors

\begin{tabular}{|c|c|c|c|c|c|c|c|c|c|}
\hline \multirow{2}{*}{$\begin{array}{l}\text { Energy } \\
\text { Group }\end{array}$} & \multirow{2}{*}{$\begin{array}{l}\text { Lower } \\
\text { Energy } \\
\text { Limit }\end{array}$} & \multicolumn{8}{|c|}{ Reflector Material } \\
\hline & & Depleted-uranıum & Alumınum & $\mathrm{Al}_{2} \mathrm{O}_{3}$ & Nickel & Iron & Molybdenum & Carbon & Zırconıum \\
\hline $\begin{array}{r}1 \\
2 \\
3 \\
4 \\
5 \\
6 \\
7 \\
8 \\
9 \\
10 \\
11 \\
12 \\
13 \\
14 \\
15 \\
16\end{array}$ & $\begin{array}{c}\infty-3 \mathrm{MeV} \\
14 \mathrm{MeV} \\
09 \mathrm{MeV} \\
04 \mathrm{MeV} \\
01 \mathrm{MeV} \\
17 \mathrm{keV} \\
3 \mathrm{keV} \\
055 \mathrm{keV} \\
100 \mathrm{eV} \\
30 \mathrm{eV} \\
10 \mathrm{eV} \\
3 \mathrm{eV} \\
1 \mathrm{eV} \\
04 \mathrm{eV} \\
01 \mathrm{eV} \\
\text { Thermal }\end{array}$ & $\begin{array}{c}004275 \\
008081 \\
005713 \\
010760 \\
006580 \\
002768 \\
0000579 \\
0000110 \\
<10^{-5}\end{array}$ & $\begin{array}{c}002319 \\
004043 \\
004255 \\
010501 \\
010670 \\
003187 \\
-0000392 \\
-0000402 \\
<10^{-4}\end{array}$ & $\begin{array}{l}002773 \\
004542 \\
004753 \\
010896 \\
009682 \\
0000924 \\
-002248 \\
-001405 \\
-000760 \\
-000314 \\
-000168 \\
-000106 \\
-0000505 \\
-0000263 \\
-0000194 \\
-0000148\end{array}$ & $\begin{array}{c}002612 \\
004846 \\
003489 \\
008871 \\
000394 \\
001708 \\
-000126 \\
-000254 \\
-000148 \\
-000684 \\
-0000373 \\
-0.000231 \\
<10^{-4}\end{array}$ & $\begin{array}{c}002391 \\
004730 \\
004042 \\
009577 \\
009787 \\
002510 \\
-000270 \\
-000224 \\
-0000776 \\
-0000350 \\
-0000197 \\
-0000125 \\
<10^{-4}\end{array}$ & $\begin{array}{c}002582 \\
004781 \\
003329 \\
008261 \\
008587 \\
002277 \\
-000129 \\
<10^{-5}\end{array}$ & 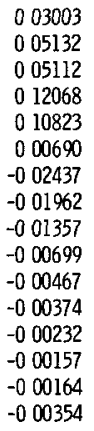 & $\begin{array}{c}002611 \\
004729 \\
004301 \\
008832 \\
008936 \\
001688 \\
-000559 \\
-000175 \\
-000317 \\
<10^{-4}\end{array}$ \\
\hline Total & & 038247 & 034888 & 027626 & 030251 & 032389 & 029688 & 028625 & 030326 \\
\hline
\end{tabular}

TABLE IV Energy Distribution of the Increase in Leakage Produced by the Introduction of Boron-containing Control Vane into the Reflector

\begin{tabular}{|c|c|c|c|c|c|c|c|c|}
\hline \multirow{2}{*}{$\begin{array}{l}\text { Energy } \\
\text { Group }\end{array}$} & \multicolumn{8}{|c|}{ Reflector Materıal } \\
\hline & Depleted Uranıum & Alumınum & $\mathrm{Al}_{2} \mathrm{O}_{3}$ & Nickel & Iron & Molybdenum & Carbon & Zırconıum \\
\hline $\begin{array}{r}1 \\
2 \\
3 \\
4 \\
5 \\
6 \\
7 \\
8 \\
9 \\
10 \\
11 \\
12 \\
13 \\
14 \\
15 \\
16\end{array}$ & $\begin{array}{c}000155 \\
000284 \\
000103 \\
-000060 \\
-000772 \\
000090 \\
000031 \\
<10^{-5}\end{array}$ & $\begin{array}{r}000017 \\
000011 \\
-000003 \\
-000124 \\
-000271 \\
000010 \\
000003 \\
-000006 \\
<10^{-5}\end{array}$ & $\begin{array}{r}000190 \\
000239 \\
000197 \\
000124 \\
-000280 \\
-000653 \\
-000694 \\
-000672 \\
-000532 \\
-000270 \\
-000159 \\
-000105 \\
-000050 \\
-000026 \\
-000019 \\
-000015\end{array}$ & $\begin{array}{c}000069 \\
000122 \\
-000081 \\
-000335 \\
-000432 \\
-000259 \\
-000015 \\
-000075 \\
-000088 \\
-000054 \\
-000033 \\
-000022 \\
-000008 \\
<10^{-5}\end{array}$ & $\begin{array}{r}000047 \\
000107 \\
-000004 \\
-000227 \\
-000425 \\
-000132 \\
-000056 \\
-000094 \\
-000053 \\
-000030 \\
-000019 \\
-000012 \\
<10^{-4}\end{array}$ & $\begin{array}{l}000036 \\
000072 \\
-000121 \\
-000289 \\
-000446 \\
-000138 \\
-000009 \\
<10^{-5}\end{array}$ & $\begin{array}{r}000383 \\
000560 \\
000385 \\
000391 \\
-000072 \\
-000430 \\
-000650 \\
-000854 \\
-000894 \\
-000577 \\
-0000432 \\
-000365 \\
-000230 \\
-000157 \\
-000164 \\
-000354\end{array}$ & $\begin{array}{r}000065 \\
000112 \\
000019 \\
-000317 \\
-000557 \\
-000328 \\
-000161 \\
-000071 \\
-000021 \\
<10^{-5}\end{array}$ \\
\hline Total & -000165 & -000367 & -002725 & -001215 & $-0,00906$ & -000891 & -003460 & -001264 \\
\hline
\end{tabular}

TABLE V Energy Distribution of the Increase in Leakage Produced by the Introduction of $\mathrm{B}+\mathrm{H}$-containing Control Vane into the Reflector

\begin{tabular}{|c|c|c|c|c|c|c|c|c|}
\hline \multirow{2}{*}{$\begin{array}{l}\text { Energy } \\
\text { Group }\end{array}$} & \multicolumn{8}{|c|}{ Reflector Material } \\
\hline & Depleted Uranıum & Alumınum & $\mathrm{Al}_{2} \mathrm{O}_{3}$ & Nickel & Iron & Molybdenum & Carbon & Zırconium \\
\hline $\begin{array}{r}1 \\
2 \\
3 \\
4 \\
5 \\
6 \\
7 \\
8 \\
9 \\
10 \\
11 \\
12 \\
13 \\
14 \\
15 \\
16\end{array}$ & $\begin{array}{r}000124 \\
000216 \\
000065 \\
-000186 \\
-000970 \\
+000187 \\
+000204 \\
+000050 \\
<10^{-5}\end{array}$ & $\begin{array}{c}0 \\
-000054 \\
-000051 \\
-000293 \\
-000421 \\
000038 \\
000222 \\
000134 \\
000049 \\
000010 \\
<10^{-5}\end{array}$ & $\begin{array}{r}000129 \\
000110 \\
000119 \\
-000025 \\
-000430 \\
-000748 \\
-000398 \\
-000245 \\
-000226 \\
-000160 \\
-000118 \\
-000091 \\
-000048 \\
-000026 \\
-000019 \\
-000015\end{array}$ & $\begin{array}{r}000052 \\
000071 \\
-000116 \\
-000564 \\
-000589 \\
-000200 \\
000100 \\
000077 \\
000010 \\
-000017 \\
-000020 \\
-000017 \\
<10^{-4}\end{array}$ & $\begin{array}{r}000018 \\
000029 \\
-000061 \\
-000445 \\
-000599 \\
-000068 \\
000251 \\
000142 \\
000038 \\
-000001 \\
-000009 \\
-000010 \\
<10^{-5}\end{array}$ & $\begin{array}{r}000024 \\
000026 \\
-000150 \\
-000469 \\
-000583 \\
-000081 \\
000221 \\
000075 \\
000012 \\
<10^{-6}\end{array}$ & $\begin{array}{l}000305 \\
000401 \\
000287 \\
000228 \\
-000191 \\
-000488 \\
-000477 \\
-000490 \\
-000535 \\
-000405 \\
-000348 \\
-000329 \\
-000221 \\
-000154 \\
-000163 \\
-000354\end{array}$ & $\begin{array}{r}000022 \\
000007 \\
-000048 \\
-000541 \\
-000740 \\
-000270 \\
000243 \\
000232 \\
000093 \\
000020 \\
<10^{-5}\end{array}$ \\
\hline Total & -000309 & -000363 & -002191 & -001225 & -000720 & -000922 & -002934 & -000975 \\
\hline
\end{tabular}


TABLE VI Absorption Fraction in Boron Control Section

(Source in Boron-free Problems Normalized to 1)

\begin{tabular}{|c|c|c|c|c|c|c|c|c|}
\hline \multirow{2}{*}{$\begin{array}{l}\text { Energy } \\
\text { Group }\end{array}$} & \multicolumn{8}{|c|}{ Reflector Material } \\
\hline & Depleted Uranium & Alumınum & $\mathrm{Al}_{2} \mathrm{O}_{3}$ & Nickel & Iron & Molybdenum & Carbon & Zirconium \\
\hline 1 & 0000606 & 0000104 & 0000148 & 0000452 & 00000827 & 00000858 & 00000871 & 00000848 \\
\hline 2 & 000140 & 0000422 & 0000447 & 0000767 & 0000324 & 0000398 & 0000428 & 0000392 \\
\hline 3 & 0000607 & 0000271 & 0000209 & 0000398 & 0000346 & 0000565 & 0000223 & 000143 \\
\hline 4 & 000366 & 000201 & 000158 & 0002802 & 0002528 & 000374 & 000144 & 000250 \\
\hline 5 & 001972 & 001087 & 001042 & 001280 & 0012631 & 001487 & 000861 & 001302 \\
\hline 6 & 001512 & 001042 & 001822 & 001431 & 0012568 & 001492 & 001486 & 001462 \\
\hline 7 & 000449 & 000398 & 001635 & 000664 & 0.005821 & 000592 & 001765 & 000748 \\
\hline 8 & 0000555 & 0000923 & 001133 & 0003851 & 0002846 & 0000922 & 001687 & 000222 \\
\hline 9 & 00000325 & 0000143 & 000642 & 0002365 & 0001094 & 00000683 & 001314 & 0000411 \\
\hline 10 & $<10^{-6}$ & 00000133 & 000237 & 0000959 & 0000393 & $<10^{-5}$ & 000652 & $<10^{-5}$ \\
\hline 11 & & $<10^{-5}$ & 000100 & 0000440 & 0000178 & & 000366 & \\
\hline 12 & & & 0000468 & 0000230 & 00000886 & & 000229 & \\
\hline 13 & & & 0000189 & 0000091 & 00000331 & & 000128 & \\
\hline 14 & & & 00000755 & 0000032 & 00000103 & & 0000706 & \\
\hline 15 & & & 00000437 & $<10^{-5}$ & $<10^{-5}$ & & 0000623 & \\
\hline 16 & & & 00000242 & & & & 0000882 & \\
\hline Total & 004619 & 002914 & 006930 & 004616 & 003894 & 004150 & 008927 & 004220 \\
\hline
\end{tabular}

The first section of Table II shows the net leakage from the core into the boron-free reflector. As seen, the positive outward leakage for neutrons above $17 \mathrm{keV}$ is remarkably alike for all reflectors. The real differences in the leakage spectrum show up only below $17 \mathrm{keV}$. Below $17 \mathrm{keV}$ the leakage becomes negative, that is, the direction of net neutron transfer is inward into the core. This leakage fraction is fairly small compared to the total net leakage, but it has a disproportionate importance, since precisely these neutrons can be affected most directly by the introduction of poison into the reflector. The neutronic difference existing between the reflectors show up very clearly in this region of the neutron-energy spectrum. Thus the in-leakage fraction for $17-\mathrm{keV}$ neutrons and below is 0.08 for a carbon reflector and 0.0009 for an aluminum reflector, a change of 2 orders of magnitude. This difference becomes even more distinct as the neutrons below $17 \mathrm{keV}$ are subdivided further, as is done in Table III.

The net leakage into a reflector containing a boron control vane is presented in the second section of Table II. The difference between these leakages (that is, the leakage into the boron-free reflector minus the leakage into the boron-containing reflector) is the parameter by which the vane poison achieves its controlling effect. This "leakage change" parameter is thus a more directly computable and analyzable measure of the control span. It is presented for four energy groups in the third section of Table II and for the full 16 energy groups in Tables IV and V.

Because of its differential nature, this leakage-change parameter would be expected to amplify the neutronic differences of the various reflectors. An inspection of Tables IV and V shows differences in the lowerneutron-energy spectra with different reflectors are especially pronounced. There is, however, one completely consistent and surprising similarity. It is shown that for all reflectors the change in the leakage for neutron energies above 1.4 (and for carbon and $\mathrm{Al}_{2} \mathrm{O}_{3}$ above $0.4 \mathrm{MeV}$ ) is positive. This literally means that the introduction of boron into the reflector results in 
fewer neutrons above $1.4 \mathrm{MeV}$ being leaked into that same reflector. This occurs in spite of the fact that in some cases $\sim 5.0 \%$ of the total neutrons absorbed by the control poison are neutrons above $1 \mathrm{MeV}$. This unexpected phenomenon is produced by a shift in the spatial distribution of the fissionneutron source caused by bringing poison close to the core-reflector interface. The proximity of the poison decreases the fission-neutron source at the core edge and thus reduces the leakage of neutrons from the core edge region. The effect of this leakage decrease is most pronounced for neutrons above $0.4 \mathrm{MeV}$, for which the transport mean free path is large.

This energy dependence of the leakage change points out a mechanism which will favor the "hard-spectrum reflectors" for designs having radially flattened power distributions. For most of the reflectors considered in this study, radial power flattening would be achieved by increasing the fuel concentration in the outer regions of the core. The degree of variation of fuel concentration would be sizeable for the hard-spectrum reflectors and quite small for the $\mathrm{Al}_{2} \mathrm{O}_{3}$ and carbon reflectors. A shift of the fission-neutron source toward the core edge produced by an actual shift of fuel would not be changed by the inward rotation of the control drums. The increase in neutron leakage obtained in this manner would thus be available for control purposes.

An accurate analysis of this effect for all of the eight reflectors concerned would require eight separate multiregion cores and consequently was not attempted. A single analysis for the aluminum-reflected core showed a core with a radially flattened power distribution (power flattening achieved by three separate fuel concentration regions) and a control span $\sim 15 \%$ higher than the unflattened case.

Another positive change in the leakage of neutrons shown in Tables IV and $\mathrm{V}$ and occurring below $3 \mathrm{keV}$ is produced, by a quite different mechanism, through the introduction of a $\mathrm{B}+\mathrm{H}$-containing control vane into the hard-spectrum reflectors ( $\mathrm{Al}, \mathrm{Ni}, \mathrm{Fe}, \mathrm{Mo}$, and $\mathrm{Zr}$ ). This phenomenon is due to the fact that prior to the introduction of the hydrogen-containing control vane the neutron population below energies of $3 \mathrm{keV}$ is vanishingly low. The introduction of the $\mathrm{B}+\mathrm{H}$ vane through its moderating ability actually acts as a source for these neutrons. As Table $\mathrm{V}$ further shows, this increase in backleakage of neutrons toward the core is reversed for energies below $30 \mathrm{eV}$ in case of the nickel and iron reflectors. This indicates that the increased absorption cross sections at these energies outweighed the neutron-moderation source. These qualitative observations about the energy distribution of the leakage neutrons imply that the hard-spectrum reflectors in this sequence of calculations have not yet realized their full control potential. The concentration of boron or the ratio of boron to hydrogen can be changed to a degree whereby the positive leakage occuring below $3 \mathrm{keV}$ is eliminated. This "unrealized control potential" provides the basis for the control vane optimization section. 
Tables VI and VII present the energy distribution of the neutrons absorbed by the boron in the boron- and the B+H-containing control vanes. The absorption of neutrons in the vane is the primary reaction which produces the control span, and it has the added advantage of being easily computed. It would thus be advantageous if the absorption fraction could be used in place of the calculated control span or even the leakage change. This, however, cannot be done simply. As is shown in Table I, for a range of reflectors the interchange of $50 \%$ of the vane boron with a hydrogenous moderator results in a lower fraction of neutrons absorbed in the reflector. The decrease in the total fraction of neutrons absorbed is then associated with an increased total control span. As shown further in Table $V$, this increase in control span is realized in spite of the fact that the hydrogenous moderator actually increases the backleakage of neutrons below $3 \mathrm{keV}$ into the core. Obviously, the importance of the neutrons absorbed and leaked back into the core is extremely dependent on their energy. This energy dependence is presented in Section IV, where it is shown that the reflector adjoint flux decreases significantly for neutron energies below $5 \mathrm{keV}$. The decrease in adjoint flux is caused by several factors. For one, the resonance absorption of the tungsten, which is a major core component, lowers the ratio of core fission to capture for these neutron energies. Further, the return probability for lower-energy neutrons is lower because of their lower mean free transport length. The existence of this adjoint-flux depression means that absorption is not the only method by which reactivity can be decreased. The moderation of neutrons, quite independent of their eventual capture, also will usually result in a loss of reactivity.

TABLE VII Absorption Fraction in $\mathrm{H}+\mathrm{B}$ Control Section

(Source in Boron-free Problem Normalized to l)

\begin{tabular}{|c|c|c|c|c|c|c|c|c|}
\hline \multirow{2}{*}{$\begin{array}{l}\text { Energy } \\
\text { Group }\end{array}$} & \multicolumn{8}{|c|}{ Reflector Materıal } \\
\hline & Depleted Uranıum & Alumınum & $\mathrm{Al}_{2} \mathrm{O}_{3}$ & Nickel & Iron & Molybdenum & Carbon & Zircontum \\
\hline 1 & 0000575 & $634 \times 10^{-5}$ & 0000111 & 0000427 & 00000479 & $000004 \%$ & $447 \times 10^{-5}$ & $444 \times 10^{-5}$ \\
\hline 2 & 000125 & 00002082 & 0000225 & 0000615 & 00001716 & 0000232 & 0000214 & 0000201 \\
\hline 3 & 0000497 & 00001342 & 00001044 & 0000238 & 00002044 & 0000397 & 00001108 & 0001289 \\
\hline 4 & 000262 & 0000972 & 0000775 & 000150 & 0001344 & 000247 & 0000703 & 0001280 \\
\hline 5 & 001174 & 0005266 & 0005084 & 000640 & 0006310 & 000853 & $00041 \%$ & 0006440 \\
\hline 6 & 001015 & 0005285 & 0008922 & 000749 & 0006492 & 000886 & 0007277 & 0007477 \\
\hline 7 & 000511 & 0003189 & 0009886 & 000674 & 0004926 & 000560 & 0010044 & 000598 \\
\hline 8 & 000236 & 0001800 & 0009737 & 000524 & 0004417 & 000270 & 0012319 & 000405 \\
\hline 9 & 000108 & 0000964 & 0008524 & 000505 & 0003443 & 000105 & 0013353 & 000239 \\
\hline 10 & 0000333 & 0000333 & 0004470 & 000275 & 0001764 & 0000334 & 000868 & 0000855 \\
\hline 11 & 0000108 & 00001417 & 0002460 & 000150 & 0000936 & 0000127 & 0.005872 & 0000361 \\
\hline 12 & $<10^{-5}$ & $617 \times 10^{-5}$ & 0001349 & 0000788 & 0000484 & $<10^{-5}$ & 0004051 & 0000158 \\
\hline 13 & & $196 \times 10^{-5}$ & 0000567 & 0000286 & 0000180 & & 0002238 & $507 \times 10^{-5}$ \\
\hline 14 & & $59 \times 10^{-6}$ & 0000222 & 00000946 & 0000058 & & 0001167 & $147 \times 10^{-5}$ \\
\hline 15 & & $18 \times 10^{-6}$ & 0000118 & 00000355 & 0000021 & & 0000956 & $48 \times 10^{-6}$ \\
\hline 16 & & $36 \times 10^{-7}$ & 00000555 & $666 \times 10^{-6}$ & $383 \times 10^{-6}$ & & 0001238 & $96 \times 10^{-7}$ \\
\hline Total & 003588 & 0018446 & 005261 & 003917 & 003080 & 003043 & 0072462 & 003060 \\
\hline
\end{tabular}

D. Correlation of Directly Calculable Control Parameters with the Control Span

One of the important objectives of the study was the definition of a parameter which would be proportional to the control span but which could 
be calculated more directly. As noted in the introduction, a simply analytical expression which would meet the above requirements does not exist. An analytical expression was thus ruled out, and the objective became the definition of a not necessarily simple but more directly computable parameter than the control span. An additional requirement of such a parameter is that it would demonstrate the dependence of the control span on neutron energy.

An obvious candidate for such a role is the already discussed "leakage change." Mathematically this quantity is represented as

$$
\text { Change in net leakage }=\sum_{j=1}^{16}\left[\mathrm{~L}_{\mathrm{OUT}}-\mathrm{L}_{\mathrm{IN}}\right] \text {, }
$$

where

$$
\begin{aligned}
\mathrm{L}_{\mathrm{OUT}}= & \text { net leakage fraction of neutrons with the reflector with } \\
& \text { control drums in the OUT position; } \\
\mathrm{L}_{\mathrm{IN}}= & \text { same as above, with drums at the IN position. }
\end{aligned}
$$

The leakage fraction is normalized with respect to a total reactor fission source of 1 and the summation is over 16 energy groups.

This parameter is plotted versus the calculated control span in Fig. 1. A line representing the ideal direct correlation which would be most advantageous for calculational purposes is also given. As seen, the

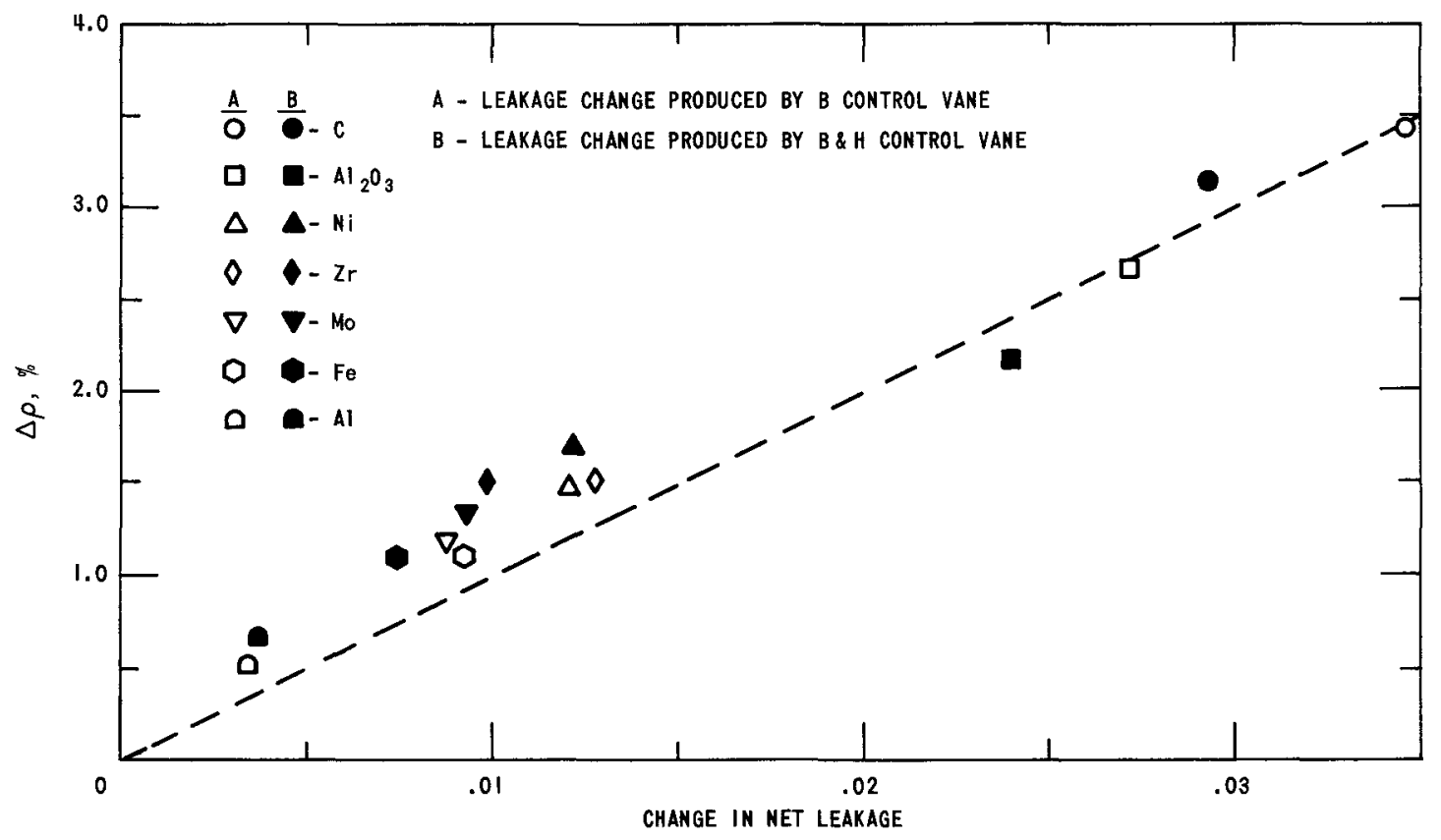

Fig. 1. Control Span vs Change in Net Leakage 
degree of correlation is not sufficient to allow the use of the leakage change in place of the control span. In particular, it is shown that the small leakage changes produced by the poisons located in the group of hard-neutronspectrum reflectors are in terms of reactivity more effective than the larger leakage changes of the softer-spectrum reflectors. This is related to the general higher importance of the harder-spectrum neutrons, which is treated further in Section IV.

The departure from a linear relationship demonstrates the necessity to weight the leakage change by some type of neutron importance. Several forms of group-by-group adjoint-flux weightings were attempted (see Fig. 2). The weighting is of the form

$$
\left[\begin{array}{l}
\text { Adjoint-flux- } \\
\text { weighted change } \\
\text { in net leakage }
\end{array}\right]=\sum_{j=1}^{16}\left[\mathrm{~L}_{\mathrm{OUT}}-\mathrm{L}_{\mathrm{IN}}\right]_{j} \phi_{\mathrm{j}}^{+} \text {, }
$$

where $\phi_{\mathrm{j}}^{+}$is in turn determined by the equations applicable to the weighting scheme:

$$
\begin{aligned}
& {\left[\begin{array}{l}
\text { Average core } \\
\text { adjoint flux }
\end{array}\right]=\frac{\int_{\text {core }} \phi_{j}^{+} d v}{\sum_{j=1}^{16} \int \phi_{j}^{+} d v} ;} \\
& {\left[\begin{array}{l}
\text { Reflector }- \\
\text { core inter }- \\
\text { face adjoint } \\
\text { flux }
\end{array}\right]=\frac{\phi_{j}^{+}}{\sum_{j=1}^{16} \phi_{j}^{+} \text {at core edge }} ;} \\
& {\left[\begin{array}{l}
\text { Average } \\
\text { reflector } \\
\text { adjoint flux }
\end{array}\right]=\frac{\int_{\text {refl }} \phi_{j}^{+} d v}{\sum_{j=1}^{16} \int_{r e f l} \phi_{j}^{+} d v} .}
\end{aligned}
$$

Of the three weighting schemes, the last, that is, the weighting by the average reflector adjoint flux, was the most successful (see Fig. 2). Both the core adjoint and the interface adjoint weightings produce two essentially separate correlations: one for the hard-spectrum reflectors, giving a $\Delta \rho$ to weighted leakage-change ratio of $\sim 1.5$, and another one for the softer-spectrum reflectors carbon and $\mathrm{Al}_{2} \mathrm{O}_{3}$, for which the ratio is 1.05. The reflector-averaged adjoint by weighting the higher-energyregion leakages more heavily brings both of these correlations quite close together. 


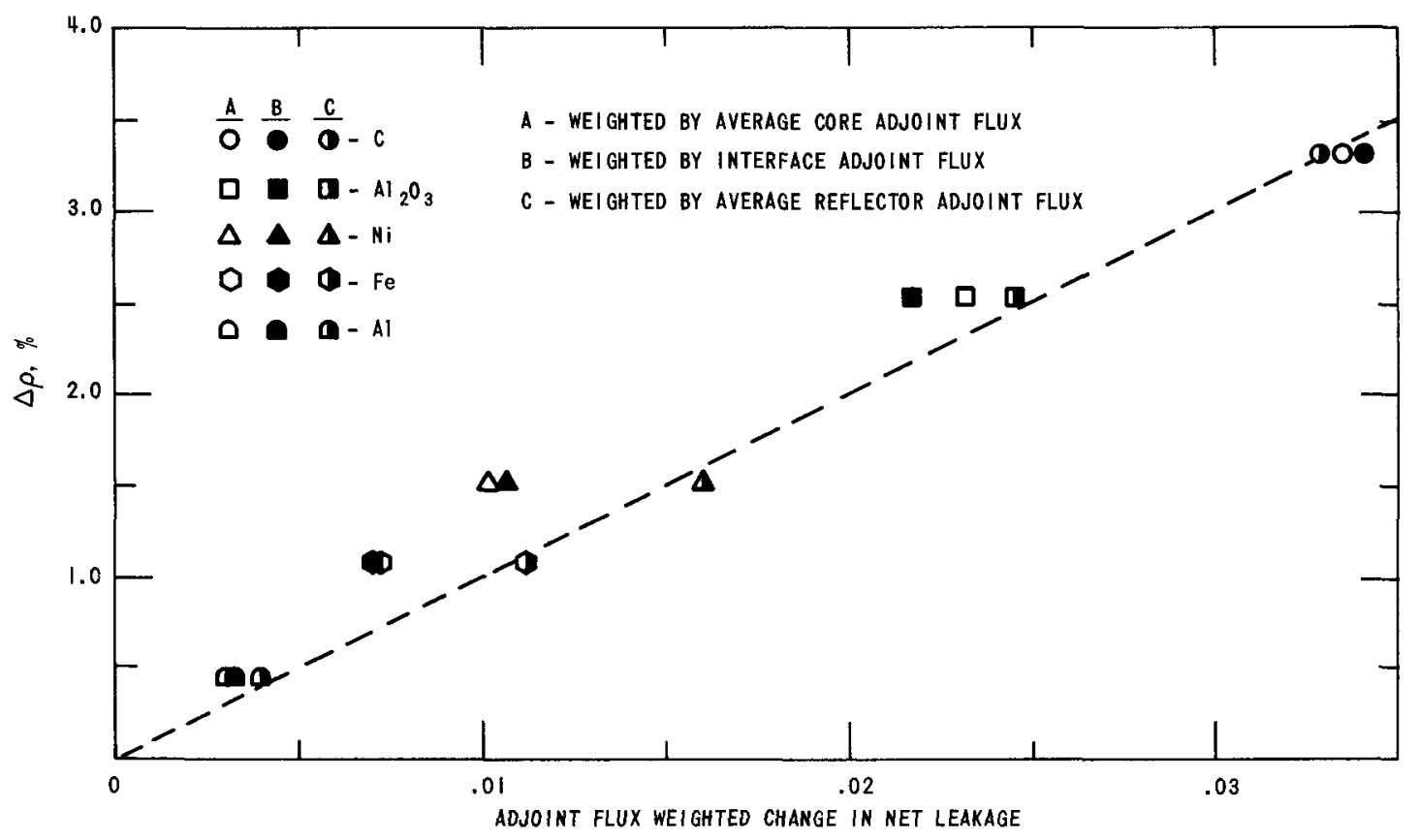

Fig. 2. Control Span vs Adjoint-flux-weighted Change in Net Leakage

The calculation of the energy-dependent leakage change has the advantage of bringing out the neutronic differences of the reflectors which are obscured in a control-span computation, but aside from that, it is still cumbersome. A much more simple computation would be the calculation of the neutron absorption fraction in the boron poison. As noted previously, neutron capture is not the only mechanism by which a control vane removes neutrons; therefore, the capture fraction could not be expected to correlate the control span for vanes having different compositions. This drawback is not a serious one in a control-span calculation since in a calculational set required to determine the control span the same vane composition appears at the positions with drums IN and at the drums OUT. Therefore, it was of interest to test the degree to which the absorption fractions of an identical control vane could be correlated to the control span.

The straightforward correlation of the unweighted absorption fraction again demonstrates the difference in importance that neutrons of various energies have (see Fig. 3). A simple weighting by the local controlvane adjoint flux improved the correlation markedly, as shown in Fig. 3 . The adjoint-flux-weighted absorption fraction was consequently used in some of the more extensive calculations required in obtaining optimum thicknesses of control vane. A code was written in FORTRAN for this purpose and is presented in Appendix C. 


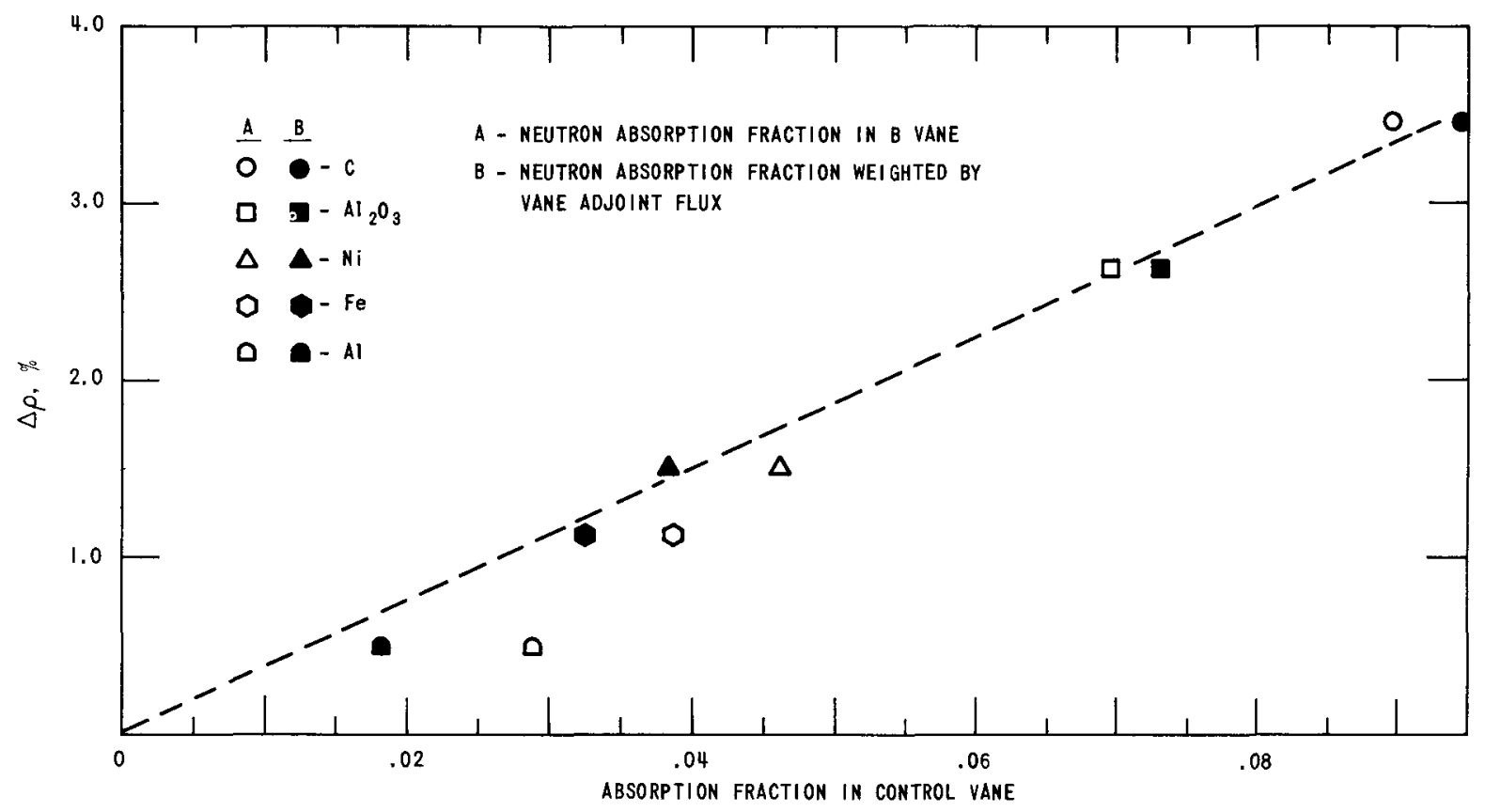

Fig. 3. Control Span vs Neutron Absorption Fraction in Control Vane 


\section{EVALUATION OF POISON-FREE REFLECTOR MATERIALS}

The ultimate limit on the amount of reactivity which can be controlled from a reflector is obviously set by the reactivity worth of the reflector itself. As will be described in more detail in Section IV, the various reflector materials differ significantly in the manner by which this maximum reactivity limit can be approached. The fraction of the maximum which can be reached by employing various design steps is, however, remarkably uniform for all materials.

This fraction is dependent most directly on the solid angle which is spanned by the control vanes when the drums are at the IN position and by the distance of the control drums from the core. For the range of design parameters used in this study, it was determined that the control span can approach $\sim 60$ to $75 \%$ of the total reactivity worth of the reflector. From the control-span point of view a good first rule in choosing a reflector material is to choose a material which has a large total reactivity worth. This worth is intimately connected with the thickness and density of the reflector. Section III presents a study of the dependence of the reflector worth for eight materials over the entire practical range of thickness and volume.

\section{A. Effect of Radial Reflector Volume on Conserved Reactivity}

Aside from some limiting and thus all other criteria-overriding design parameters, the most important characteristics determining the choice of a radial reflector material will be its volume and weight. The interdependence of weight and volume is straightforward if only the radial reflector is considered. In general, this will not be a realistic approach since the important design-merit criterion is the total weight of the reactor and associated equipment, of which the radial reflector constitutes only a part. This overall weight is likely to be influenced more directly by the volume or thickness of the radial reflector, since increases in reflector thickness will usually result in increases in the weights of associated reactor equipment. Further, the thickness of the reflector is more directly related to its neutronic effectiveness. Reflector thickness is therefore the more important criterion and will be considered first.

It has become standard practice to evaluate reflector effectiveness in terms of reflector savings. This parameter gives a direct indication of the saving in core volume that a reflector can produce. For the present study, however, the core volume is determined and held fixed by such overriding specifications as total and specific core power; therefore, it is more appropriate to evaluate the effect that a reflector has on a fixed-volume core. For this reason the concentration of fuel in the core or the critical mass of a fixed core volume was chosen as a measure of radial reflector effectiveness. 
The calculations were performed in cylindrical geometry by diffusion theory with the 16-energy-group cross-section set described in Appendix A. A constant axial buckling was maintained for all calculations, and the axial leakage produced by the buckling varied slightly between 11 and $12 \%$ of the total neutrons produced. The important radial leakage which directly determines radial reflector effectiveness varied from $32 \%$ for the bare core to $17 \%$ for the thickest $(50 \mathrm{~cm}) \mathrm{Al}_{2} \mathrm{O}_{3}$ radial reflector. All problems were iterated to a critical $\mathrm{U}^{235}$ concentration.

The change in the net radial leakage produced by the reflector, which is expressed in terms of the change in critical mass, is thus the index of reflector merit. The savings in the total $\mathrm{U}^{235}$ inventory are of little importance by themselves; what makes them important indirectly is that they are proportional to the amount of reactivity which is available in a given reflector for control purposes.

The rotation of control drums into the IN position has a similar neutronic effect as the removal of the reflector section extending beyond the poison of the control vane. In the same way, the rotation of the drums into the OUT position removes the reactivity-enhancing effect of the outer regions of the radial reflector extending beyond the control drums. The important point is that the poison subtracts reactivity in both locations and that therefore the control span is directly proportional to the difference of these subtracted reactivities. Therefore, to determine the ultimate limit of the control span for a given reflector it is necessary to compare the effectiveness of two reflector thicknesses. One thickness representing the control drums in IN position is the distance of the outer radius of the control drum from the core-reflector interface; the second thickness is the distance from the inner edge of the control vane to the core-reflector interface when the drum is in the OUT position.

With this in mind, Figs. 4 and 5 can be used to provide a good indication of what influence a certain radial reflector thickness will have upon the ultimately achievable control span. It is assumed that at the IN position of the drums the poison is located close to the core-reflector interface, then the achievable control span is proportional to the decrease in the critical mass produced by the reflector of a given thickness. Table VIII presents the data in tabular form. These data have been used to construct merit scales for reflectors of various thicknesses. Thus, for a $10-\mathrm{cm}$-thick reflector, the merit scale would run (beginning with the most advantageous reflector):

Mo, $\mathrm{Al}_{2} \mathrm{O}_{3}, \mathrm{Ni}$, Depleted U, $\mathrm{Zr}, \mathrm{C}, \mathrm{Fe}$, and $\mathrm{Al}$.

For a $20-\mathrm{cm}$ reflector it would be:

$$
\mathrm{Al}_{2} \mathrm{O}_{3}, \mathrm{Mo}, \mathrm{Zr}, \mathrm{Ni}, \mathrm{C} \text {, Depleted U, Fe, and } \mathrm{Al} \text {. }
$$

For a 30-cm reflector:

$$
\mathrm{Al}_{2} \mathrm{O}_{3}, \mathrm{Z}_{\mathrm{r}}, \mathrm{C}, \mathrm{Mo}, \mathrm{Ni}, \mathrm{Fe} \text {, Depleted U, and } \mathrm{Al} \text {. }
$$




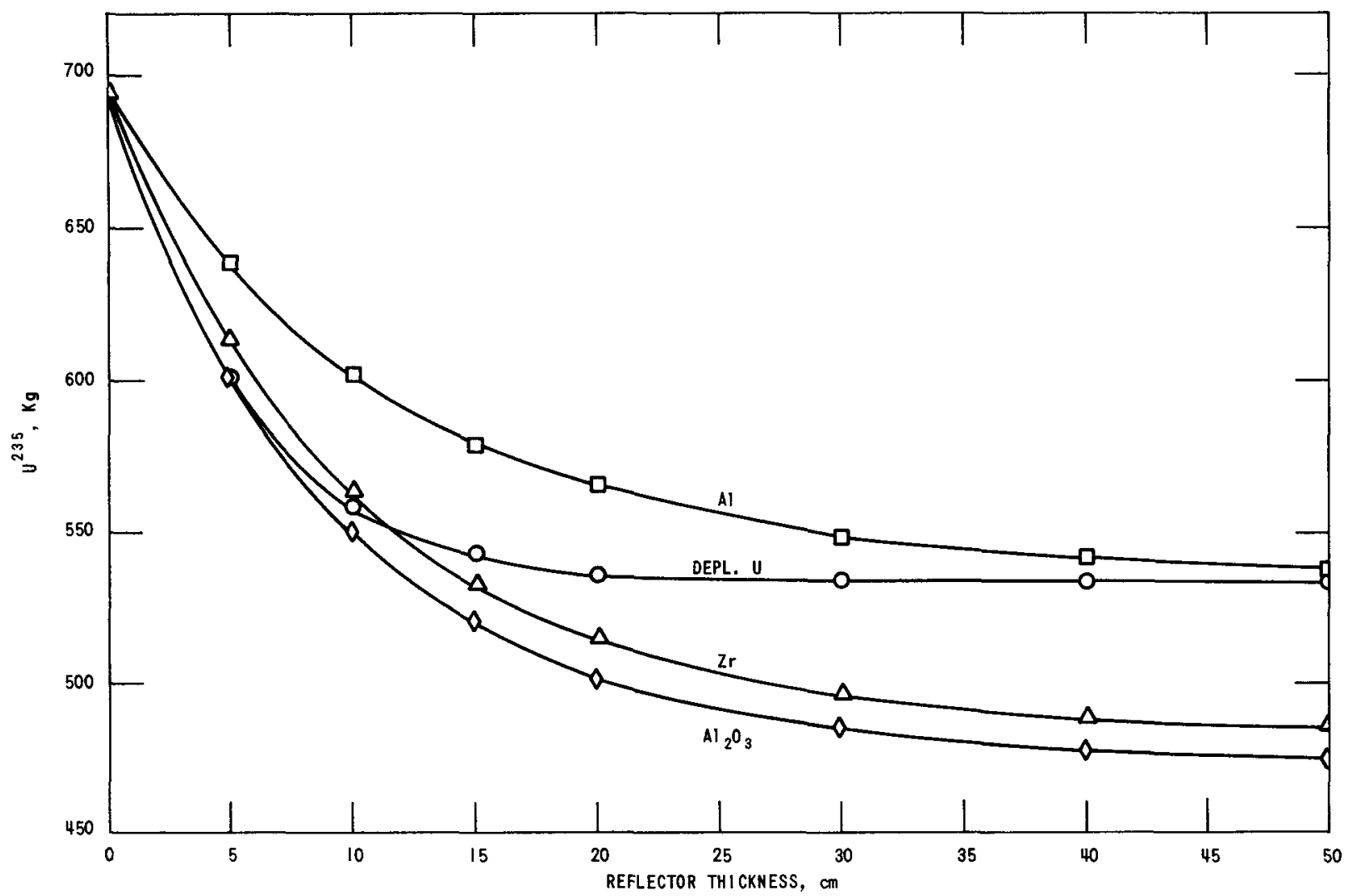

Fig. 4. Critical Mass vs Reflector Thickness (of $\mathrm{Al}, \mathrm{Al}_{2} \mathrm{O}_{3}, \mathrm{Zr}$, and Depleted $\mathrm{U}$ ) for a Constant-volume Core

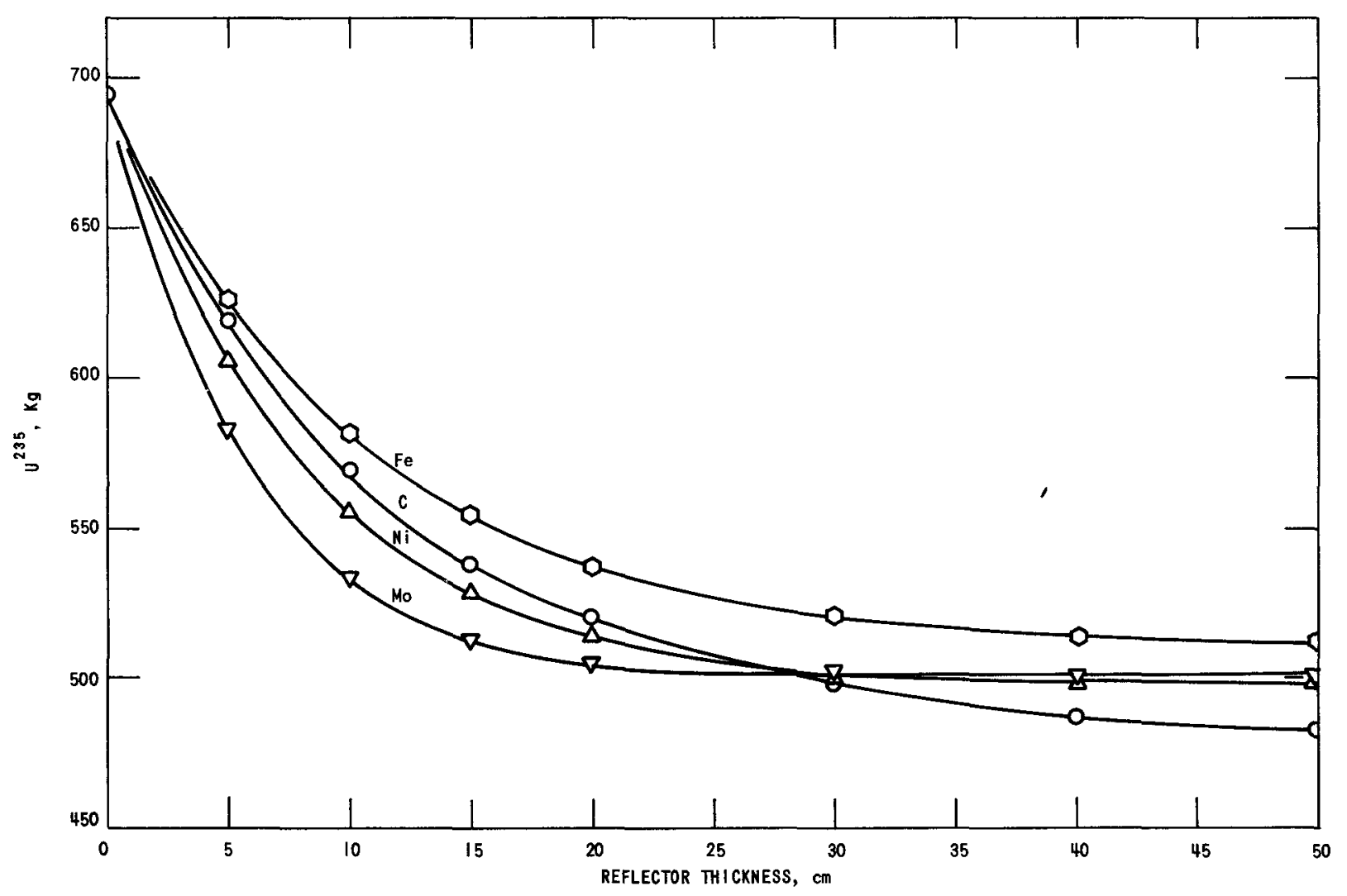

Fig. 5. Critical Mass vs Reflector Thickness (of $\mathrm{Fe}, \mathrm{Ni}, \mathrm{Mo}$, and $\mathrm{C}$ ) for a Constant-volume Core 
TABLE VIII. Critical Mass vs Radial Reflector Mass for a Constant-volume Core

\begin{tabular}{|l|l|l|r|r|r|r|r|r|}
\hline \multirow{2}{*}{$\begin{array}{l}\text { Reflector } \\
\text { Material }\end{array}$} & Mass & \multicolumn{7}{|c|}{ Reflector Thickness, cm } \\
\cline { 3 - 9 } Depleted & Core Fuel & 600.6 & 558 & 542 & 536.1 & 533 & 533 & 533 \\
$\mathrm{U}$ & Reflector & 1362 & 2920 & 4648 & 6553 & 10900 & 15955 & 21725 \\
$\mathrm{Al}$ & Core Fuel & 639 & 603 & 579 & 564 & 548 & 541 & 538 \\
& Reflector & 217 & 462 & 735 & 1037 & 1724 & 2525 & 3437 \\
$\mathrm{Al}_{2} \mathrm{O}_{3}$ & Core Fuel & 601.3 & 550 & 520.6 & 503.3 & 485.5 & 478 & 475 \\
$\mathrm{Ni}$ & Reflector & 272 & 579 & 921.7 & 1300 & 2161 & 3164 & 4308 \\
$\mathrm{Ne}$ & Core Fuel & 606 & 555 & 528 & 514 & - & 500 & 499 \\
$\mathrm{Fe}$ & Reflector & 659 & 1405 & 2236 & 3154 & - & 7677 & 10455 \\
$\mathrm{Mo}$ & Core Fuel & 625 & 581 & 554 & 537 & 520 & 514 & 511 \\
& Reflector & 586 & 1248 & 1986 & 2800 & 4656 & 6817 & 9283 \\
$\mathrm{C}$ & Core Fuel & 582.6 & 532 & 512 & 504 & 500 & 499 & 499 \\
& Reflector & 751 & 1601 & 2548 & 3594 & 5976 & 8749 & 11913 \\
$\mathrm{Zr}$ & Core Fuel & 617 & 567 & 537 & 518 & 497 & 486 & 481 \\
& Reflector & 139 & 297 & 472 & 667 & 1109 & 1623 & 2210 \\
& Core Fuel & 613 & 563 & 532.3 & 514 & 495.5 & 488 & 485.6 \\
& Reflector & 482 & 1026 & 1633 & 2304 & 3830 & 5608 & 7636 \\
\hline
\end{tabular}

The $20-\mathrm{cm}$ merit scale coincides closely with the reflector merit scale obtained in the initial evaluation of reflectors presented in Section. II, for which calculations were made with a $25-\mathrm{cm}$-thick reflector in spherical geometry.

Figures 4 and 5 demonstrate well the crucial importance of the distance between the core and the control drum. The first 5-cm thickness can account for 20 to $50 \%$, depending on the reflector material, of the total reflector worth. In the design of a reactor system this important parameter will probably be fixed by other than control considerations. Thus, once it is determined it could well figure in the selection of the reflector material. For example compare an iron and a molybdenum reflector (see Fig. 5). If the control drum is almost adjoining the core, a molybdenum reflector would have a better ultimate control potential at any thickness than a comparable iron reflector. If, however, an unreducible distance of $5 \mathrm{~cm}$ exists between the core and control drum, the situation is reversed. For a reflector of $25-\mathrm{cm}$ thickness an iron reflector could achieve a total control span $\sim 10 \%$ larger than a molybdenum reflector of the same thickness.

The ultimate thickness of the reflector will usually be determined by some weight or volume criteria. If the control span is the limiting parameter determining reflector thickness, then a reflector of $\sim 30 \mathrm{~cm}$ would 
be about the maximum thickness that should be considered for most materials. Actually, as shown in Figs. 4 and 5, for most materials even an increase above $20 \mathrm{~cm}$ in thickness results in relatively small increases in reflector effectiveness. The maximum thickness of the reflector, however, usually will be significantly larger than the important average distance of the control-vane poison from the core when the drums are in the OUT position. This is so since for some of the reflector materials the control vanes themselves can have an appreciable thickness. The average poison distance will be decreased further because of the curvature of the control drum. For this reason the amount of reactivity lost to the poison in the OUT position is larger than would be estimated from Figs. 4 and 5.

As will be shown in Section IV, even the fairly small amounts of reactivity lost for a 25 -cm-thick reflector can be significant. The control span is proportional to the difference in reactivity existing between two control-drum positions. Therefore, even a relatively small change in the absolute reactivity can be considerably amplified in the difference. Thus, increasing reflector thickness from 20 to $24 \mathrm{~cm}$ resulted in increases in obtainable control span of $21 \%$ for $\mathrm{Al}_{2} \mathrm{O}_{3}$ and of $14 \%$ for nickel reflectors. Increases past 25 to $30 \mathrm{~cm}$ would result in increases of only $\sim 5-10 \%$ in the achievable control span for $\mathrm{C}, \mathrm{Zr}$, and $\mathrm{Al}_{2} \mathrm{O}_{3}$ radial reflectors. For the other reflector materials the increases would be even smaller.

\section{B. Effect of Radial Reflector Weight on Conserved Reactivity}

The differences between reflectors would be expected to be grossly amplified if the reflector effectiveness is correlated on a mass rather than on a volume basis. As noted, the mass of the radial reflector influences the total mass of the reactor and associated equipment assembly to a lesser degree than its thickness. For the heavy-metal reflectors, however, the mass of the radial reflector itself can become very substantial. The variation of the fuel inventory with respect to reflector weight is presented in Table VIII and in Figs. 6 and 7. A merit ranking based on reflector mass is very different than an equivalent ranking based on reflector thickness. For example, a ranking which would roughly correspond to an achievable control span of $\sim 4.5 \% \Delta \mathrm{k}$ requires reflectors in order of increasing mass as follows:

$$
\text { C, } \mathrm{Al}_{2} \mathrm{O}_{3}, \mathrm{Zr}, \mathrm{Mo}, \mathrm{Ni}, \mathrm{Fe}, \mathrm{Al} \text {, and Depleted U. }
$$

The variation in the radial reflector masses represented by the above ar rangement are quite extreme. The carbon reflector required for a control span of $\sim 4.5 \% \triangle \mathrm{k}$ weighs $\sim 600 \mathrm{~kg}$, the depleted-uranium reflector $\sim 10,000 \mathrm{~kg}$.

It should be noted here again that these weight estimates and the curves of Figs. 6 and 7 are to be used more for the relative comparison of reflector materials than in the absolute sense. The computational model employed in the generation of the curves is after all a very straightforward one. A symmetric radial reflector of a constant and identical density is used for all the eight reflector materials. It is probable that in the design 
of an actual reflector a weight saving of $20 \%$ or even higher can be realized without reducing the achievable control span. Thus, for example, the density of the reflector material located between the control drums and also the density of the reflector material located between the core and control drums could be reduced. Further possibilities in weight reduction exist if composite rather than one material reflectors are employed.

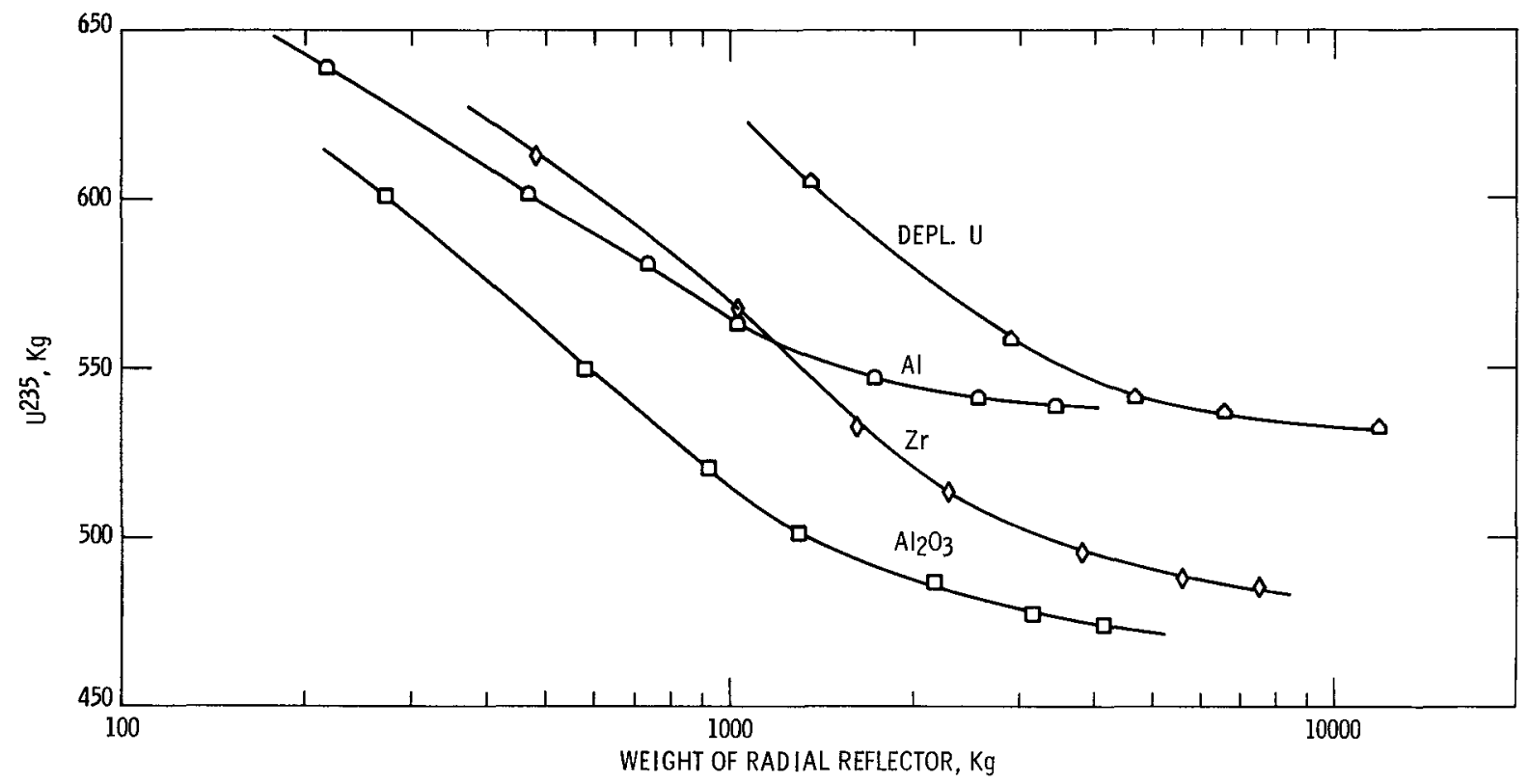

Fig. 6. Critıcal Mass vs Radıal Reflector Mass (for A1, $\mathrm{Al}_{2} \mathrm{O}_{3}$, $\mathrm{Zr}$, and Depleted U) for a Constant-volume Core

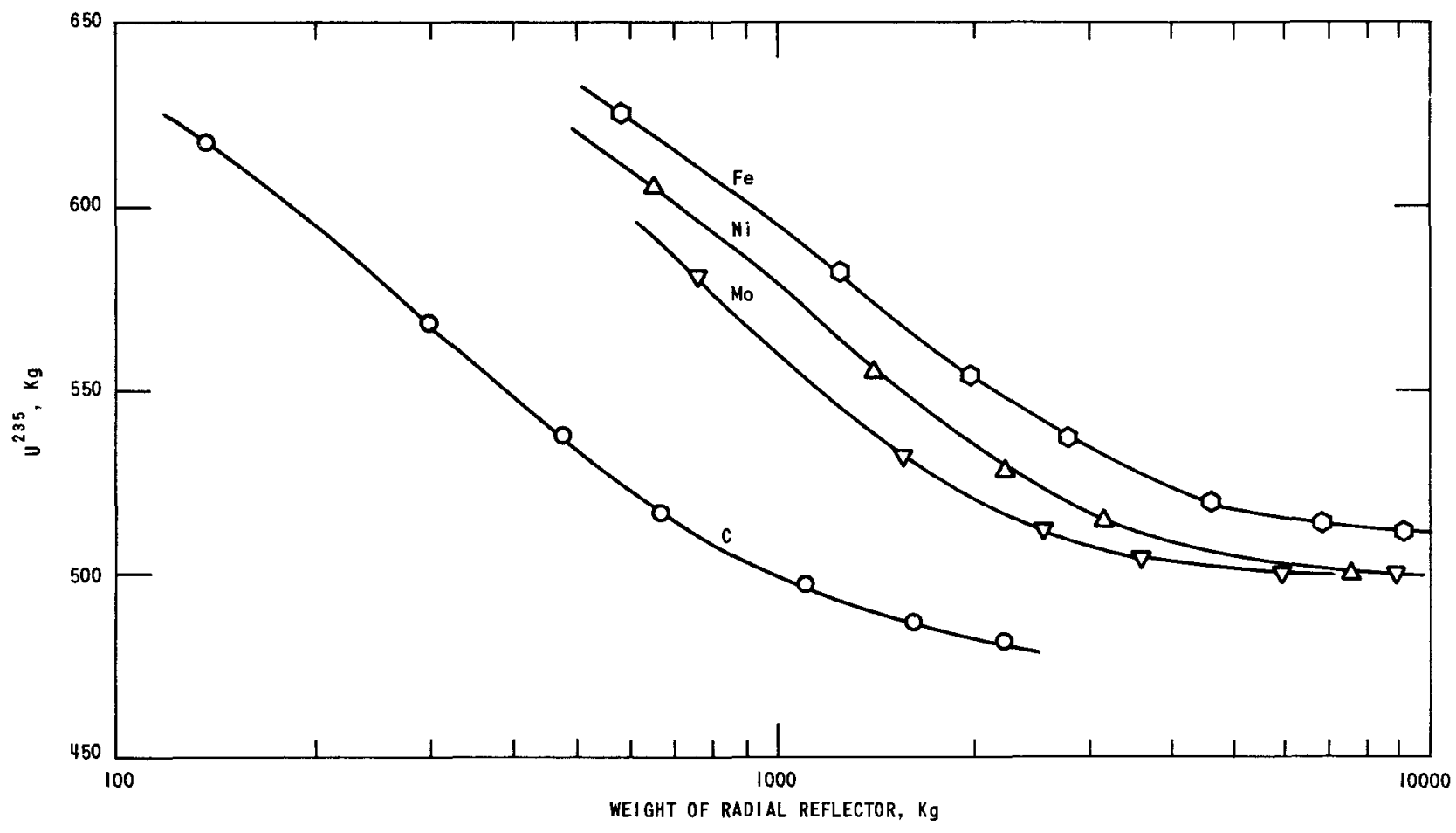

Fig. 7. Critical Mass vs Radial Reflector Mass (for Fe, Ni, Mo, and C) for a Constant-volume Core 


\section{OPTIMIZATION OF CONTROL MECHANISMS}

Two control-vane parameters independent of other design considerations exhibit fairly well-defined optima with respect to the total control span: 1) control-vane thickness and 2) control-vane composition. The optimum values of these parameters are influenced by imposed design conditions, such as the reflector thickness, the nature of the region between the core and the reflector, control-drum diameter, the distance of the control drum from the core-reflector interface, and especially the reflector composition. Only the important reflector composition is taken as a systematic variable in this comparison, although the influence of some of the other design conditions are estimated.

The nuclear properties of the reflector materials separated from the perturbing effect of the control poison are analyzed in Section III. In the optimization of the control mechanism presented in this section a reflector thickness was chosen which approaches an infinite effective thickness for most of the reflector materials. Thus, the reflector thicknesses in all of the studies is $24 \mathrm{~cm}$, the control-drum diameter is $20 \mathrm{~cm}$, and the outer edge of the drum is $4 \mathrm{~cm}$ from the core-reflector interface.

\section{A. Control-vane Geometry}

Figure 8 shows a schematic representation of a control drum and control vane. Most of the indicated dimensions do not have an optimum with respect to reactor controllability. For them the controllability cri-

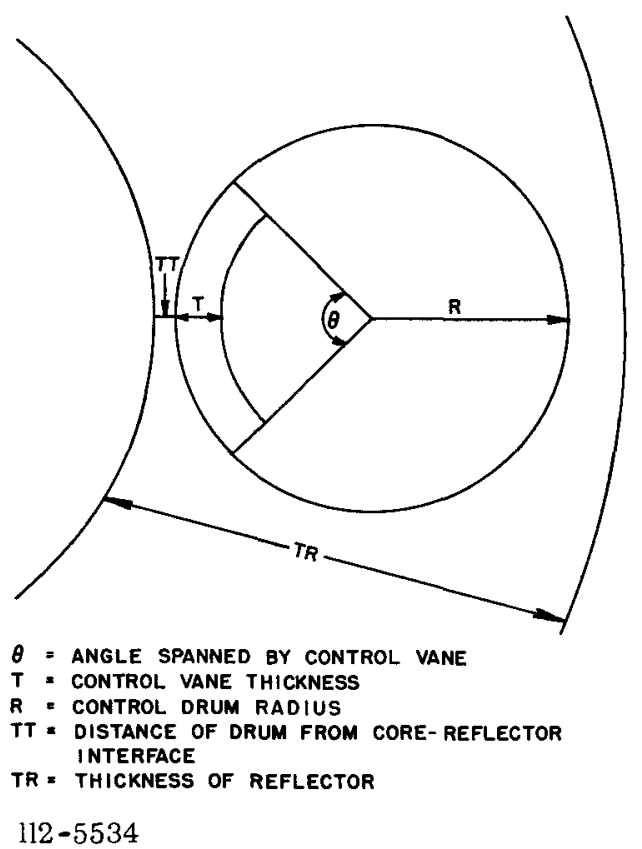

Fig. 8. Schematic Representation of Control-vane Geometry terion can only indicate a preferred design direction. The design values of these dimensions have to be imposed by some other criteria. For this study what are believed to be practical values have been chosen. These include:

TT-- The distance between the control drum and the core edge. Both the thickness of this region and its composition very strongly affect the potential control span. Every design effort should be made to minimize this distance both in terms of thickness and total absorptivity. For this study $\mathrm{T} T$ is $4 \mathrm{~cm}$, and the region is composed of reflector material. The sensitivity of the control span with respect to $T \mathrm{~T}$ can be inferred from the following calculated values: Reduction of $\mathrm{TT}$ to $2 \mathrm{~cm}$ resulted in an increase in the control span by $22 \%$ for the $\mathrm{Al}_{2} \mathrm{O}_{3}$ and by 
$30 \%$ for the nickel reflector. The $4-\mathrm{cm}$ value was chosen in these studies because it corresponds to a reasonably minimum design value.

TR--Reflector thickness. For optimum control, TR should be maximized. However, the effect of increasing TR past $25 \mathrm{~cm}$ is small for most reflector compositions. For the present study, TR is assumed to be $24 \mathrm{~cm}$.

R--Control-drum radius. This parameter should be maximized and should assume the maximum value allowed for it by the TR and TT dimensions. For this study $\mathrm{R}$ is chosen to be $10 \mathrm{~cm}$.

$\theta--$ The angle spanned by the control vane. This parameter is fairly independent of other design specifications. It has been difficult in the present study to evaluate its precise influence on the control span, since primarily one-dimensional calculational methods have been employed. In the present study, $\theta$ is assumed to be $120^{\circ}$. In most cases this assumption does not affect the conclusions directly since the conclusions are based on one-dimensional calculations. For these calculations $\theta$ determines only the total volume of the control vane and the material balance of the concentric curtain mocking up the control vane.

B. Control-vane Thickness

The control-vane thickness $T$ (see Fig. 8) differs from the above dimensions in that, in general, it will have a well-defined optimum with respect to the total control span. The optimum thickness varies with the reflector material and is also a function of the control-vane composition. The control span is defined as the reactivity change produced by transferring the control-vane poison from the IN to the OUT position of the drum. The poison is thus not removed, but merely transferred to a region of lower importance. The reactivity held by the poison while the control vane is in the OUT position directly reduces the total available control span. Further, as $\mathrm{T}$ is increased while the control-drum diameter is kept constant, the average distance over which the poison is transported between the IN and OUT positions is reduced. The effect of these geometric properties on the control span are amplified by the self-shielding of the poison.

An analytical determination of an optimum thickness of the control vane is given in Appendix $E$. In order to make the derivation tractable, no self-shielding of the poison is assumed. The purpose of the derivation is to illustrate directly the role of poison-transfer distances in the creation of an optimum vane thickness. This analytical optimum vane thickness for a nonself-shielded vane is $1 / 3 \mathrm{R}$. 
The loss of reactivity produced by control poison while the drums are at the OUT position is shown in Fig. 9 for three of the reflector materials studied. The curve for the $\mathrm{Al}_{2} \mathrm{O}_{3}$ reflector demonstrates both the self-shielding effect of the boron poison and the increase in reactivity loss which is produced when the vane poison of the drum in the OUT position is moved closer to the core by increased control-vane thickness. The first part of the curve departs from linearity as the effectiveness of the added boron is reduced by self-shielding. This effect is reversed for the larger control-vane thicknesses for which the reactivity effect of moving the control poison closer to the core becomes dominant. The same trends, though in a less pronounced degree, can be observed for the other two reflector materials.

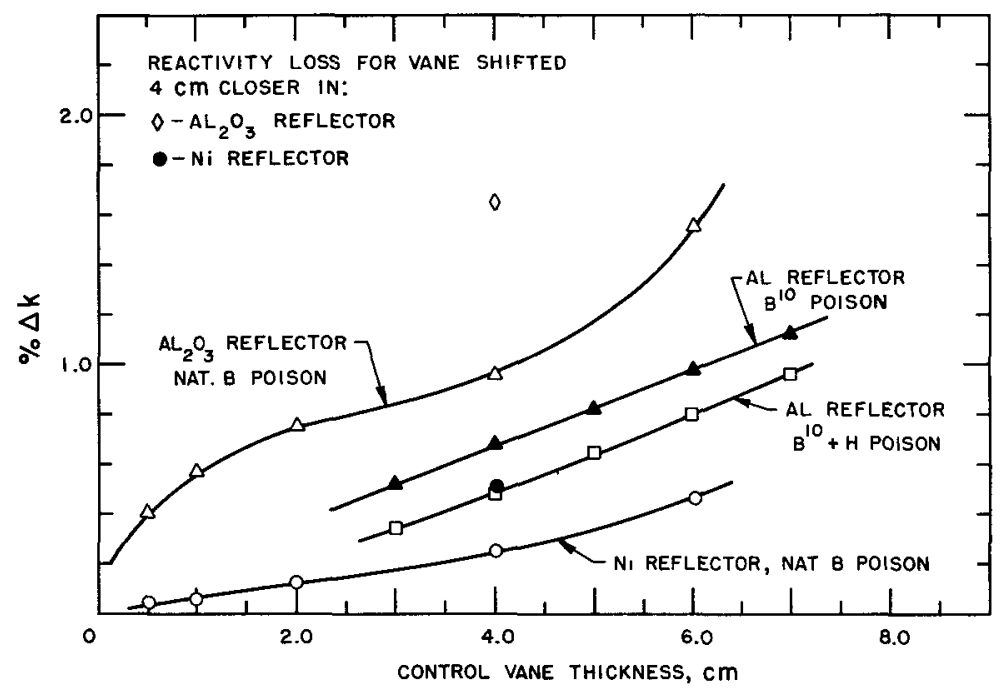

112-5535

Fig. 9. Reactivity Loss Produced by Control Vane at the OUT Position

The curves for the aluminum reflector also show one of the mechanisms which determine the composition dependence for optimum control. It is shown that the substitution of hydrogen for boron reduces the reactivity loss by the control drum in the OUT position for all thicknesses of the control vane. This reactivity shift will not occur in the same degree for the control vanes at the IN position. The lower-energy neutrons which are preferentially absorbed by the boron and hydrogen mixture have a relatively high importance close to the core but a very low importance further away from it.

In addition, two special data points on Fig. 9 (indicated by a diamond and afilled-in circle) show the effect of a decrease in the diameter of the control drum. Such a decrease will move the control poison closer to the core while the drums are at the OUT position and will result in a larger reactivity loss. For both cores cited, an inward shift of $4 \mathrm{~cm}$ (reduction of control-drum diameter from 20 to $16 \mathrm{~cm}$ ) results in almost 
doubling the reactivity loss while the drums are at the OUT position. For the $\mathrm{Al}_{2} \mathrm{O}_{3}$ reflector the reactivity loss is increased from 0.95 to $1.65 \% \Delta \mathrm{k}$; for the nickel reflector from 0.24 to $0.5 \% \Delta \mathrm{k}$. These increases reflect directly upon the total control span which for a typical $\mathrm{Al}_{2} \mathrm{O}_{3}$-reflected case is reduced from $\sim 5$ to $4.3 \% \Delta \mathrm{k}$ and for nickel from $\sim 5$ to $4.7 \% \Delta \mathrm{k}$. The qualitative effect of decreasing control-drum diameter in different reflectors can be estimated from Figs. 4 and 5. The loss in the achieveable control span would be maximum for the low-absorption reflectors $\mathrm{Al}_{2} \mathrm{O}_{3}, \mathrm{Al}, \mathrm{Zr}$, and $\mathrm{C}$, and considerably less for the heavy-metal reflectors $\mathrm{Mo}, \mathrm{Ni}$, and $\mathrm{U}$.

A detailed picture of the dependence of control on control-vane thickness for four neutronically different reflectors is shown in Figs. 10 to 13. Though beryllium is not a direct part of this evaluation, it is included in this comparison because it demonstrates well the role of the degraded neutron spectrum of a reflector. Spectrum softening significantly increases the self-shielding of boron and makes thick control vanes pointless. Once a control vane is essentially black, increase of thickness only results in moving the control poison of the drum in the OUT position closer to the core and produces a smaller control span.

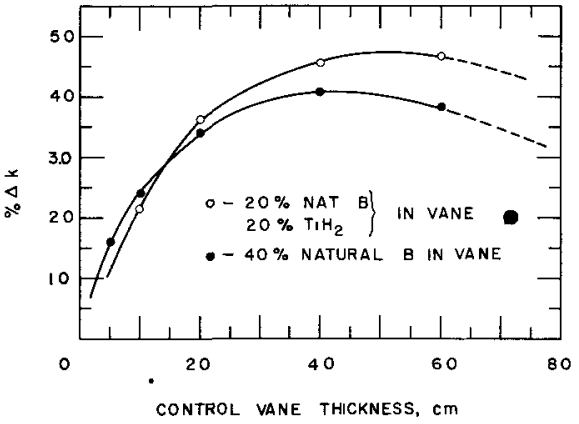

$112-5536$

Fig. 10. Control Span vs Control-vane Thickness for $\mathrm{Al}_{2} \mathrm{O}_{3}$-reflected Reactor

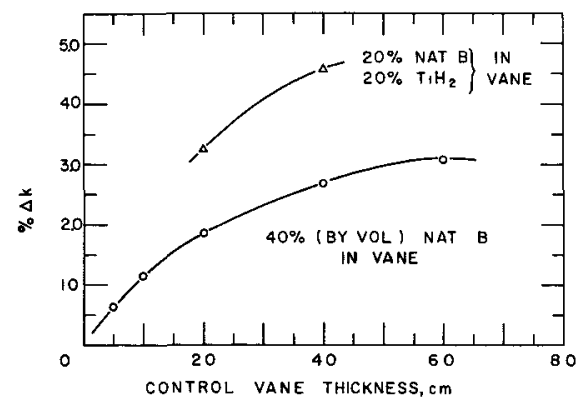

$112-6163$

Fig. 12. Control Span vs Control-vane Thickness for Nickel-reflected Reactor

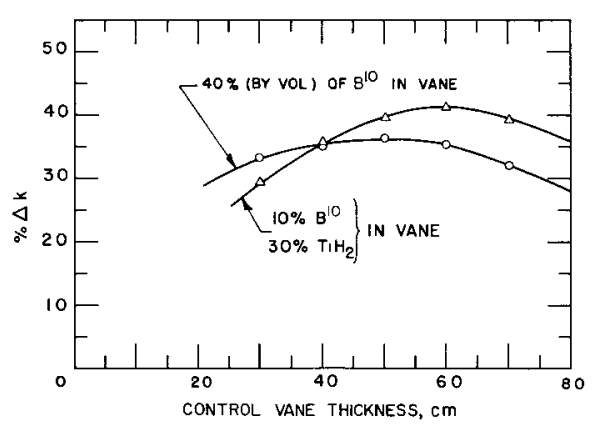

$112-5537$

Fig. 11. Control Span vs Control-vane Thickness for Aluminumreflected Reactor

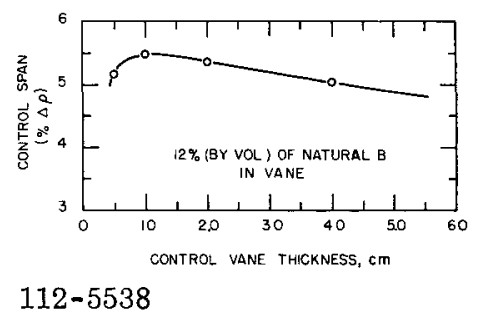

Fig. 13. Control Span vs Control-vane Thickness for Beryllium reflected Reactor 
The figures show that the optimum vane thicknesses of reflector materials $\mathrm{Al}, \mathrm{Ni}, \mathrm{Al}_{2} \mathrm{O}_{3}$, and $\mathrm{Be}$ decrease roughly in proportion to the degree of reflector-spectrum softness. For the control-drum diameter used in the present calculations $(20 \mathrm{~cm})$, the optimum thicknesses are quite large for the nickel and aluminum reflectors, and the optima peaks are fairly broad. For designs employing smaller control-drum diameters, the optimum vane thickness would be smaller and the optimum peaks more sharply defined.

The curves also show the effect on optimum thickness produced by the composition of the control vane. The substitution of a hydrogenous moderator for part of the boron poison produces a larger total control span over part of the range of control-vane thicknesses. Besides increasing the maximum achievable control span, the hydrogenous moderator also shifts the optimum to thicker vanes.

\section{Control-vane Composition}

The goal in optimizing control-vane composition can be stated as follows: obtain the maximum possible reactivity los s with a fixedvolume control vane. The emphasis on volume is important. There are some design limitations which restrict the volume in an absolute sense. These include control-drum diameter and provisions for cooling the control vane. There are several other design considerations which make it preferable to have the minimum vane volume. Some of these include weight and the moment of inertia of the reactivity penalty due to increased vane thickness, and limits on rotational speeds of the control drum.

At the start of the study a number of absorbers were evaluated. It became apparent that the choice of the absorber is not very crucial, since invariably absorber concentrations which are fairly black to thermal and resonance neutrons are used. Though it is true that some of the rare earth resonance absorbers have resonance peaks which exceed by far the resonance levels of rhenium (the material chosen as a representative resonance absorber in this evaluation), these resonance peaks, because of extreme self-shielding, did not contribute significantly to the total absorption of the vane.

The most important requirement of the absorber is a high specific (with respect to volume) capture rate of fast neutrons, and sufficient resonance and thermal capture to render the vane black to those neutrons. Because of its high atomic density, natural boron can compete in this respect with all of the possible absorbers. The $B^{10}$ isotope is a significantly better absorber per unit volume. For this reason, the present study was made with natural boron and the $\mathrm{B}^{10}$ isotope in all comparative evaluations. Several calculational checks of the effect of using an $(n, \gamma)$ resonance absorber like rhenium were also carried out. Table IX shows 
that, in most of the analyzed reflector spectra, rhenium is comparable in terms of volumetric absorptivity to natural boron but falls far short of it in terms of weight. The $\mathrm{B}^{10}$ is otope exceeds rhenium considerably on both counts. Therefore, bor on is the neutronically preferred absorber, although as study of heat generation in the control vane shows (see Section V), some other considerations, such as heat transfer or structure, could require the use of an $(n, \gamma)$ absorber.

TABLE IX Comparison of Poison Materials in Spectra of Var Ious Reflectors

\begin{tabular}{|c|c|c|c|c|c|c|c|c|c|}
\hline & \multirow{2}{*}{$\begin{array}{c}\text { Poison } \\
\text { Mater Ial }\end{array}$} & \multicolumn{8}{|c|}{ Reflector Materıal } \\
\hline & & $\begin{array}{l}\text { Depleted } \\
\text { Uranıum }\end{array}$ & Alumınum & $\mathrm{Al}_{2} \mathrm{O}_{3}$ & Niobium & Iron & Molybdenum & Carbon & Zırconium \\
\hline $\begin{array}{l}\text { Spectrum-averaged } \\
\text { Capture Cross } \\
\text { Section (b) }\end{array}$ & $\begin{array}{l}\mathrm{B} \\
\mathrm{B}^{10} \\
\operatorname{Re}\end{array}$ & $\begin{array}{l}0280 \\
140 \\
061\end{array}$ & $\begin{array}{l}0288 \\
144 \\
0635\end{array}$ & $\begin{array}{l}159 \\
795 \\
331\end{array}$ & $\begin{array}{l}0746 \\
373 \\
185\end{array}$ & $\begin{array}{l}0287 \\
143 \\
0623\end{array}$ & $\begin{array}{l}0290 \\
145 \\
0634\end{array}$ & $\begin{array}{c}991 \\
495 \\
899\end{array}$ & $\begin{array}{l}0352 \\
176 \\
0784\end{array}$ \\
\hline $\begin{array}{l}\text { Spectrum-averaged } \\
\text { Macroscopic Capture } \\
\text { Cross Section of } \\
\text { Pure Material (cm-l) }\end{array}$ & $\begin{array}{l}B \\
B^{10} \\
\operatorname{Re}\end{array}$ & $\begin{array}{l}00382 \\
0197 \\
00395\end{array}$ & $\begin{array}{l}00393 \\
0202 \\
00411\end{array}$ & $\begin{array}{ll}0 & 217 \\
1 & 12 \\
0 & 214\end{array}$ & $\begin{array}{l}0102 \\
0525 \\
0120\end{array}$ & $\begin{array}{l}00391 \\
0201 \\
00403\end{array}$ & $\begin{array}{l}00395 \\
0203 \\
00410\end{array}$ & $\begin{array}{l}135 \\
695 \\
0582\end{array}$ & $\begin{array}{l}00480 \\
0247 \\
00507\end{array}$ \\
\hline $\begin{array}{l}\text { Relative Absorptivity } \\
\text { per kg of Material } \\
\text { (normalızed to boron) }\end{array}$ & $\begin{array}{l}\mathrm{B} \\
\mathrm{B}^{10} \\
\operatorname{Re}\end{array}$ & $\begin{array}{l}10 \\
54 \\
01296\end{array}$ & $\begin{array}{l}10 \\
54 \\
0130\end{array}$ & $\begin{array}{ll}10 & 0 \\
54 & \\
0 & 123\end{array}$ & $\begin{array}{l}10 \\
54 \\
0146\end{array}$ & $\begin{array}{l}10 \\
54 \\
0128\end{array}$ & $\begin{array}{l}10 \\
54 \\
0129\end{array}$ & $\begin{array}{ll}1 & 0 \\
5 & 4 \\
0 & 0536\end{array}$ & $\begin{array}{l}10 \\
54 \\
0131\end{array}$ \\
\hline
\end{tabular}

The reflector spectrum is computed at the IN position of the control vane, $\sim 4 \mathrm{~cm}$ from core-reflector interface

The variable implied under control-vane composition is therefore not the mixing of absorptive materials, but the mixing of absorber and a hydrogenous moderator. The enhancement of boron effectiveness by the simple addition of moderator is well known; note, however, that although this procedure might have some other justifications, it does not necessarily contribute to the optimization of a fixed-volume control vane. For optimization purposes, the volume available to the control material must be kept constant; therefore, the addition of a moderator can take place only at the expense of displaced poison. For a number of reflectors, this procedure can actually result in significantly increased control spans.

The hydrogenous moderator considered in these studies is $\mathrm{TiH}_{2}$, chosen because of availability and quite high hydrogen density. Other hydrogenous materials could serve as well, and the present results would apply to them in direct ratio of their hydrogen density.

Figures 14 to 16 show the enhanced total control span that can be achieved in an $\mathrm{Al}, \mathrm{Al}_{2} \mathrm{O}_{3}$, or $\mathrm{Ni}$ reflector by interchanging some boron with $\mathrm{TiH}_{2}$. Some of the enhancements are quite respectable, and the optimum effectiveness mixtures occur at surprisingly low boron concentrations. The figures do not show the enhancing effect of the hydrogenous moderator to full advantage since the hydrogen-containing control vane in general has a different optimum vane thickness than the control vane of pure boron. The vane thicknesses used in the calculation of Figs. 14 to 16 are close to the optima for a pure boron vane. This 
increase in control span is not produced solely by increased absorption per boron atom (though this, of course, does take place). As shown by Tables I, VI, and VII, removal of boron and its replacement by a hydrogenous moderator results in an actually lowered total number of neutrons absorbed. It is of interest thus to consider the mechanisms which produce this change.

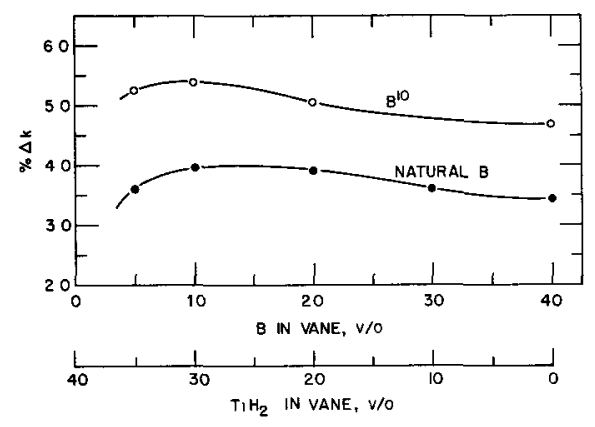

$112-5539$

Fig. 14. Control Span vs Control-vane Composition for $\mathrm{Al}_{2} \mathrm{O}_{3}$ reflected Reactors
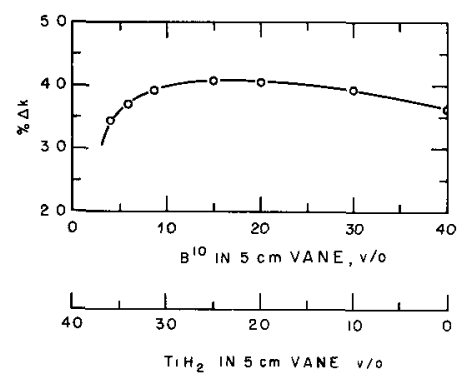

$112-6162$

Fig. 15. Control Span vs Control-vane Composition for Aluminum reflected Reactors

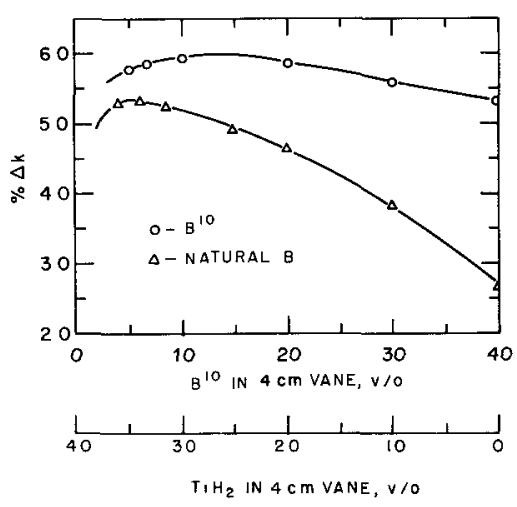

$112-5540$

Fig. 16 Control Span vs Controlvane Composition for Nickel-reflected Reactors

One of the mechanisms, already mentioned, is shown graphically in Fig. 9. The substitution of hydrogen for boron reduces the reactivity lost to the control-vane poison when the drums are in the OUT position. This is so because the lower-energy neutrons which are preferentially absorbed in the hydrogen-containing vane have a very low importance in the outer regions of the reflector.

Another important effect is shown in Figs. 17 to 19, where the energy dependence of the relative real and adjoint fluxes are given $4 \mathrm{~cm}$

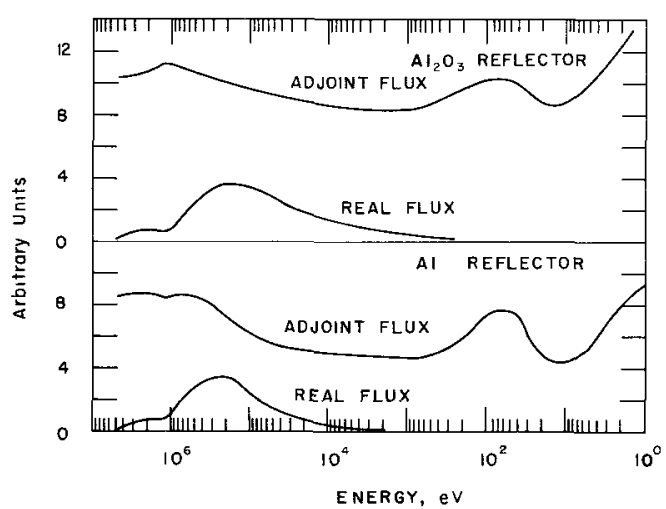

$112-5541$

Fig. 17. Relative Real and Adjont Fluxes $4.2 \mathrm{~cm}$ from the Core-Reflector In terface for $\mathrm{Al}$ and $\mathrm{Al}_{2} \mathrm{O}_{3}$ Reflectors

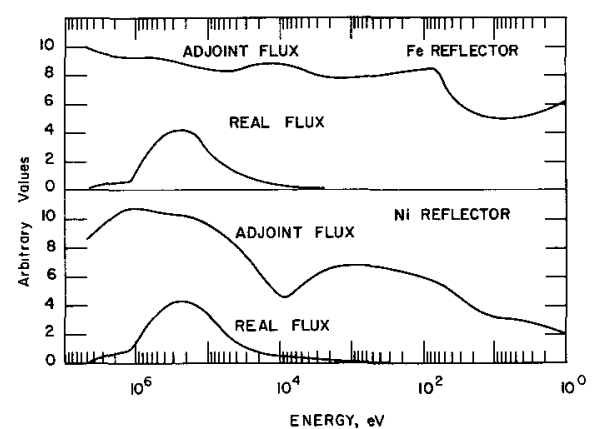

$112-6161$

Fig. 18. Relative Real and Adjoint Fluxes $4.2 \mathrm{~cm}$ from the CoreReflector Interface for $\mathrm{Ni}$ and Fe Reflectors 


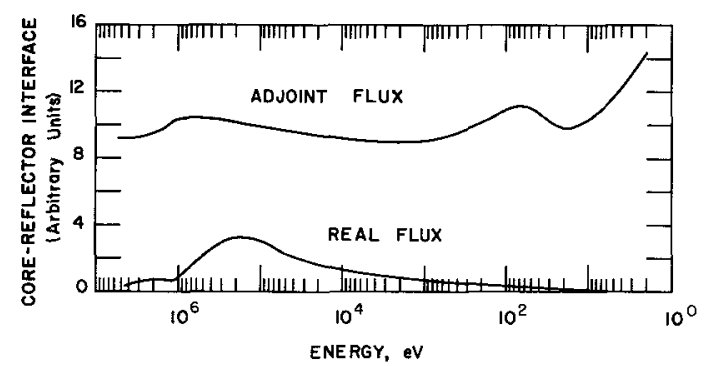

$112-6160$

Fig. 19. Relative Real and Adjoint Fluxes $4.2 \mathrm{~cm}$ from the Core-Reflector Interface for $C$ Reflector inside the reflector; this is at the position of the control vane when the control drums are fully IN. The most important feature demonstrated is that around the energy region of maximum real flux density $(0.4$ to $0.04 \mathrm{MeV})$ the adjoint flux invariably decreases with decreasing energy. This means that the moderation of neutrons from this energy region results in a direct reactivity loss. The steepness of the gradient indicates for which reflectors this reactivity loss would be maximum.

One might expect that for some reflectors, even in the absence of boron, the addition of hydrogen would produce a negative reactivity effect which may override such positive effects as increased neutron reflection back into the core. This reactivity loss should be especially strong for the nickel and aluminum reflectors and much weaker for carbon and iron reflectors.

The reactivity effect of hydrogen in the reflector is of interest quite apart from its influence on the control effectiveness of a mixed hydrogen and boron control vane. Hydrogen is used as the coolant of rocket reactors; therefore its reactivity worth is very important to the dynamics of these reactors. Consequently, the hydrogen worth has been measured in several ZPR- 9 assemblies that had an aluminum reflector. The experiments showed the reactivity effect of adding hydrogen is dependent on the position in the reflector, being negative in the region adjoining the core. Theoretically it was of interest to determine to what degree the effect is influenced by the properties of the core and to what degree by the (fairly uncertain) cross sections of the aluminum reflector. Especially for the aluminum reflector the scattering resonances make uncertain the reliability of the resonance-region group-averaged cross section $^{4}$ (see Appendix A). Accordingly, the available cross sections for aluminum (see Appendix A) were modified and the calculations repeated. The results (analogous to those of Figs. 17-19) are given in Fig. 20. A change in aluminum cross sections by $10 \%$ in either direction only shifts the absolute values of the calculated real and adjoint fluxes; it does not affect the flux gradients

The negative reactivity effect produced by moderation is significantly enhanced by the presence of boron or any other resonance and thermal absorber. The degree of enhancement is illustrated in Fig. 21, which gives the calculated real and adjoint fluxes inside a $4-\mathrm{cm}$ control vane of natural boron in $\mathrm{Al}_{2} \mathrm{O}_{3}$ and nickel reflectors.

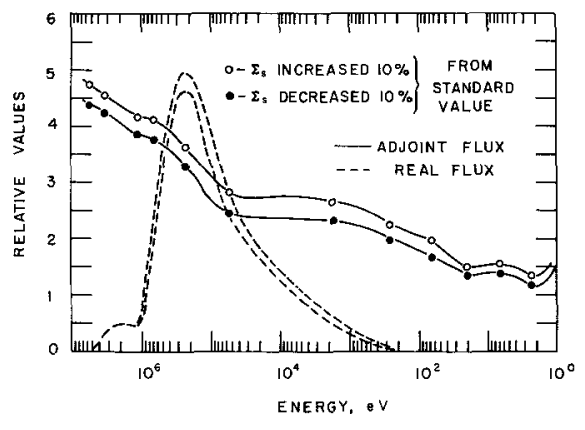

$112-6164$

Fig. 20. Relative Real and Adjoint Fluxes in Aluminum Reflector $4.0 \mathrm{~cm}$ from Core-Reflector Interface 


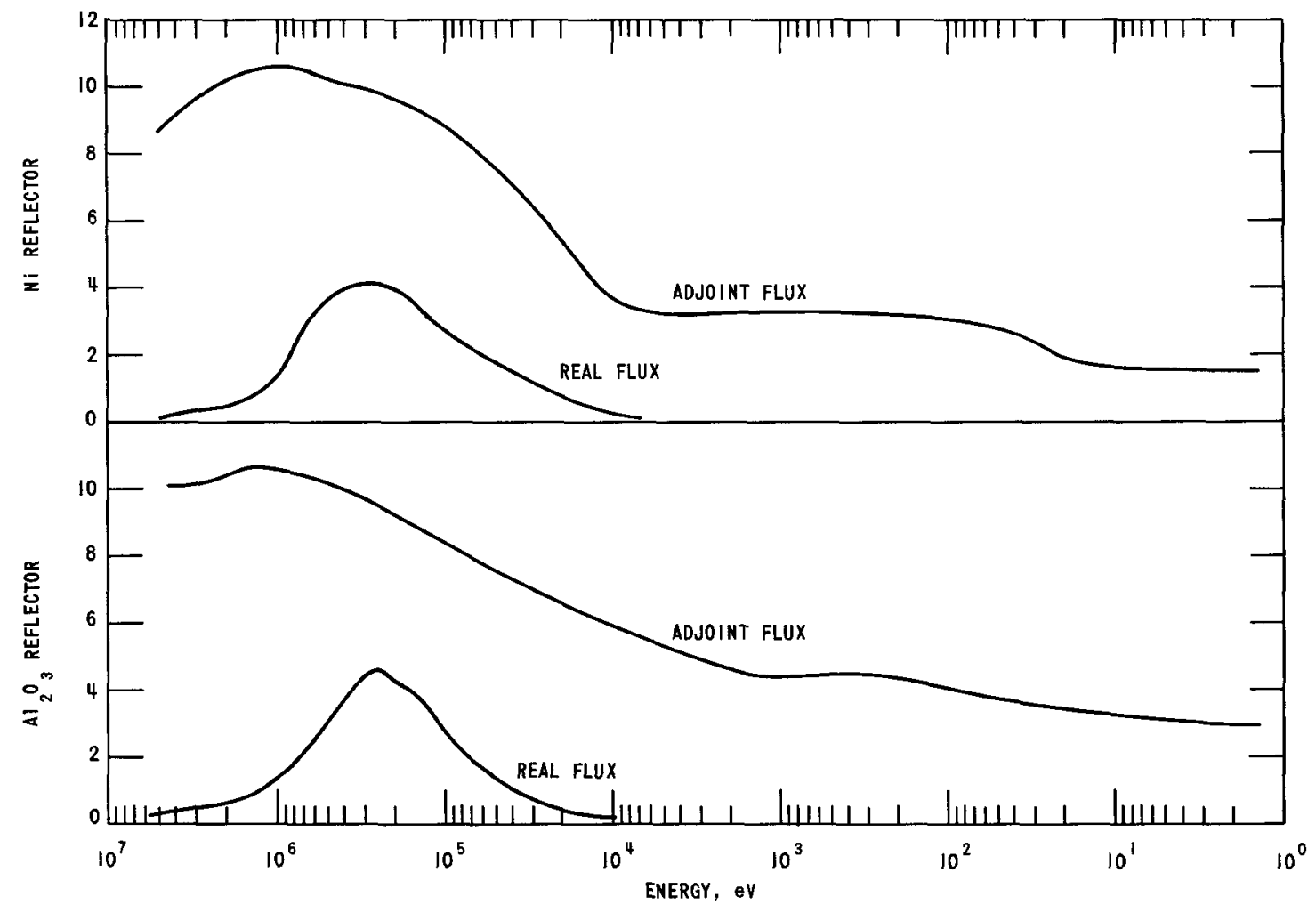

Fig. 21. Relative Real and Adjoint Fluxes Inside Control Vane Located in $\mathrm{Al}_{2} \mathrm{O}_{3}$ and $\mathrm{Ni}$ Reflectors at the IN Position

It can therefore be concluded that, in general, for reflectors having neutron spectra which are harder than those found in a carbon reflector, the substitution of hydrogen for some of the natural boron poison can increase the total control effectiveness. This enhancement is not so pronounced if enriched boron is displaced. In that case the motive for using a hydrogenous moderator would be the minimization of the expensive $B^{10}$ inventory. Figure 16 shows that for a nickel reflector the $B^{10}$ content could be reduced by a factor of 3 with insignificant loss in total control span. 


\section{CONTROL-VANE HEATING}

A. Heating Reactions

An inevitable byproduct of a fission reaction are several types of secondary, heat-generating nuclear reactions. These secondary reactions form the sole heat source outside of the core proper and thus can assume primary importance. The reactions can be divided into three general classes:

1. exothermic neutron-induced reactions [i.e., $(n, \alpha)$ or $(n, \gamma)$ reactions];

2. elastic and inelastic scattering of fast neutrons:

3. gamma heating (attenuation of gamma radiation is produced by the core and by secondary neutron capture or inelastic scattering).

The intensity of the reactions is directly proportional to the specific power of the core. For the high-performance reactors considered in this analysis, the heat source generated by the secondary reactions reached such levels as definitely to become a design problem. This is particularly true in control-vane design for which the exothermic neutron reactions, especially the $(n, \alpha)$ reaction in boron, can produce uniquely high rates of heat generation.

Figure 22 presents calculated heating rates for all three classes of reactions for a 2 - cm-thick control vane located in a beryllium reflector. The heating values presented are core-midplane (that is, maximum) values. The average power at core midplane is assumed to be $6.5 \mathrm{MW} /$ iter. A beryllium reflector was chosen for this comparison since it amplifies the adverse characteristics of the secondary heating problem.

Of the three reactions, the predominant $(n, \alpha)$ reaction and the fastneutron heating reaction will be treated in more detail. Gamma heating depends very strongly on the nature and the amount of structural material in the vane (i.e., iron, tungsten, or other metals). Structural considerations are not within the scope of this study; therefore, gamma heating cannot be treated properly here. In the cases illustrated by Fig. 22, the structure is assumed to contain $16 \mathrm{v} / 0$ tungsten.

B. Influence of Heat Generation Rate on Vane Design

It is very possible that the high total rate of heat generation produced by the $(n, \alpha)$ reaction in boron and the truly extreme spatial dependence will 
be a major factor in determining a realistic vane design. The problem of cooling a control vane could at first appear of only secondary importance. Its solution could then be postponed to the final design stages. It is appropriate therefore to emphasize it at this point.

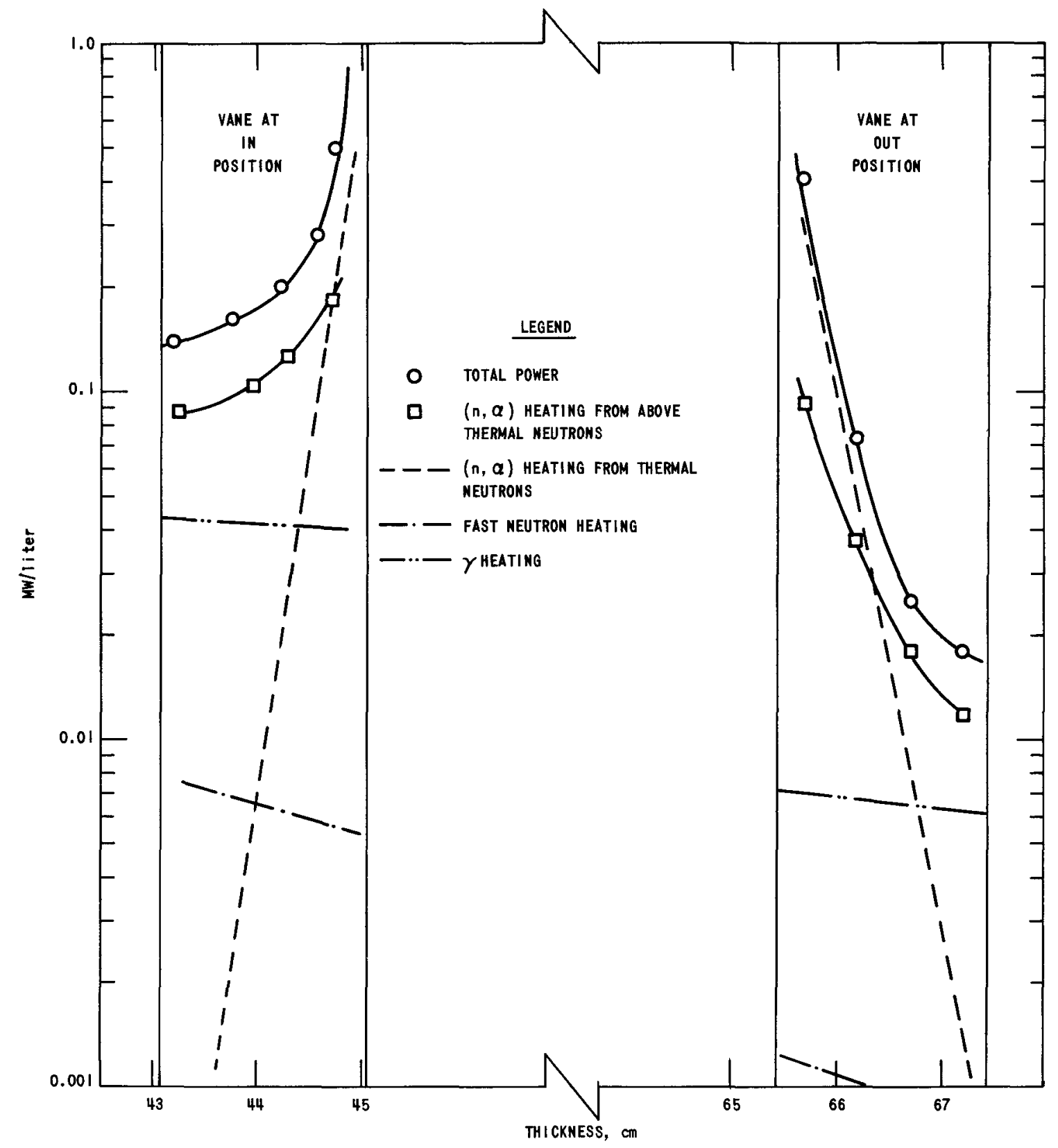

Fig. 22. Power Distribution for 2 -cm-thick Vane in Beryllium Reflector

A simple numerical comparison will illustrate the potentially high rates of heat production which are inherent in the $(n, \alpha)$ reaction. The energy generated by a fission reaction is $\sim 192 \mathrm{MeV}$, by an $(n, \alpha)$ reaction in boron, $\sim 2.7 \mathrm{MeV}$, so that the ratio of reaction energies is $\sim 70$. This 
ratio is counterweighted by the following parameters: The capture cross section of boron is considerably higher than the fission cross section of $\mathrm{U}^{235}$, being greater, depending strongly on the incident spectrum, by a factor of 2 to 10 . The atomic density of boron inside a control vane will greatly exceed the atomic density of $\mathrm{U}^{235}$ in the core (typically by a factor of 10 to 20). Therefore, given fluxes of comparable magnitude, the rate of the $(n, \alpha)$ reaction can exceed the fission rate in the core by factors of 20 to 200. This higher reaction rate can result in comparable or even higher volumetric heat-production rates in the vane than achieved in the core. This very high power density presents a sufficiently challenging problem of design in itself. The real difficulty, however, is not so much the absolute magnitude of the power density as its spatial distribution. In some reflectors (such as $\mathrm{Be}, \mathrm{C}$, and partially in $\mathrm{Al}_{2} \mathrm{O}_{3}$ ) a good fraction of the $(n, \alpha)$ reactions are produced by thermal and near-thermal neutrons. Neutrons below $1 \mathrm{eV}$ have a transport mean free path of $\sim 0.1 \mathrm{~cm}$ in a typical control vane; thus fluxes of neutrons of this energy decay very rapidly inside the vane. This rapid decay can produce extraordinarily steep power gradients. Figures 22 to 24 present examples of possible power gradients. The examples shown in Figs. 22 and 23 amplify the problem because of the

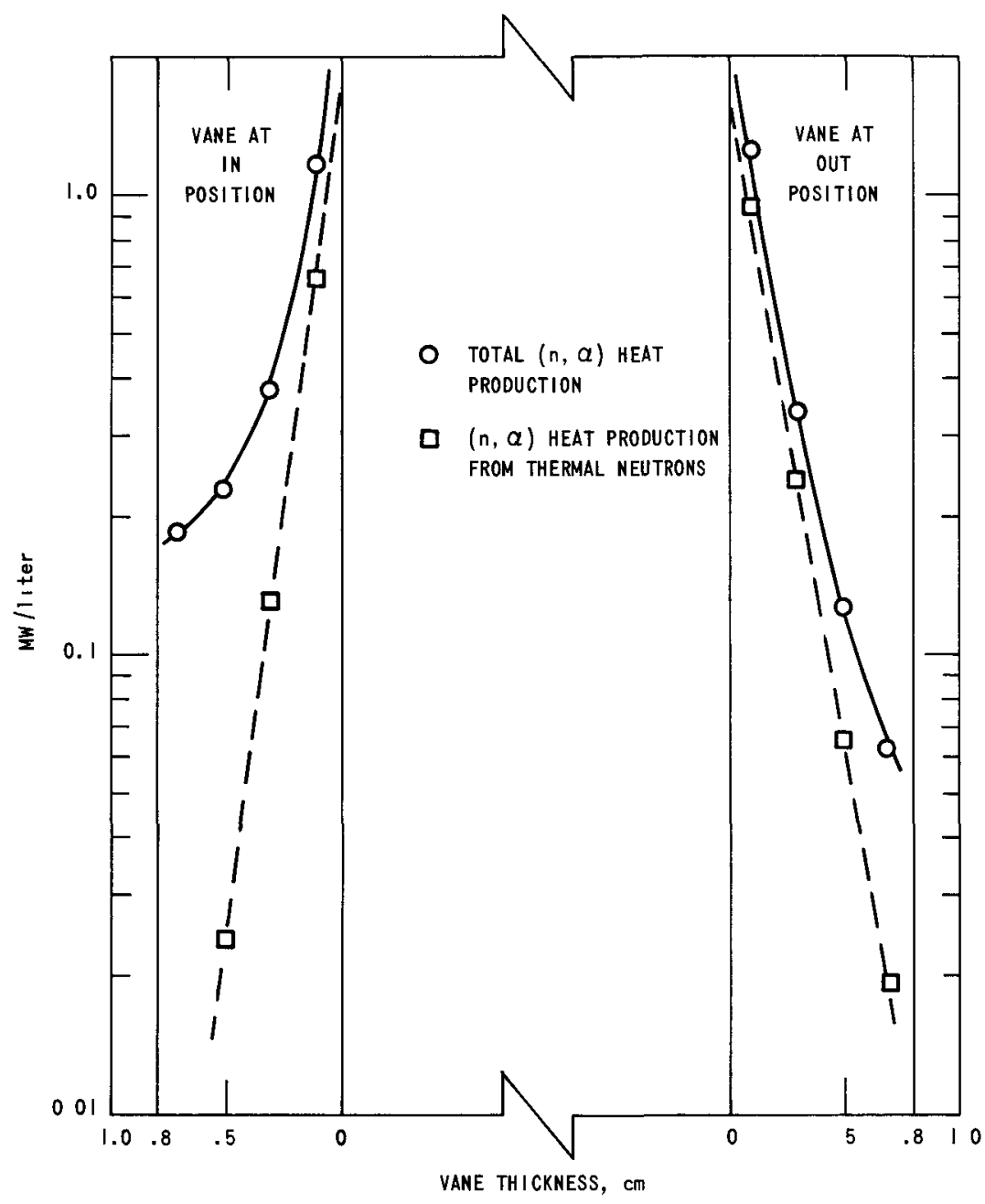

Fig 23. Power Distrıbution in Control Vanes of Beryllium-reflected Reactor 


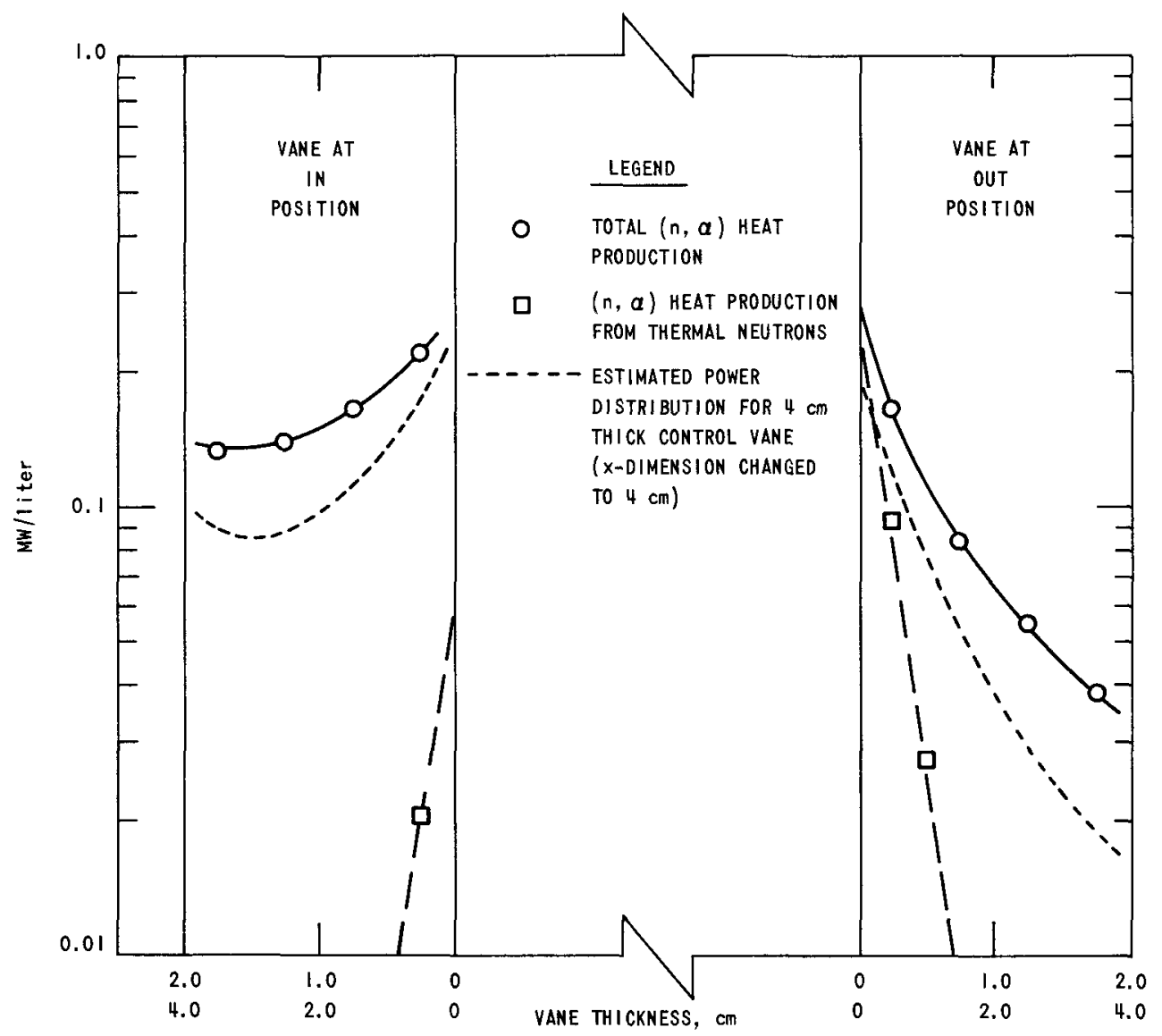

Fig. 24. Power Distribution in Control Vanes of $\mathrm{Al}_{2} \mathrm{O}_{3}$-reflected Reactor

presence of the beryllium reflector, but otherwise do not present the worst possible case either in terms of the control-vane boron density or in terms of core power. It should be noted that the abscissa for all the graphs is expanded and that the ordinate is logarithmic. In actuality, therefore, the power gradient is much steeper than is qualitatively indicated in the figures. Further, especially in the case of the control vane located in a beryllium reflector, the peak itself is produced almost entirely by thermal neutrons and is thus almost a surface phenomenon. This means that the power peak is proportional to the local surface-to-volume ratio, which increases by almost a factor of 2 in the corners of the vane.

Heat-transfer and thermal-stress problems are not within the scope of this report, and it cannot be stated here whether vanes for which the calculations of Figs. 22 to 24 were made are indeed practical. It is, however, obvious even for a nonspecialist in these disciplines that the problems are formidable. For this reason the neutronic heat source and the associated calculations are presented in some detail in this section. First, consider some possible design alternatives which might be tried if the power produced in the vanes does indeed become a limiting parameter. 
The first and most effective design change would be to employ a less moderating reflector. The differences in the power gradients and absolute power rates between a vane in a beryllium reflector (see Figs. 22 and 23) and a vane in an $\mathrm{Al}_{2} \mathrm{O}_{3}$ reflector (see Fig. 24) are quite sizable. Control vanes in the less moderating reflectors would exhibit even flatter power distributions than shown in Fig. 24. The absolute power rate in the hard-spectrum reflectors might be comparable, especially if control requirements force the use of boron enriched in the $\mathrm{B}^{10}$ isotope. Reducing the density of the reflector also has a power-flattening effect in the control vane.

Other fairly obvious design alternatives are based on an increased control-vane porosity and a reduced atomic density of boron. It is probable that in most design situations not much latitude will be available in these parameters since control-vane thickness and boron concentration will be fixed by the requirements for controllability. An additional design possibility is the grading of the boron loading in the control vane, which could be particularly practical if boron enriched in the $\mathrm{B}^{10}$ is otope were employed. The atomic density of boron could then be maintained constant throughout the vane, and the required grading in the macroscopic capture cross section could be achieved by varying the $\mathrm{B}^{10}$ enrichment. Grading of the boron density will produce only a small change in the reactivity-controlling capability of the control vane if the total capture density is maintained constant.

An effective method of producing a more uniform power distribution is the inclusion of a hydrogeneous moderator inside the vane. Since the addition of a moderator is accompanied by a reduction of the atomic density of boron, the edge power peak is reduced almost in direct proportion to the volume of hydrogeneous moderator added. The total rate of heat generation of the vane will not change substantially since the moderator will raise the reaction rate in the self-shielded and low-specific-power sections of the control vane.

A radical solution could be to use an $(n, \gamma)$ absorber rather than boron. Even if the reaction-rate density and the energy produced per reaction would be similar for the $(n, \gamma)$ absorber, the local heat production would be much lower. This is so since the generated $\gamma$ energy is dissipated over a large volume and only partially deposited in the vane. Of the $(n, \gamma)$ absorbers analyzed, rhenium was found to be one of the most effective. Volumetrically, rhenium has similar absorptive properties in a wide range of neutron spectra as does boron. A more detailed comparison of rhenium and boron absorbers is given in Table IX.

C. Calculations of $(n, \alpha)$ Heating

Tables $X$ and $X I$ present the spatial and energy distributions of the $(n, \alpha)$ reaction rate for near optimum (in terms of thickness) control vanes 
located in a beryllium and an $\mathrm{Al}_{2} \mathrm{O}_{3}$ reflector, respectively. The relative reaction rates per boron atom are given so that the results can be normalized to various core powers. The fluxes shown in the tables were calculated by the DSN transport code in the $\mathrm{S}_{4}$ approximation.

TABLE X Distribution of (n $\alpha$ ) Reaction Rate in $1-\mathrm{cm}$ Control Vane in Beryilium Reflector (Control vane at IN position)

\begin{tabular}{|c|c|c|c|c|c|c|c|c|c|c|c|c|c|}
\hline $\begin{array}{l}\text { Lower } \\
\text { Energy } \\
\text { Limit } \\
\text { of Group }\end{array}$ & $\sigma_{C}^{B}$ & $\begin{array}{l}\phi_{1} \text { at } \\
0125 \mathrm{~cm} \\
\text { from } \\
\text { Vane } \\
\text { Edge }^{*}\end{array}$ & $\phi_{1} \sigma_{C}^{B}$ & $\frac{\left(\phi_{1} \sigma_{C}^{\mathrm{B}}\right)_{1}}{\sum_{11}^{16}\left(\phi_{1} \sigma_{C}^{\mathrm{B}}\right)_{1}} \%$ & $\begin{array}{l}\phi_{2} \text { at } \\
0375 \mathrm{~cm} \\
\text { from } \\
\text { Vane } \\
\text { Edge }^{*}\end{array}$ & $\phi_{2} \sigma_{C}^{B}$ & $\frac{\left(\phi_{2} \sigma_{c}^{B}\right)_{1}}{\sum_{11}^{16}\left(\phi_{2} \sigma_{C}^{B}\right)_{1}} \%$ & $\begin{array}{l}\phi_{3} \text { at } \\
0625 \mathrm{~cm} \\
\text { from } \\
\text { Vane } \\
\text { Edge }\end{array}$ & $\phi_{3} \sigma_{C}^{B}$ & $\frac{\left(\phi_{3} \sigma_{c}^{B}\right)_{1}}{\sum_{1}^{16}\left(\phi_{3} \sigma_{c}^{B}\right)_{1}} \%$ & $\begin{array}{l}\phi_{4} \text { at } \\
0875 \mathrm{~cm} \\
\text { from } \\
\text { Vane } \\
\text { Edge }^{\circ}\end{array}$ & $\phi_{4} \sigma_{C}^{B}$ & $\frac{\left(\phi_{4} \sigma_{c}^{B}\right)_{1}}{\sum_{11}^{16}\left(\phi_{4} \sigma_{c}^{B}\right)_{1}} \%$ \\
\hline $3 \mathrm{MeV}$ & 004 & $539 \times 10^{-4}$ & $216 \times 10^{-5}$ & 0047 & $519 \times 10^{-4}$ & $208 \times 10^{-5}$ & 004 & $499 \times 10^{-4}$ & $200 \times 10^{-5}$ & 002 & $480 \times 10^{-4}$ & $192 \times 10^{-5}$ & 0007 \\
\hline $14 \mathrm{MeV}$ & 006 & $184 \times 10^{-3}$ & $110 \times 10^{-4}$ & 024 & $179 \times 10^{-3}$ & $107 \times 10^{-4}$ & 019 & $174 \times 10^{-3}$ & $104 \times 10^{-4}$ & 012 & $169 \times 10^{-3}$ & $101 \times 10^{-4}$ & 004 \\
\hline $09 \mathrm{MeV}$ & 004 & $1 \% \times 10^{-3}$ & $784 \times 10^{-5}$ & 017 & $190 \times 10^{-3}$ & $760 \times 10^{-5}$ & 014 & $183 \times 10^{-3}$ & $732 \times 10^{-5}$ & 081 & $177 \times 10^{-3}$ & $708 \times 10^{-5}$ & 027 \\
\hline $04 \mathrm{MeV}$ & 008 & $613 \times 10^{-3}$ & $490 \times 10^{-4}$ & 106 & $593 \times 10^{-3}$ & $474 \times 10^{-4}$ & 087 & $572 \times 10^{-3}$ & $458 \times 10^{-4}$ & 051 & $552 \times 10^{-3}$ & $442 \times 10^{-4}$ & 017 \\
\hline $01 \mathrm{MeV}$ & 027 & $109 \times 10^{-2}$ & $294 \times 10^{-3}$ & 639 & $106 \times 10^{-2}$ & $286 \times 10^{-3}$ & 523 & $103 \times 10^{-2}$ & $278 \times 10^{-3}$ & 308 & $100 \times 10^{-2}$ & $270 \times 10^{-3}$ & 102 \\
\hline $17 \mathrm{keV}$ & 061 & $797 \times 10^{-3}$ & $486 \times 10^{-3}$ & 106 & $788 \times 10^{-3}$ & $481 \times 10^{-3}$ & 879 & $780 \times 10^{-3}$ & $476 \times 10^{-3}$ & 527 & $773 \times 10^{-3}$ & $472 \times 10^{-3}$ & 179 \\
\hline $3 \mathrm{keV}$ & 150 & $412 \times 10^{-3}$ & $618 \times 10^{-3}$ & 134 & $416 \times 10^{-3}$ & $624 \times 10^{-3}$ & 1141 & $421 \times 10^{-3}$ & $632 \times 10^{-3}$ & 699 & $428 \times 10^{-3}$ & $642 \times 10^{-3}$ & 243 \\
\hline $055 \mathrm{keV}$ & 340 & $190 \times 10^{-3}$ & $646 \times 10^{-3}$ & 140 & $196 \times 10^{-3}$ & $666 \times 10^{-3}$ & 1217 & $204 \times 10^{-3}$ & $694 \times 10^{-3}$ & 768 & $215 \times 10^{-3}$ & $731 \times 10^{-3}$ & 277 \\
\hline $01 \mathrm{keV}$ & 80 & $854 \times 10^{-4}$ & $683 \times 10^{-3}$ & 148 & $913 \times 10^{-4}$ & $730 \times 10^{-3}$ & 1334 & $995 \times 10^{-4}$ & $796 \times 10^{-3}$ & 881 & $111 \times 10^{-3}$ & $888 \times 10^{-3}$ & 337 \\
\hline $30 \mathrm{eV}$ & 1640 & $195 \times 10^{-4}$ & $320 \times 10^{-3}$ & $6 \%$ & $227 \times 10^{-4}$ & $372 \times 10^{-3}$ & 680 & $302 \times 10^{-4}$ & $495 \times 10^{-3}$ & 548 & $416 \times 10^{-4}$ & $682 \times 10^{-3}$ & 258 \\
\hline $10 \mathrm{eV}$ & 290 & I $68 \times 10^{-4}$ & $487 \times 10^{-3}$ & 106 & $196 \times 10^{-4}$ & $568 \times 10^{-3}$ & 1038 & $239 \times 10^{-4}$ & $693 \times 10^{-3}$ & 767 & $310 \times 10^{-4}$ & $899 \times 10^{-3}$ & 341 \\
\hline $3 \mathrm{eV}$ & 520 & $901 \times 10^{-5}$ & $469 \times 10^{-3}$ & 102 & $105 \times 10^{-4}$ & $546 \times 10^{-3}$ & 998 & $143 \times 10^{-4}$ & $744 \times 10^{-3}$ & 824 & $235 \times 10^{-4}$ & $122 \times 10^{-2}$ & 462 \\
\hline $\mathrm{leV}$ & 920 & $300 \times 10^{-5}$ & $276 \times 10^{-3}$ & 60 & $359 \times 10^{-5}$ & $330 \times 10^{-3}$ & 60 & $626 \times 10^{-5}$ & $576 \times 10^{-3}$ & 638 & $149 \times 10^{-4}$ & $137 \times 10^{-2}$ & 519 \\
\hline $04 \mathrm{eV}$ & 1510 & $633 \times 10^{-6}$ & $956 \times 10^{-4}$ & 208 & $945 \times 10^{-6}$ & $143 \times 10^{-3}$ & 26 & $210 \times 10^{-5}$ & $317 \times 10^{-3}$ & 351 & $898 \times 10^{-5}$ & I $36 \times 10^{-2}$ & 515 \\
\hline $0 \mathrm{leV}$ & 2730 & $845 \times 10^{-7}$ & $231 \times 10^{-4}$ & 050 & $287 \times 10^{-6}$ & $784 \times 10^{-4}$ & 143 & $140 \times 10^{-5}$ & $382 \times 10^{-3}$ & 423 & $712 \times 10^{-5}$ & $194 \times 10^{-2}$ & 735 \\
\hline Thermal & 6730 & $194 \times 10^{-6}$ & $131 \times 10^{-3}$ & 285 & $863 \times 10^{-6}$ & $581 \times 10^{-3}$ & 1062 & $428 \times 10^{-5}$ & $288 \times 10^{-2}$ & 3119 & $235 \times 10^{-4}$ & $158 \times 10^{-1}$ & 5988 \\
\hline & & & $46 \times 10^{-3}$ & 10000 & & $547 \times 10^{-3}$ & 10000 & & $903 \times 10^{-3}$ & 10000 & & $2634 \times 10^{-3}$ & 10000 \\
\hline
\end{tabular}

* Radial positions of calculated fluxes (cm from core centerlıne) $\phi_{1} \quad \begin{array}{llllllll}43165 & \phi_{2} \cdot 43415 & \phi_{3} & 43665 & \phi_{4} & 43915\end{array}$

TABLE XI Distribution of ( $\mathrm{n}$ a) Reaction Rate in 2-cm Control Vane in $\mathrm{Al}_{2} \mathrm{O}_{3}$ Reflector

(Control vane at IN position)

\begin{tabular}{|c|c|c|c|c|c|c|c|c|c|c|c|c|c|}
\hline $\begin{array}{l}\text { Lower } \\
\text { Energy } \\
\text { Limit } \\
\text { of Group }\end{array}$ & $\sigma_{C}^{B}$ & $\begin{array}{l}\phi_{1} \text { at } \\
025 \mathrm{~cm} \\
\text { from } \\
\text { Vane } \\
\text { Edge }\end{array}$ & $\phi_{1} \sigma_{C}^{B}$ & $\frac{\left(\phi_{1} \sigma_{c}^{B}\right)_{1}}{\sum_{1=1}^{16}\left(\phi_{1} \sigma_{c}^{B}\right)_{1}} \%$ & $\begin{array}{c}\phi_{2} \text { at } \\
075 \mathrm{~cm} \\
\text { from } \\
\text { Vane } \\
\text { Edge }\end{array}$ & $\phi_{2} \sigma_{C}^{B}$ & $\frac{\left(\phi_{2} \sigma_{c}^{B}\right)_{1}}{\sum_{11}^{16}\left(\phi_{2} \sigma_{c}^{B}\right)_{1}} \%$ & $\begin{array}{c}\phi_{3} \text { at } \\
125 \mathrm{~cm} \\
\text { from } \\
\text { Vane } \\
\text { Edge* }\end{array}$ & $\phi_{3} \sigma_{C}^{B}$ & $\frac{\left(\phi_{3} \sigma_{c}^{\mathrm{B}}\right)_{1}}{\sum_{11}^{16}\left(\phi_{3} \sigma_{c}^{\mathrm{B}}\right)_{1}} \%$ & $\begin{array}{c}\phi_{4} \text { at } \\
175 \mathrm{~cm} \\
\text { from } \\
\text { Vane } \\
\text { Edge }^{\star}\end{array}$ & $\phi_{4} \sigma_{C}^{B}$ & $\frac{\left(\phi_{4} \sigma_{c}^{\mathrm{B}}\right)_{1}}{\sum_{11}^{16}\left(\phi_{4} \sigma_{c}^{B}\right)_{1}}$ \\
\hline $3 \mathrm{MeV}$ & 004 & $999 \times 10^{-4}$ & $400 \times 10^{-5}$ & 022 & $920 \times 10^{-4}$ & $368 \times 10^{-5}$ & 019 & $850 \times 10^{-4}$ & $340 \times 10^{-5}$ & 015 & $788 \times 10^{-4}$ & $315 \times 10^{-5}$ & 010 \\
\hline $14 \mathrm{MeV}$ & 006 & $319 \times 10^{-3}$ & $191 \times 10^{-4}$ & 103 & $302 \times 10^{-3}$ & $181 \times 10^{-4}$ & 093 & $286 \times 10^{-3}$ & $172 \times 10^{-4}$ & 075 & $272 \times 10^{-3}$ & $163 \times 10^{-4}$ & 053 \\
\hline $09 \mathrm{MeV}$ & 004 & $288 \times 10^{-3}$ & $115 \times 10^{-4}$ & 062 & $270 \times 10^{-3}$ & $108 \times 10^{-4}$ & 056 & $253 \times 10^{-3}$ & $101 \times 10^{-4}$ & 045 & $237 \times 10^{-3}$ & $0.95 \times 10^{-4}$ & 031 \\
\hline $04 \mathrm{MeV}$ & 008 & $864 \times 10^{-3}$ & $691 \times 10^{-4}$ & 374 & $817 \times 10^{-3}$ & $654 \times 10^{-4}$ & 336 & $773 \times 10^{-3}$ & $618 \times 10^{-4}$ & 273 & $731 \times 10^{-3}$ & $585 \times 10^{-4}$ & 192 \\
\hline $01 \mathrm{MeV}$ & 027 & $137 \times 10^{-2}$ & $370 \times 10^{-3}$ & 2003 & $132 \times 10^{2}$ & $356 \times 10^{-3}$ & 1829 & $126 \times 10^{-2}$ & $340 \times 10^{-3}$ & 1499 & $121 \times 10^{-2}$ & $327 \times 10^{-3}$ & 1073 \\
\hline $17 \mathrm{keV}$ & 061 & $882 \times 10^{-3}$ & $538 \times 10^{-3}$ & 2913 & $874 \times 10^{-3}$ & $533 \times 10^{-3}$ & 2739 & $871 \times 10^{-3}$ & $531 \times 10^{-3}$ & 2341 & $876 \times 10^{-3}$ & $534 \times 10^{-3}$ & 1752 \\
\hline $3 \mathrm{keV}$ & 150 & $283 \times 10^{-3}$ & $425 \times 10^{-3}$ & 2301 & $295 \times 10^{-3}$ & $443 \times 10^{-3}$ & 2277 & $311 \times 10^{-3}$ & $467 \times 10^{-3}$ & 2059 & $332 \times 10^{-3}$ & $498 \times 10^{-3}$ & 1634 \\
\hline $055 \mathrm{keV}$ & 340 & $714 \times 10^{-4}$ & $243 \times 10^{-3}$ & 1316 & $804 \times 10^{-4}$ & $273 \times 10^{-3}$ & 1403 & $937 \times 10^{-4}$ & $319 \times 10^{-3}$ & 1407 & $113 \times 10^{-3}$ & $384 \times 10^{-3}$ & 1260 \\
\hline $01 \mathrm{keV}$ & 80 & $152 \times 10^{-4}$ & $122 \times 10^{-3}$ & 661 & $193 \times 10^{-4}$ & $154 \times 10^{-3}$ & 791 & $278 \times 10^{-4}$ & $222 \times 10^{-3}$ & 979 & $421 \times 10^{-4}$ & $337 \times 10^{-3}$ & 1106 \\
\hline $30 \mathrm{eV}$ & 1640 & $145 \times 10^{-5}$ & $238 \times 10^{-4}$ & 129 & $235 \times 10^{-5}$ & $385 \times 10^{4}$ & 198 & $460 \times 10^{-5}$ & $754 \times 10^{-4}$ & 332 & $130 \times 10^{-4}$ & $2.13 \times 10^{3}$ & 699 \\
\hline $10 \mathrm{eV}$ & 290 & $553 \times 10^{-6}$ & $160 \times 10^{-4}$ & 087 & $109 \times 10^{-5}$ & $316 \times 10^{-4}$ & 162 & $213 \times 10^{-5}$ & $618 \times 10^{-4}$ & 273 & $715 \times 10^{-5}$ & $207 \times 10^{-3}$ & 679 \\
\hline $3 \mathrm{eV}$ & 520 & $812 \times 10^{-7}$ & $422 \times 10^{-5}$ & 023 & $255 \times 10^{-6}$ & $133 \times 10^{-4}$ & 068 & $881 \times 10^{-6}$ & $458 \times 10^{-4}$ & 202 & $312 \times 10^{-5}$ & $162 \times 10^{-3}$ & 531 \\
\hline $1 \mathrm{eV}$ & 920 & $407 \times 10^{-8}$ & $374 \times 10^{-6}$ & 002 & $228 \times 10^{-7}$ & $210 \times 10^{-5}$ & 011 & $100 \times 10^{-6}$ & $920 \times 10^{-4}$ & 406 & $132 \times 10^{-5}$ & $121 \times 10^{-3}$ & 397 \\
\hline $04 \mathrm{eV}$ & 1510 & $377 \times 10^{-8}$ & $569 \times 10^{-6}$ & 003 & $160 \times 10^{-7}$ & $242 \times 10^{-5}$ & 012 & $754 \times 10^{-7}$ & $114 \times 10^{-4}$ & 050 & $396 \times 10^{-6}$ & $598 \times 10^{-4}$ & $1 \%$ \\
\hline $01 \mathrm{eV}$ & 2730 & $494 \times 10^{-9}$ & $135 \times 10^{-6}$ & 001 & $327 \times 10^{-8}$ & $893 \times 10^{-6}$ & 005 & $244 \times 10^{-7}$ & $666 \times 10^{-5}$ & 029 & $204 \times 10^{-6}$ & $557 \times 10^{-4}$ & 183 \\
\hline Thermal & 6730 & $207 \times 10^{-10}$ & $139 \times 10^{-7}$ & - & $305 \times 10^{-9}$ & $205 \times 10^{-6}$ & 001 & $498 \times 10^{-8}$ & $335 \times 10^{-5}$ & 015 & $923 \times 10^{-7}$ & $621 \times 10^{-4}$ & 204 \\
\hline & & & $18468 \times 10^{-3}$ & 1000 & & $19460 \times 10^{-3}$ & 1000 & & $22679 \times 10^{-3}$ & 1000 & & $30481 \times 10^{-3}$ & 1000 \\
\hline
\end{tabular}

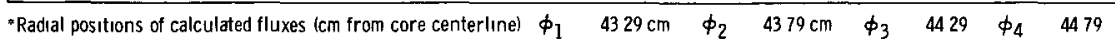


The "vane edge" referred to in the tables is the outside boundary of the control vane, which, when the control drums are at the IN position, will be nearest to the core. Contrary to first expectations, this will in general be the position of lowest density of heat production since the major portion of the $(n, \alpha)$ reactions are produced by low-energy neutrons which are produced in the reflector. Thus the power spike will appear at the inner edge of the control vane, which receives the incident reflector flux when the vane is both at the IN and OUT positions. This is illustrated in the energy and spatial distributions of the $(n, \alpha)$ reaction rate presented in Table $X$. Table $X$ shows that the reaction rate due to thermal neutrons is $\sim 100$ times higher at $0.125 \mathrm{~cm}$ from the reflector than at $0.875 \mathrm{~cm}$ from it.

In order to transform the relative reaction rates presented in Tables $\mathrm{X}$ and $\mathrm{XI}$ to absolute values, it is necessary to assume an average core power. For the calculations which produced Figs. 23 and 24 the average power at core midplane was assumed to be $8.0 \mathrm{MW}$. (The average over the whole core is $5.7 \mathrm{MW}$.) The absolute fluxes are then obtained as follows:

$$
\begin{aligned}
& {\left[\begin{array}{l}
\text { Absolute flux of } \\
\text { neutrons of energy } \\
\text { group i }
\end{array}\right]=\left[\frac{0.008 \mathrm{MW}}{\mathrm{cm}^{3}}\right]\left[\begin{array}{l}
\text { Power fraction } \\
\text { produced by } \\
\text { group i neutrons }
\end{array}\right]\left[\frac{\mathrm{cm}^{3}}{\sum_{\mathrm{f}(\mathrm{i})} \mathrm{cm}^{2}}\right] } \\
& {\left[\frac{\text { fissions }}{3.04 \times 10^{-17} \mathrm{MW}-\mathrm{sec}}\right] }
\end{aligned}
$$

All that remains after obtaining absolute fluxes and reaction rates is to multiply them by the reaction energy:

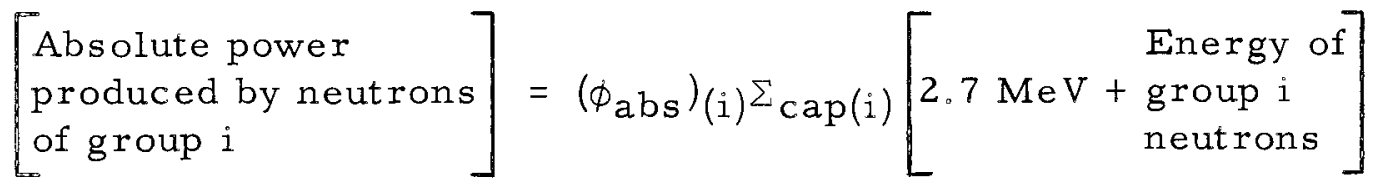

$$
\begin{aligned}
& {\left[\frac{1.60 \times 10^{-19} \mathrm{MW}-\mathrm{sec}}{\mathrm{MeV}}\right] .}
\end{aligned}
$$

Usually the energy of the incident neutron will contribute but a small fraction of the total energy produced. Thus, as shown in Table XI even for the hardest flux position of a control vane located in an $\mathrm{Al}_{2} \mathrm{O}_{3}$ reflector, only $\sim 5 \%$ of the reacting neutrons have energies above $0.4 \mathrm{MeV}$.

D. Fast-neutron Heating

The extremely intense neutron fluxes present in the high-performance reactors analyzed in this study bring the heating induced by elastically and inelasticaily scattered neutrons to appreciable levels. In regions of low 
absorption containing low-atomic-weight materials, this heating can reach values similar to that of gamma heating.

The problem was analyzed when the inclusion of a hydrogenous moderator inside the control vane was considered. It was found that in the presence of any $(n, \alpha)$ absorber, fast-neutron heating contributes a small fraction of the total heat generated. Typically, even for the highest moderator fraction containing control vanes, this total did not exceed $8 \%$ of the $(n, \alpha)$ reaction rate. Such a level of power generation, while not important in the control vane, can become a substantial heat source when competing exothermic reactions are absent. This is illustrated in Fig. 25, which shows the fast-neutron heating in a beryllium reflector.

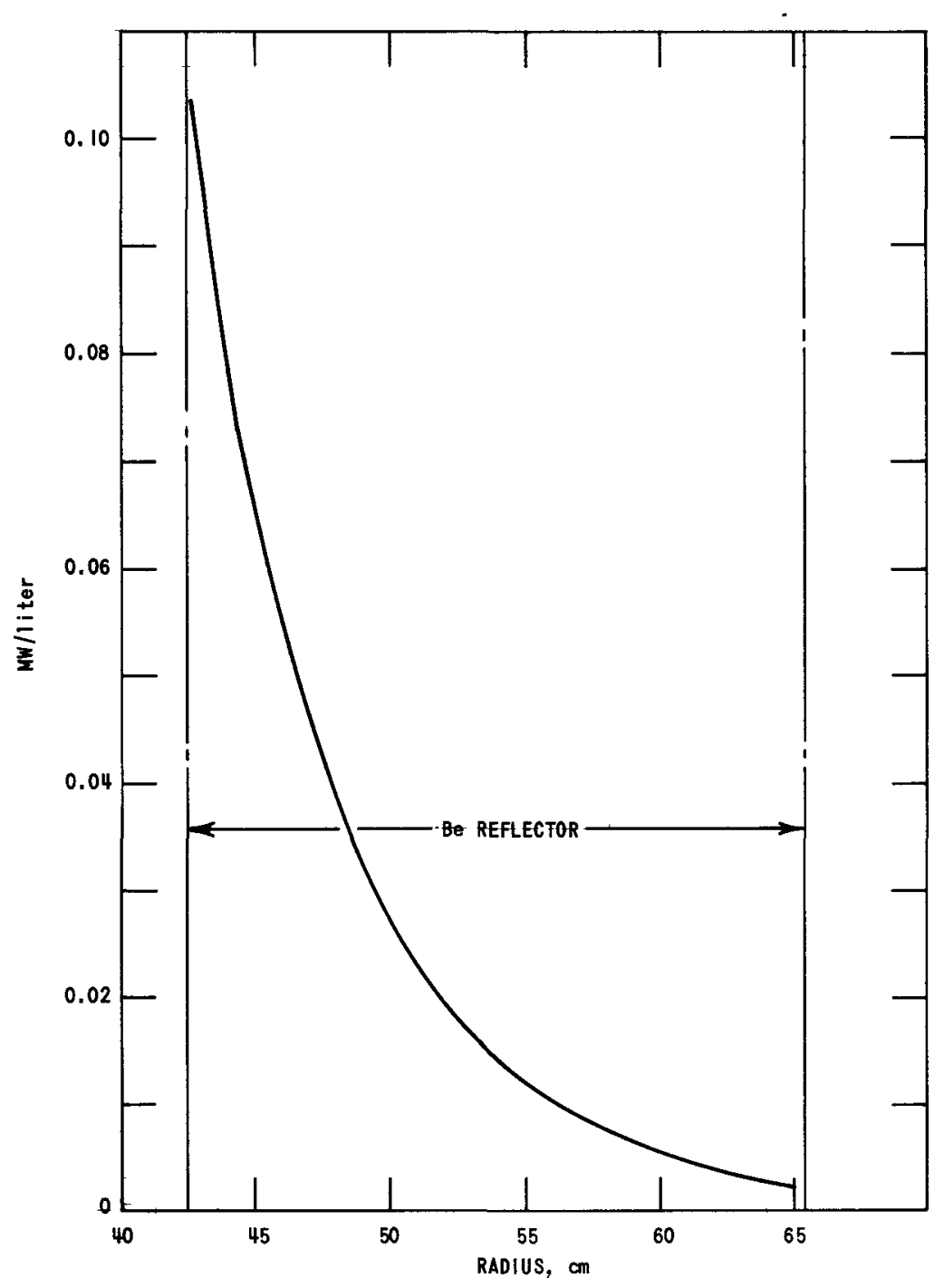

Fig. 25. Fast-neutron Heating in Beryllium Reflector

The heating effect of elastically scattered neutrons is easy to estimate. The energy loss per neutron is simply proportional to its initial 
energy. The energy transferred to the scattering material can be obtained from the following relationships:

$$
\xi=\ln \frac{E_{1}}{E_{2}}=1+\frac{\alpha}{1-\alpha} \ln \alpha,
$$

where

$$
\alpha=\left(\frac{A-1}{A+1}\right)^{2}
$$

and $A$ is the atomic weight of scatterer. For beryllium, $\alpha$ is 0.64 and the average energy loss per scattering reaction is $\sim 19 \%$ of the incident neutron energy. The calculation of the absolute reaction rates is identical to the process outlined for the $(n, \alpha)$ reactions. The average power in the core midplane to which the heating values of Fig. 25 are normalized is also 8.0 $\mathrm{MW} /$ liter.

The heating produced by inelastically scattered neutrons is more involved. The calculation of a single reaction rate for each neutronenergy group is insufficient since inelastically scattered neutrons can lose energies according to the various excitation levels that are available. Table XII shows the details of a calculation of the average energy loss per reaction for tungsten. The complete cross-section set for tungsten is given in Appendix A. The thus-computed average energy loss was used in calculating the fast-neutron heating shown in Fig. 25.

\begin{tabular}{|c|c|c|c|c|c|c|c|c|c|c|c|}
\hline $\begin{array}{l}\text { Energy } \\
\text { Group } 1\end{array}$ & $\begin{array}{l}\text { Lower } \\
\text { Energy } \\
\text { Limit, } \\
\mathrm{MeV}\end{array}$ & $\begin{array}{c}\text { Total } \\
\text { Removal } \\
\text { Cross } \\
\text { Section, } \\
\sigma_{1-k}+\sigma_{c^{\prime}}, b\end{array}$ & $\begin{array}{l}\text { Fraction of } \\
\text { Neutrons } \\
\text { Absorbed }\end{array}$ & $\begin{array}{c}\text { Energy } \\
\text { Transfer } \\
\text { per } \\
\text { Absorption, } \\
\text { MeV }\end{array}$ & $\begin{array}{l}\text { Fraction } \\
\text { Scattered } \\
\text { to }\}+1\end{array}$ & $\begin{array}{c}\text { Energy } \\
\text { Transfer } \\
\text { per J+1 } \\
\text { Scatterıng, } \\
\mathrm{MeV}\end{array}$ & $\begin{array}{l}\text { Fraction } \\
\text { Scattered } \\
\text { to }+2\end{array}$ & $\begin{array}{c}\text { Energy } \\
\text { Transfer } \\
\text { per } 1+2 \\
\text { Scatterıng } \\
\text { MeV }\end{array}$ & $\begin{array}{l}\text { Fraction } \\
\text { Scattered } \\
\text { to } 1+3\end{array}$ & $\begin{array}{c}\text { Energy } \\
\text { Transfer } \\
\text { per J }+3 \\
\text { Scattering. } \\
\text { MeV }\end{array}$ & $\begin{array}{c}\text { Total } \\
\text { Energy } \\
\text { Transfer } \\
\text { per } \\
\text { Reaction, } \\
\text { Mev }\end{array}$ \\
\hline 1 & 30 & 2446 & 00072 & 5 & 0287 & 28 & 0288 & 385 & 0418 & 435 & 377 \\
\hline 2 & 14 & 2840 & 0014 & 22 & 0213 & 105 & 0461 & 155 & 0311 & 195 & 157 \\
\hline 3 & 09 & 2109 & 0021 & 115 & 0478 & 050 & 0432 & 090 & 0068 & 110 & 073 \\
\hline 4 & 04 & 084 & 0076 & 065 & 077 & 040 & 0154 & 06 & & & 045 \\
\hline 5 & $0 \mathrm{I}$ & 0162 & 071 & 025 & 029 & 02 & & & & & 0235 \\
\hline 6 & 0017 & 0289 & 081 & 0051 & & & & & & & 0041 \\
\hline
\end{tabular}

TABLE XII. Energy Transfer per Neutron Scatterıng and Absorption Event in Tungsten 


\section{CONCLUSIONS}

This study is not of the type that can be summarized in a few allinclusive conclusions. The most appropriate general conclusion would in effect just paraphrase the abstract: a comparative study evaluating a range of control and reflector materials suited for fast nuclear rocket reactors has been made. The results of the study are presented in a form facilitating various comparisons. Which of the reflector materials or control mechanism designs are best or even workable, depends on the specific design objectives.

Backing off from such comprehensive and thus not very useful generalizations to a more modest plateau, a number of interesting observations concerning the results of the study can be made. Each is elaborated in the report itself and is stated here for additional emphasis.

About the design of the control mechanism:

For each specific reactor design situation, a quite well-defined optimum design of the control vane exists. Both the control-vane thickness and composition have optima with respect to the control span that they produce. These optimum values will usually be quite different in reflector materials.

About the choice of reflector materials:

If the control-vane design does not have any a priori restrictions. then the choice of a reflector material can to a large $\frac{-}{\text { degree }}$ be based on weight or structural considerations, since the maximum achievable control span (based of course on an optimum vane design in each case) is fairly similar for most reflector materials. This maximum control span value is more dependent on the radii of the core and control drum, on the thickness of the reflector, and especially on the distance between the control drum and the core-reflector interface than upon the choice of reflector material.

The above generalization does not apply to the "very moderating" materials: $\mathrm{Be}, \mathrm{Li}, \mathrm{H}$, and their compounds. When used as reflectors for fast-spectrum cores, these materials present unique design difficulties. In effect, the cores themselves will usually have to be modified; thus it is difficult to make a fair comparison between the "very moderating" and the remaining class of reflector materials. It is believed that the following statement will usually apply: Fast-spectrum cores and thick moderating reflectors are basically incompatible. The design steps required to integrate these very different regions into operating a reactor system may cancel the neutronic advantages that a moderating reflector offers. Thin moderating reflectors ( $\mathrm{such}$ as $<8 \mathrm{~cm}$ for berylluim) could be advantageous in case of small-volume cores for which controllability does not pose a problem. These types of reactors have not been considered in this study. 
About the choice of control materials:

Surprisingly enough, the choice of a poison material has fairly little influence upon the maximum achievable control span, since the "optimum control vanes" which should be the basis of comparison are invariably quite black to thermal and resonance-energy neutrons. This means that the resonance-capture cross sections in which the various absorbers can differ by orders of magnitude are self-shielded to such a degree that the differences become ineffectual. The fast-neutron capture cross sections, on the other hand, are fairly similar for most absorbers. For this reason, in a comparative study natural boron was shown to be as effective as absorbers having resonance captures many times higher. The noted optimization of control-vane composition thus refers not to the choice of a poison material, but to the determination of an optimum ratio of poison hydrogenous material. It was determined that for most reflector materials the achievable control span could be increased substantially by the introduction of hydrogenous moderator into the control vane.

An ancillary but potentially very important consideration in the choice of the control material can be the heat generated in the control vane. For example, if boron is to be used as the absorber, the exothermic $(\mathrm{n}, \alpha)$ reaction can produce specific power levels in the control vane which are similar to core power and which have extremely steep spatial gradients. It is possible that these steep power levels would force the adaption of an $(n, \gamma)$ type of absorber. Promising candidates for this role are rhenium and europium.

This study is closed with a true feeling of uneasiness that so many possibilities have not been explored fully nor have even been mentioned: fueled reflectors, multiregion and multimaterial reflectors, partly fueled control drums, partly poisoned reflectors (to make such light weight materials as beryllium acceptable), and so on. The list itself illustrates the fact that in order to be tractable at all, the scope of the study had to be restricted. Hopefully, the restrictions were judiciously chosen. 


\section{APPENDIX A}

Cross Sections Employed in Control Study and Correlation of Experimental and Calculated Results

In the present study a familiar and widely used cross-section set ${ }^{11}$ was employed, supplemented by some additional nuclide cross sections required but not present in the original set. Here only the cross sections for these additional materials ( $W, R e, B^{10}$ and fission-spectrum-weighted $H$ ) will be described.

One major advantage gained by use of a widely distributed crosssection set is that many general studies concerning its validity are avail. able. Some of the more directly appiicable studies are presented in Refs. 2 3, 4 and 12. These discuss measurements performed with critical assemblies which are related in volume and spectral characteristics to the reactors treated in the present study. Such measurements as a rule are "core oriented" and do not concern themselves much about reflector properties. As a consequence, though applicable general experimental data is quite plentiful, only a few directly reflector-oriented studies are available. ${ }^{5-7}$ In this Appendix a recent measurement of reflector-located boron worth and the influence of light-element cross sections on reflector properties will be discussed.

\section{Tungsten Cross Sections}

One of the initial analytical tasks in the study of rocket reactors at Argonne was the evaluation of available microscopic data for tungsten and the generation of cross sections for tungsten. Actually, the study resulted in the generation of a number of cross-section sets for tungsten which differed in various details, such as spectra over which the cross sections were averaged, in averaging methods, and in the basic microscopic data used. The methods employed and the data sources used are presented in Ref。13. Subsequently the generated cross-section sets were subjected to experimental and calculational comparisons. ${ }^{34}$ The purposes of the comparisons were to evaluate the sensitivity of various calculated reactor parameters to differences in the cross-section sets for tungsten and to determine which of the sets had the highest degree of agreement with experiment. For the type of reactor neutron spectra considered in this study, the cross-section set shown in Table A-I was found to be very satisfactory.

The properties of assemblies containing up to $70 \mathrm{v} / \mathrm{o}$ tungsten were calculated within the known limitations of the calculational methods used, and no systematic error could be assigned to the tungsten cross sections. The mean neutron energy of these assemblies was $0.2 \mathrm{MeV}$; thus any selfshielding in the tungsten resonances is not important. The cross-section set can be used successfully also for significantly softer neutron spectra if the tungsten concentration does not exceed $20 \%$. For higher tungsten 
concentrations the self-shielding built into the capture cross sections of the resonance region is not sufficient, and the cross sections below $500 \mathrm{eV}$ should be re-evaluated.

TABLE A-I. Cross Sections (b) for Natural Tungsten

\begin{tabular}{|c|c|c|c|c|c|c|c|c|c|}
\hline $\begin{array}{l}\text { Energy } \\
\text { Group j }\end{array}$ & $\sigma_{\mathrm{n}, \gamma}$ & $\sigma_{\mathrm{REM}}$ & $\sigma_{\mathrm{TR}}$ & $\sigma_{\mathrm{J} \rightarrow \mathrm{j}}$ & $\sigma_{\mathrm{J} \rightarrow \mathrm{j}+1}$ & $\sigma_{\mathrm{J} \rightarrow \mathrm{j}+2}$ & $\sigma_{\mathrm{J} \rightarrow \mathrm{J}+3}$ & $\sigma_{\mathrm{J} \rightarrow \mathrm{J}+4}$ & $\sigma_{\mathrm{J} \rightarrow \mathrm{J}+5}$ \\
\hline 1 & 0.026 & 2.478 & 4.562 & 3.657 & 1.262 & 0.33 & 0.54 & 0.28 & 0.04 \\
2 & 0.072 & 2.476 & 4.625 & 4.512 & 1.004 & 0.99 & 0.36 & 0.05 & 0.02 \\
3 & 0.10 & 1.468 & 4.379 & 5.051 & 0.878 & 0.39 & 0.08 & & \\
4 & 0.09 & 0.554 & 4.626 & 6.042 & 0.444 & 0.02 & & & \\
5 & 0.13 & 0.308 & 6.641 & 7.62 & 0.178 & & & \\
6 & 0.263 & 0.309 & 9.617 & 9.828 & 0.046 & & & \\
7 & 0.651 & 0.750 & 12.838 & 12.242 & 0.099 & & & \\
8 & 1.824 & 1.926 & 15.170 & 13.292 & 0.102 & & & \\
9 & 3.238 & 3.345 & 17.812 & 14.520 & 0.107 & & & \\
10 & 0.645 & 0.728 & 13.489 & 12.807 & 0.083 & & & \\
11 & 8.359 & 8.759 & 41.564 & 32.925 & 0.400 & & & \\
12 & 7.745 & 7.921 & 13.871 & 5.972 & 0.176 & & & \\
13 & 3.101 & 3.185 & 8.409 & 5.243 & 0.084 & & & \\
14 & 3.741 & 3.810 & 9.237 & 5.447 & 0.069 & & & \\
15 & 7.326 & 7.542 & 12.890 & 5.367 & 0.0216 & & & \\
16 & 14.412 & 14.412 & 20.0 & 5.607 & - & & & \\
\hline
\end{tabular}

Rhenium Cross Sections

Rhenium is potentially of importance in the nuclear rocket field as an alloying material for tungsten. Neutronically it is a rather undesirable material because of its large capture cross section. If it is to be used at all, it can be used only in fast-spectrum reactors and even then preferably at low concentrations.

The large capture cross section does present the possiblilty that rhenium could be used as a control material. Its volumetric absorption is equal to that of natural boron in most spectra. In other aspects, such as on a weight or cost basis, rhenium is inferior to boron; thus it would be used only if structural or $n, \alpha$ reaction heating problems made the use of bor on impossible.

Basic microscopic data for rhenium is presently quite incomplete. This is especially true for the inelastic scattering levels. Accordingly, an interim cross-section set for rhenium was constructed which uses newly available capture data, ${ }^{15}$ but borrows the inelastic scattering matrix from tungsten. In the present study this limitation did not cause any difficulty. As a core material rhenium is invariably used at a fairly low concentration, and the inelastic scattering is of only minor importance when rhenium is evaluated as a control material.

This interim cross-section set for rhenium is shown in Table A-II. The set should not be used for problems in which rhenium makes up more than $10 \%$ of the core composition. 
TABLE A-II. Rhenium Cross Sections (b)

\begin{tabular}{|c|c|c|c|c|c|c|c|c|c|}
\hline $\begin{array}{c}\text { Energy } \\
\text { Group }\end{array}$ & $\sigma_{\mathrm{n}, \gamma}$ & $\sigma_{\mathrm{REM}}$ & $\sigma_{\mathrm{TR}}$ & $\sigma_{\mathrm{j} \rightarrow \mathrm{J}}$ & $\sigma_{\mathrm{j} \rightarrow \mathrm{J}+1}$ & $\sigma_{\mathrm{j} \rightarrow \mathrm{j}+2}$ & $\sigma_{\mathrm{J} \rightarrow \mathrm{j}+3}$ & $\sigma_{\mathrm{J} \rightarrow \mathrm{j}+4}$ & $\sigma_{\mathrm{J} \rightarrow \mathrm{J}+5}$ \\
\hline 1 & 0.11 & 2.563 & 4.059 & 3.657 & 1.263 & 0.33 & 0.54 & 0.28 & 0.04 \\
2 & 018 & 2.584 & 4.452 & 4.512 & 1.004 & 0.99 & 036 & 0.05 & \\
3 & 025 & 1.618 & 3.946 & 5.051 & 0.878 & 0.39 & 0.08 & 0.02 & \\
4 & 0.33 & 0.794 & 4.437 & 6.042 & 0.444 & 0.02 & & & \\
5 & 0.68 & 0.818 & 7.120 & 7.62 & 0.178 & & & \\
6 & 1.4 & 1.445 & 10.752 & 9.828 & 0.045 & & & \\
7 & 3.16 & 3.259 & 15.340 & 12.242 & 0.099 & & & \\
8 & 8.16 & 8.262 & 21.554 & 13.292 & 0.102 & & & \\
9 & 34.2 & 34.307 & 48.83 & 14.520 & 0.107 & & & \\
10 & 5.645 & 5.728 & 18.53 & 12807 & 0.083 & & & \\
11 & 8.359 & 8.759 & 4168 & 32.925 & 0.40 & & & \\
12 & 7.745 & 7.921 & 13.89 & 5.972 & 0.176 & & & \\
13 & 3.101 & 3.185 & 8.43 & 5.243 & 0.084 & & & \\
14 & 3.741 & 3.81 & 9.26 & 5.447 & 0.069 & & & \\
15 & 7.326 & 7.542 & 12.91 & 5.367 & 0.216 & & & \\
16 & 14.412 & 14.412 & 20.02 & 5.607 & - & & & \\
\hline
\end{tabular}

The suitability of rhenium as a control poison was investigated by evaluating its effective capture cross section in a number of reflector spectra. The effective capture cross sections weighted by the reflector spectrum existing with the drums in IN position are presented in Table A-III.

TABLE A-III Averaged Rhenıum Cross Sections (b) $42 \mathrm{~cm}$ Inside Various Reflectors

\begin{tabular}{|c|c|c|c|c|c|c|c|c|c|}
\hline \multirow{2}{*}{$\begin{array}{l}\text { Energy } \\
\text { Group }\end{array}$} & \multicolumn{9}{|c|}{$\phi \sigma \sigma_{C}^{R e}$} \\
\hline & $\sigma R e$ & Depleted U & $\mathrm{Al}$ & $\mathrm{Al}_{2} \mathrm{O}_{3}$ & $\mathrm{~N}_{1}$ & $\mathrm{Fe}$ & Mo & $\mathrm{C}$ & $\mathrm{Zr}$ \\
\hline 1 & 006 & 0089 & 0105 & 0118 & 0.081 & 0083 & 0101 & 0133 & 0112 \\
\hline 2 & 011 & 0.355 & 0.641 & 0.789 & 0473 & 0337 & 0529 & 0777 & 0616 \\
\hline 3 & 015 & 0645 & 0853 & 0745 & 115 & 0630 & 120 & 0807 & 0940 \\
\hline 4 & 028 & 543 & 596 & 526 & 818 & 547 & 764 & 473 & 766 \\
\hline 5 & 058 & 2784 & 2020 & 2163 & 2523 & 28.74 & 2511 & 1740 & 2616 \\
\hline 6 & 1.2 & 1625 & 1726 & 366 & 2616 & 1744 & 2328 & 2885 & 2761 \\
\hline 7 & 3.16 & 480 & 676 & 4089 & 948 & 540 & 916 & 4285 & 1583 \\
\hline 8 & 816 & 0375 & 204 & 45.78 & 1420 & 0449 & 109 & 649 & 677 \\
\hline 9 & 342 & 0010 & 0821 & 8584 & 3659 & 0010 & 0.120 & 1607 & 390 \\
\hline 10 & 470 & & 0.103 & 451 & 2400 & & & 1607 & 0658 \\
\hline 11 & 550 & & & 2695 & 15.95 & & & 803 & 0110 \\
\hline 12 & 790 & & & 2180 & 1382 & & & 861 & \\
\hline 13 & 5000 & & & 725 & 360 & & & 3670 & \\
\hline 14 & 250 & & & 177 & 060 & & & 1170 & \\
\hline 15 & 280 & & & 140 & 021 & & & 1330 & \\
\hline \multirow[t]{3}{*}{16} & 860 & & & 327 & 0060 & & & 860 & \\
\hline & & 5579 & 5474 & 4104 & 2122 & 5856 & 6823 & 10722 & 9037 \\
\hline & & 0609 & 0635 & 3315 & 185 & 0623 & 0634 & 899 & 0784 \\
\hline
\end{tabular}

\section{Boron-10 Cross Section}

The $\mathrm{B}^{10}$ cross sections were generated by increasing the capture cross section of the set for natural boron ${ }^{11}$ given by a factor of 5 and by adjusting the $\sigma_{\mathrm{TR}}$ and $\sigma_{\mathrm{REM}}$ reaction cross sections accordingly. The 
resulting cross-section set is shown in Table A-IV. Flux-averaged cross sections for natural boron are shown in Tables $\mathrm{A}-\mathrm{Va}$ and $\mathrm{b}$.

TABLE A-IV. $B^{10}$ Cross Sections (b)

\begin{tabular}{|c|c|r|r|r|r|r|r|r|l|}
\hline $\begin{array}{c}\text { Energy } \\
\text { Group } j\end{array}$ & $\sigma_{n, \gamma}$ & $\sigma_{R E M}$ & $\sigma_{T R}$ & $\sigma_{j \rightarrow j}$ & $\sigma_{j \rightarrow j+1}$ & $\sigma_{j \rightarrow j+2}$ & $\sigma_{j \rightarrow j+3}$ & $\sigma_{j \rightarrow j+4}$ & $\sigma_{j \rightarrow j+5}$ \\
\hline 1 & 0.20 & 0.87 & 1.68 & 0.81 & 0.67 & & & & \\
2 & 0.30 & 0.72 & 2.03 & 1.31 & 0.42 & & & & \\
3 & 0.20 & 1.08 & 2.30 & 1.22 & 0.88 & & & & \\
4 & 0.40 & 0.90 & 2.59 & 1.69 & 0.50 & & & & \\
5 & 1.35 & 1.73 & 4.24 & 2.51 & 0.38 & & & & \\
6 & 3.05 & 3.41 & 6.52 & 3.11 & 0.36 & & & & \\
7 & 7.50 & 7.87 & 10.97 & 3.1 & 0.37 & & & & \\
8 & 17.00 & 17.38 & 20.47 & 3.09 & 0.38 & & & & \\
9 & 40.0 & 40.38 & 43.47 & 3.09 & 0.38 & & & & \\
10 & 82.0 & 82.53 & 85.47 & 2.94 & 0.53 & & & & \\
11 & 145.0 & 145.58 & 148.47 & 2.89 & 0.58 & & & & \\
12 & 260.0 & 260.53 & 263.47 & 2.94 & 0.53 & & & & \\
13 & 460.0 & 460.58 & 463.47 & 2.89 & 0.58 & & & & \\
14 & 755.0 & 755.7 & 758.47 & 2.77 & 0.70 & & & & \\
15 & 1365 & 1365.46 & 1368.47 & 3.01 & 0.46 & & & & \\
16 & 3346.5 & 3346.5 & 3349.97 & 3.47 & - & & & & \\
\hline
\end{tabular}

TABLE A-Va. Averaged Cross Sections (b) for Natural Boron $4.2 \mathrm{~cm}$ Inside Various Reflectors

\begin{tabular}{|c|c|c|c|c|c|c|c|c|c|}
\hline $\begin{array}{c}\text { Energy } \\
\text { Group }\end{array}$ & $\sigma_{\mathrm{c}}^{\mathrm{B}}$ & $\phi(\text { Depleted U })^{*}$ & $\phi \sigma_{\mathrm{C}}^{\mathrm{B}}$ & $\phi(\mathrm{A} 1)$ & $\phi \sigma_{\mathrm{C}}^{\mathrm{B}}$ & $\phi\left(\mathrm{Al}_{2} \mathrm{O}_{3}\right)$ & $\phi \sigma_{\mathrm{C}}^{\mathrm{B}}$ & $\phi(\mathrm{Ni})$ & $\phi \sigma_{\mathrm{C}}^{\mathrm{B}}$ \\
\hline 1 & 0.04 & 1.48 & 0.059 & 1.75 & 0.070 & 1.97 & 0.079 & 1.35 & 0.054 \\
2 & 0.06 & 3.23 & 0.194 & 5.83 & 0.350 & 7.17 & 0.430 & 4.30 & 0.258 \\
3 & 0.04 & 4.30 & 0.172 & 5.69 & 0.228 & 4.97 & 0.199 & 7.65 & 0.306 \\
4 & 0.08 & 19.4 & 1.552 & 21.28 & 1.702 & 18.8 & 1.504 & 29.2 & 2.336 \\
5 & 0.27 & 48.0 & 12.96 & 34.83 & 9.404 & 37.3 & 10.07 & 43.5 & 11.74 \\
6 & 0.61 & 13.54 & 8.26 & 14.38 & 8.772 & 30.5 & 18.60 & 21.8 & 13.30 \\
7 & 1.50 & 1.52 & 2.280 & 2.14 & 3.21 & 12.94 & 19.41 & 3.0 & 4.50 \\
8 & 3.40 & 0.046 & 0.156 & 0.25 & 0.850 & 5.61 & 19.07 & 1.74 & 5.92 \\
9 & 8.0 & 0.0003 & 0.0024 & 0.024 & 0.192 & 2.51 & 20.08 & 1.07 & 8.56 \\
10 & 16.4 & & & 0.0022 & 0.036 & 0.96 & 15.74 & 0.51 & 8.36 \\
11 & 29.0 & & & & & 0.49 & 14.21 & 0.29 & 8.41 \\
12 & 52.0 & & & & & 0.276 & 14.35 & 0.175 & 9.10 \\
13 & 92.0 & & & & & 0.145 & 13.34 & 0.072 & 6.62 \\
14 & 151.0 & & & & & 0.071 & 10.72 & 0.024 & 3.62 \\
15 & 273.0 & & & & & 0.050 & 13.65 & 0.0075 & 2.05 \\
16 & 669.3 & & & & & 0.038 & 25.43 & 0.0007 & 0.468 \\
\hline Tota1 & & 91.52 & 25.63 & 86.17 & 24.81 & 123.8 & 196.9 & 114.7 & 85.60 \\
\hline$\phi \sigma_{\mathrm{c}}^{\mathrm{B}} / \phi$ & & & 0.280 & & 0.288 & & 1.59 & & 0.746 \\
\hline
\end{tabular}


TABLE A-Vb. Averaged Cross Sections (b) for Natural Boron $4.2 \mathrm{~cm}$ Inside Various Reflectors

\begin{tabular}{|c|c|c|c|c|c|c|c|c|}
\hline $\begin{array}{l}\text { Energy } \\
\text { Group }\end{array}$ & $\phi(\mathrm{Fe})$ & $\phi \sigma{ }_{c}^{B}$ & $\phi(\mathrm{Mo})$ & $\phi \sigma_{C}^{B}$ & $\phi(c)$ & $\phi \sigma \underset{\mathrm{C}}{\mathrm{B}}$ & $\phi(\mathrm{Zr})$ & $\phi \sigma \underset{\mathrm{C}}{\mathrm{B}}$ \\
\hline 1 & 1.38 & 0.055 & 1.68 & 0.067 & 2.22 & 0.088 & 1.87 & 0.075 \\
\hline 2 & 3.06 & 0.184 & 4.81 & 0.289 & 7.06 & 0.424 & 5.60 & 0.336 \\
\hline 3 & 4.20 & 0.168 & 8.0 & 0.320 & 5.38 & 0.215 & 6.26 & 0.250 \\
\hline 4 & 19.54 & 1.563 & 27.3 & 2.184 & 16.89 & 1.351 & 27.36 & 2.189 \\
\hline 5 & 49.56 & 13.38 & 43.3 & 11.69 & 30.00 & 8.10 & 45.10 & 12.180 \\
\hline 6 & 14.53 & 8.86 & 19.4 & 11.83 & 24.04 & 14.66 & 23.01 & 14.04 \\
\hline 7 & 1.71 & 2.565 & 2.9 & 4.35 & 13.56 & 20.34 & 5.01 & 7.515 \\
\hline 8 & 0.055 & 0.187 & 0.134 & 0.456 & 7.96 & 27.064 & 0.83 & 2.822 \\
\hline 9 & 0.0003 & 0.0024 & 0.0035 & 0.028 & 4.7 & 37.60 & 0.114 & 0.912 \\
\hline 10 & & & & & 2.27 & 37.23 & 0.014 & 0.230 \\
\hline 11 & & & & & 1.46 & 42.34 & 0.002 & 0.058 \\
\hline 12 & & & & & 1.09 & 56.67 & & \\
\hline 13 & & & & & 0.734 & 67.53 & & \\
\hline 14 & & & & & 0.468 & 70.67 & & \\
\hline 15 & & & & & 0.475 & 129.7 & & \\
\hline 16 & & & & & 1.00 & 669.3 & & \\
\hline Total & 94.03 & 26.96 & 107.53 & 31.21 & 119.31 & 1183.3 & 115.17 & 40.51 \\
\hline$\phi \sigma_{\mathrm{c}}^{\mathrm{B}} / \phi$ & & 0.287 & & 0.290 & & 9.915 & & 0.352 \\
\hline
\end{tabular}

Some past studies have indicated that the capture rate of boron is difficult to estimate correctly in fast reactor spectra. For example, in the study of Ref. 16 the central worth coefficient of boron, which is almost entirely determined by the capture reaction, was consistently underestimated by $\sim 30 \%$ in comparison with the experimental values. Since the capture cross section of boron itself is one of the best known cross sections, the fault lies in the calculation of the neutron spectrum. Such a consistent error would be inconvenient in the present study; thus pains were taken to explore the accuracy with which the cross-section set used presently computes the boron reaction rate. It was determined that in quite a wide range of spectra the cross-section set presented in Table A-V predicts the central $\mathrm{B}^{10}$ reactivity worth within $5-10 \%$ of the experimental value. ${ }^{2-6}$

Fission-spectrum-weighted Cross Sections for Hydrogen

The hydrogen cross sections used in the study are given in $\mathrm{Ta}-$ ble A-VI. Because of the limitations on the size of the downscattering matrix imposed by the multigroup codes, only fine downscattering could be employed. Although not exact, this does represent the downscattering produced by hydrogen quite satisfactorily. Only $\sim 0.02 \%$ of the neutrons are scattered to lower energies than the energy interval represented by five groups. The strong forward-scattering component of the hydrogen scattering reaction is represented by an artificial negative $j-j$ scattering cross section. 
TABLE A-VI. Fission-spectrum-averaged Cross Sections (b) for Hydrogen

\begin{tabular}{|c|c|c|c|c|c|c|c|c|c|}
\hline $\begin{array}{l}\text { Energy } \\
\text { Group J }\end{array}$ & $\sigma_{\mathrm{n}}$ & $\sigma_{\mathrm{REM}}$ & $\sigma_{\mathrm{TR}}$ & $\sigma_{\mathbf{J} \rightarrow \mathrm{J}}$ & $\sigma_{\mathrm{J} \rightarrow \mathrm{J}+1}$ & $\sigma_{\mathrm{j} \rightarrow \mathrm{j}+2}$ & $\sigma_{\mathrm{J} \rightarrow \mathrm{j}+3}$ & $\sigma_{\mathrm{J} \rightarrow \mathrm{J}+4}$ & $\sigma_{\mathrm{J} \rightarrow \mathrm{J}+5}$ \\
\hline 1 & - & 1.386 & 0.061 & -0.776 & 0.739 & 0.231 & 0.231 & 0.139 & 0.046 \\
\hline 2 & - & 2.047 & 0.095 & -1.097 & 0.731 & 0.731 & 0.439 & 0.121 & 0.025 \\
\hline 3 & - & 3.181 & 1.32 & -1.861 & 1.767 & 1.060 & 0.294 & 0.049 & 0.011 \\
\hline 4 & - & 3.624 & 1.82 & -1.804 & 2.718 & 0.752 & 0.127 & 0.022 & 0.005 \\
\hline 5 & - & 4.080 & 2.93 & -1.150 & 3.387 & 0.571 & 0.100 & 0.018 & 0.004 \\
\hline 6 & - & 7.2961 & 5.20 & -2.0961 & 6.022 & 1.045 & 0.187 & 0.0296 & 0.0125 \\
\hline 7 & - & 9.0212 & 6.33 & -2.6912 & 7.372 & 1.349 & 0.209 & 0.0608 & 0.0304 \\
\hline 8 & 0.001 & 9.635 & 6.666 & -2969 & 7880 & 1.220 & 0.360 & 0.1220 & 0.0520 \\
\hline 9 & 0.004 & 9.611 & 6.669 & -2.942 & 6.719 & 1.920 & 0.680 & 0.1920 & 0.0960 \\
\hline 10 & 0.008 & 11.6518 & 6.622 & -4.9798 & 7.757 & 2.719 & 0.780 & 02319 & 0.1559 \\
\hline 11 & 0.014 & 12.1249 & 6.676 & -5.4489 & 8.494 & 2.418 & 0.719 & 0.360 & 0.1199 \\
\hline 12 & 0.025 & 11864 & 6.817 & -5.047 & 7.906 & 2.364 & 1.182 & 0.387 & - \\
\hline 13 & 0.045 & 12.380 & 6.830 & -5.550 & 7.409 & 3.684 & 1.242 & - & - \\
\hline 14 & 0.070 & 13.386 & 6.847 & -6.539 & 9.982 & 3.334 & - & - & - \\
\hline 15 & 0.130 & 11.150 & 6.920 & -4.230 & 11.020 & - & - & - & - \\
\hline 16 & 0.27 & 027 & 7.09 & 6.8 & - & - & - & - & - \\
\hline
\end{tabular}

The cross sections were found to be satisfactory in the calculation of central worth of hydrogen in a number of tungsten-containing assemblies of the ZPR-9 program. The calculated central worth was within $\sim 15 \%$ of the experimental values. The cross sections were less satisfactory when used in the calculation of the worth of uniformly distributed (over the core or reflector) hydrogen. For these cases discrepancies of $\sim 50 \%$ were obtained between the experimental and calculated values.

Comparison of Calculated and Experimental Results

As noted previously, sufficient experimental data of a general nature exist to verify the adequacy of the cross sections used in this study for performing core-oriented calculations. The satisfactory use of these cross sections strongly suggests that they are applicable for the reflector evaluations which have been performed; however, not much experimental data for direct verification of such reflector calculations are available. Two types of measurements which do fall into the reflector study category were performed in the ZPR-9 experimental program and they will be reviewed here briefly.

The first concerned the measurement of reactivity rates and fission ratios in a full-density aluminum reflector. There was some concern about the ability to calculate reaction rates in an aluminum reflector since in the past aluminum and other light metals have proved troublesome when cores containing large volume fractions of these materials were analyzed. The difficulty is caused by the elastic scattering resonances of the light metal which occur for neutron energies of $500 \mathrm{keV}$ and below. This energy region is important for fast and intermediate reactors. Except for the elastic scattering resonances, all other neutron cross sections are fairly smooth functions in this energy region. The energy divisions of the 16-group set 
are much too coarse to define the energy variation of the resonances; thus the self-shielding produced by the resonances must be incorporated a priori into the cross-section set. A possible method of achieving this is the use of the ELMOE code in calculating the self-shielded cross sections. ${ }^{17}$ The ELMOE code is a cross-section-generation routine based on several hundred fine energy groups over which the scattering resonances are represented explicitly. Several options are avallable for calculating the fine-group spectrum, which is then used in generating the coarse-group self-shielded cross sections. The influence of this self-shielding on the coarse-group cross sections is analyzed in Refs. 18 and 19. The effect of these differences on the calculated reflector flux is shown in Table A-VII. Presented are experimental fission reaction rates of $\mathrm{U}^{235}$ and $\mathrm{U}^{238}$ at various reflector positions alongside corresponding calculated values obtained by two calculational methods. The first column of the calculated values was obtained from a computation which employed the completely unshielded (that is, infinite dilution) cross section for aluminum as given in the standard cross-section set of Ref. ll. The second column represents reaction rates obtained by using self-shielded cross sections for aluminum computed by the ELMOE code. It is encouraging to note that in most cases the use of the ELMOE-corrected set resulted in a better agreement between theory and experiment. The improvement is not large, however, and since the infinite-dilution standard set produced an agreement between calculated and experimental reaction rates within 5-10\%, the standard cross-section set was judged to be sufficient for the purposes of this analysis.

TABLE A-VII. Several Measured and Calculated Properties of an Aluminum Reflector (For ZPR-9 Assemblies No. I and 3)

\begin{tabular}{|c|c|c|c|c|c|c|}
\hline & \multicolumn{3}{|c|}{ Assembly No. 1} & \multicolumn{3}{|c|}{ Assembly No. 3} \\
\hline & Meas & $\mathrm{Calc}^{\mathrm{a}}$ & Calc ${ }^{b}$ & Meas & $\mathrm{Calc}^{\mathrm{a}}$ & $\mathrm{Calc}^{\mathrm{b}}$ \\
\hline Distance from core, $\mathrm{cm}$ & \multicolumn{6}{|c|}{$\mathrm{U}^{235}$ reaction rates ${ }^{\mathrm{c}}$} \\
\hline 5 & 0245 & 0.29 & 0.297 & 0.24 & 0.27 & 0.278 \\
\hline 10 & 0.22 & 0.235 & 0.241 & 0.18 & 0.195 & 0201 \\
\hline \multirow[t]{2}{*}{15} & 0.17 & 0.16 & 0.164 & 0.14 & 0.15 & 0.154 \\
\hline & \multicolumn{6}{|c|}{$\mathrm{U}^{238}$ reaction rates $\mathrm{c}$} \\
\hline 5 & - & 0.175 & 0.161 & 0.125 & 0.145 & 0.132 \\
\hline 10 & - & 0.12 & 0.111 & 0.08 & 0.085 & 0.078 \\
\hline \multirow[t]{2}{*}{15} & - & 0.07 & 0.065 & 0.06 & 0.06 & 0.056 \\
\hline & \multicolumn{6}{|c|}{$\mathrm{U}^{238} / \mathrm{U}^{235} \mathrm{f}_{1} \mathrm{ssion}$ ratio } \\
\hline 5 & - & 0.0258 & 0.0232 & 00180 & 0.0205 & 0.0184 \\
\hline 10 & - & 0.0208 & 0.0191 & 0.0125 & 0.0152 & 00140 \\
\hline 15 & - & 0.0175 & 0.0164 & 00098 & 0.0132 & 0.0120 \\
\hline Edge fuel worth, Ih $/ \mathrm{kg}$ & 24.0 & 20.8 & 25.2 & 12.0 & 12.3 & 13.3 \\
\hline
\end{tabular}

\footnotetext{
aluminum cross sections of Ref. 11 .

bAluminum cross sections corrected for resonance scattering by ELMOE code.

${ }^{c}$ Reaction rates normalized to $l$ at core center. All calculations performed by multigroup diffusion code in cylindrical geometry
} 
The second directly applicable experiment performed in the course of the ZPR-9 program was designed to duplicate the calculational model used in computing the control-vane reactivity worth in this study. For this purpose a ring of $\mathrm{B}^{10}$-containing stainless steel cans concentric with the core was loaded in the aluminum reflector of ZPR-9 Assembly No. 6. The ring was located $\sim 4 \mathrm{~cm}$ from the core-reflector interface. The experiment thus duplicated the calculational model for the control drums in IN condition. Because of the spatial discreteness of the ZPR-9 lattice, it is impossible to achieve a continuous and truly concentric ring. The arrangement of the final experimental configuration is shown schematically in Fig. A-1, in which the core midplane is pictured. The ring of boron cans shown extends along the whole axial distance of the core. The average radial distance of the boron cans from the core center varied by less than $1 \mathrm{~cm}$ from an ideal circular radius of $42.5 \mathrm{~cm}$. A more serious departure from ideal ring conditions was the discontinuity of the ring caused by the square nature of the ZPR-9 lattice. The total angle spanned by the boron cans was $274^{\circ}$ or $76 \%$ of the total radial angle.

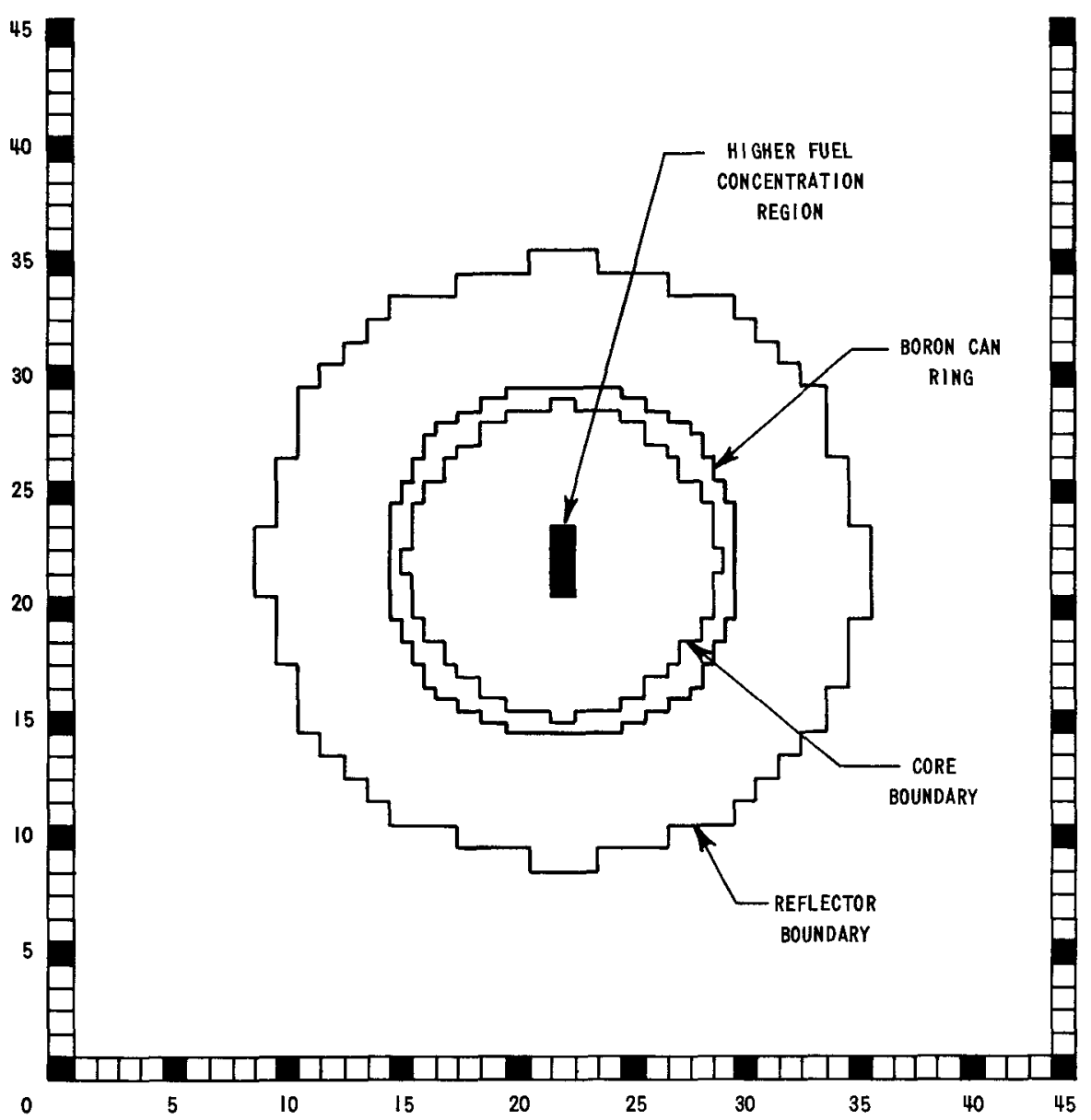

Fig. A-1. Schematic Representation of Boron Ring Experiment in ZPR-9

Assembly 6 
A total of $2.16 \mathrm{~kg}$ of $\mathrm{B}^{10}$ were loaded into the reflector in the form of $2 \times 2 \times 1 / 8$-in. stainless steel clad cans. 528 such cans each containing $\sim 4.1 \mathrm{~g}$ of $\mathrm{B}^{10}$ were required to complete the ring along the whole axial height $(61 \mathrm{~cm})$ of the $260-$ liter core. The reactivity change produced by the addition of the boron was compensated by loading $2.06 \mathrm{~kg}$ of $\mathrm{U}^{235}$ in the central region of the core indicated in Fig. A-1. The $\mathrm{U}^{235}$ was added in the form of $1 / 16$-in. plates, increasing the $U^{235}$ concentration in the central 3 drawers by $25 \%$.

The reactivity change produced by the loading of poison and of fuel was monitored in a stepwise manner by the positive period method. The total experimental worth of the boron $\mathrm{ring}$ was determined to be $\sim 0.75 \% \Delta \mathrm{k}$. Since this is produced by a ring which is only $76 \%$ complete, the equivalent full ring worth is $\sim 1.0 \% \triangle \mathrm{k}$.

Table A-VIII presents the results of calculations equivalent to the experimental conditions. The calculations were performed in two sets: the first set disregards the increase in the central fuel concentration; the second set includes the centrally loaded $\mathrm{U}^{235}$, both in the boron-free and the boron-ring-containing problem. The effect of including the reactivity loss compensating $\mathrm{U}^{235}$ on the calculated worth of the boron ring is below $1 \%$ of the total ring worth. In both cases the calculated reactivity worth overestimates the experimentally measured value by $\sim 16 \%$.

TABLE A-VIII. Reflector-located Boron Ring Problems

\begin{tabular}{|l|c|c|c|c|}
\hline \multicolumn{1}{|c|}{ Description of Problem } & keff & $\begin{array}{c}\text { Radial } \\
\text { Core Leakage }\end{array}$ & $\begin{array}{c}\text { Total } \\
\text { Core Leakage }\end{array}$ & $\begin{array}{c}\text { Worth of } \\
\text { Bing }\end{array}$ \\
\hline $\begin{array}{l}\text { Base problem. } \\
\text { ZPR-9 Assembly No. 6. }\end{array}$ & 1.01106 & 0.1979 & 0.3563 & $1.18 \% \Delta \mathrm{k}$ \\
$\begin{array}{l}\text { B ring added in reflector. } \\
\begin{array}{l}\text { No B ring. 2.06 kg of U } \\
\text { added to central region. }\end{array}\end{array}$ & 0.99916 & 0.2086 & 0.3669 & 0.3547 \\
$\begin{array}{l}\text { B ring. With 2.06 kg of } \mathrm{U}^{235} \\
\text { in central region. }\end{array}$ & 1.0155 & 0.1964 & 0.3654 & $1.17 \% \Delta \mathrm{k}$ \\
\hline
\end{tabular}

${ }^{a}$ Cylindrical geometry. DSN code in $\mathrm{S}_{4}$ approximation.

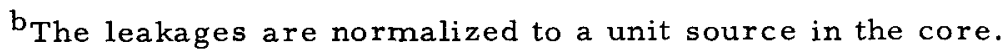




\section{APPENDIX B}

A FORTRAN Neutron-balance Code for the CDC-160A Computer

Practically all of the numerous available multigroup diffusion or transport theory codes provide as output spatial flux distributions and region-integrated fluxes. Such data can subsequently be used to obtain integrated or spatially dependent reaction rates of any neutron reaction or used to calculate energy-dependent neutron balances for each region.

Of particular importance to this study is the fraction of neutrons transferred between regions. The code presented in this Appendix was written specifically to calculate these fractions. The neutron leakages from the core and the reflector and the energy-dependent capture rate in the control poison were computed. These calculated quantities were used extensively in the evaluation of reflector and control poison materials.

The code is written in FORTRAN for the CDC-160A computer. The input data to the code consist of energy-dependent region-integrated fluxes provided by any multigroup diffusion or transport theory code and the macroscopic cross sections of the respective regions. The mathematics of the code is based on the simple neutron-balance equations:

$$
\left[\begin{array}{l}
\text { Leakage from } \\
\text { region } 1, \\
\text { energy group } \mathrm{J}
\end{array}\right]=\left[\begin{array}{l}
\text { Total neutron } \\
\text { source into region } 1, \\
\text { energy group J }
\end{array}\right]-\left[\begin{array}{l}
\text { Total neutron loss } \\
\text { term from region } 1, \\
\text { energy group J }
\end{array}\right] \text {, }
$$

where

$$
\begin{aligned}
& {\left[\begin{array}{l}
\text { Total source } \\
\text { region 1, } \\
\text { group j }
\end{array}\right]=\chi_{\mathrm{j}}^{*}\left[\begin{array}{l}
\text { normalization } \\
\text { factor }
\end{array}\right]+\sum_{\mathrm{k}=1}^{j} \int_{\mathrm{reg} 1} \phi_{\mathrm{k}}^{*} \sum_{\mathrm{k} \rightarrow \mathrm{j}}+\left[\begin{array}{l}
\text { Leakage from } \\
\text { other regions }
\end{array}\right] \text {, }} \\
& {\left[\begin{array}{l}
\text { Total loss term } \\
\operatorname{region~1,~} \\
\text { group j }
\end{array}\right]=\sum_{k=j=1}^{M} \int_{\text {reg 1 }} \phi_{j}^{*} \Sigma_{j \rightarrow k}+\int_{\text {reg } 1} \phi_{j}^{*} \Sigma_{\text {cap }}+\int_{\text {reg } 1} \phi_{j}^{*} \Sigma_{\chi_{j}} .}
\end{aligned}
$$

The cross-section set used in the code and in the analysis was the 16-group set described in Appendix A. The code has a comprehensive output which gives the energy dependence of each separate source and loss term, and the sums over the 16 energy groups. The input allows problems to be run consecutively so that the leakage-loss term of one region can be used as the leakage-source term for the adjoining region.

The input specifications, the FORTRAN representation of the code, and a complete sample calculation are given in the pages following.

The code of this Appendix was used to process the results of calculations on which the evaluations of reflector materials given in Section II are based. These processed results are presented in Section II 
in various ways designed to illustrate the particular reflector property under discussion. In this Appendix the calculated data are summarized in Tables B-I through B-VI. The tables could be useful if the study is extended to other reflector materials or if additional comparisons are made.

TABLE B-I Test Problem for NEUTRON BALANCE Code

$\mathrm{Al}_{2} \mathrm{O}_{3}$ reflected core of assembly No 6 type in cylındrical geometry Fluxes obtained by the MACH-1 code

\begin{tabular}{|c|c|c|c|c|c|c|c|c|c|c|c|c|c|c|c|c|}
\hline k & $\int_{\operatorname{core}} \emptyset$ & ${ }^{\Sigma}$ rema & \multicolumn{2}{|c|}{$\Sigma_{\text {rem }}{ }^{\emptyset \theta}$} & \multicolumn{2}{|c|}{$\Sigma_{k-k+1}$} & \multicolumn{2}{|c|}{$\Sigma_{k-k+1} \int \emptyset$} & \multicolumn{2}{|c|}{$\Sigma_{k-k+2}$} & $\Sigma_{k-k+2} \sqrt{\emptyset}$ & \multicolumn{2}{|c|}{$\Sigma_{k-k+3}$} & $\Sigma_{k-k+3} \int \emptyset$ & $\Sigma_{k-k+4}$ & $\Sigma_{k \rightarrow k+4} \int \emptyset$ \\
\hline 1 & 19704 & 0089102 & \multicolumn{2}{|l|}{017557} & \multicolumn{2}{|c|}{0041742} & \multirow{2}{*}{\multicolumn{2}{|c|}{0082248}} & \multicolumn{2}{|c|}{0011415} & & \multicolumn{2}{|c|}{0016112} & & 0008533 & \\
\hline 2 & 47339 & 008023 & \multicolumn{2}{|l|}{037980} & \multicolumn{2}{|c|}{002887} & & & \multicolumn{2}{|c|}{0028180} & & \multicolumn{2}{|c|}{0010852} & & 0001502 & \\
\hline 3 & 48156 & 0058794 & \multicolumn{2}{|l|}{028313} & \multicolumn{2}{|c|}{003065} & \multicolumn{2}{|c|}{013667} & \multicolumn{2}{|c|}{0013778} & 0022492 & \multicolumn{2}{|c|}{0002379} & & 0000456 & \\
\hline 4 & 139031 & 0028947 & \multicolumn{2}{|c|}{0402453} & \multicolumn{2}{|c|}{0017057} & \multicolumn{2}{|c|}{014760} & 00008 & & 013340 & 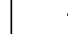 & & 0031747 & - & \\
\hline 5 & 193460 & 0020044 & 038777 & & & 77356 & 023 & 145 & - & & 0066350 & & & 0051372 & - & 0016813 \\
\hline 6 & 76994 & 0024935 & 019198 & & & 27613 & 014 & & & & 0011706 & & & 0011456 & - & 00071103 \\
\hline 7 & 10331 & 0045066 & 0046558 & & & 38117 & 002 & & - & & & & & & & 00021960 \\
\hline 8 & 02244 & 0097232 & 0021819 & & & 3818 & 000 & & - & & & 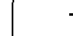 & & & & \\
\hline 9 & 006746 & 020477 & 0013814 & & & 39286 & 000 & 8567 & & & & & & & - & \\
\hline 10 & 002486 & 029660 & $73735 \times$ & $10^{-3}$ & & 38837 & 000 & 2650 & - & & & 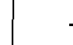 & & & - & \\
\hline 11 & $8571 \times 10^{-}$ & 062570 & $53629 \times$ & $10^{-3}$ & & 1280 & 000 & 0965 & - & & & 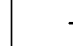 & & & - & \\
\hline 12 & $7595 \times 10^{-}$ & 059654 & $45307 x$ & $10^{3}$ & & 6004 & 000 & 0967 & - & & & 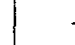 & & & & \\
\hline 13 & $11655 \times 10^{-}$ & 025265 & $29446 \times$ & $10^{3}$ & & 4114 & 000 & 0456 & & & & & & & - & \\
\hline 14 & $4969 \times 10$ & 045233 & $22476 x$ & $10^{3}$ & & 42093 & 000 & 0479 & & & & & & & & \\
\hline 15 & $2442 \times 10^{-}$ & 11863 & $28969 x$ & $10^{-3}$ & & 6660 & 000 & 0209 & - & & & 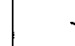 & & & - & \\
\hline 16 & $3222 \times 10$ & 30893 & $99537 \times$ & $10^{-3}$ & & - & 000 & 0163 & - & & & & & & - & \\
\hline k & $\Sigma_{k-k+5}$ & $\Sigma_{k}-k+5 \delta \emptyset$ & $\sum_{k 1}^{5} \Sigma_{k-k+1}$ & $\Sigma_{\mathrm{Ca}}$ & & $\Sigma_{\text {Leak }}^{\Sigma_{\text {Leak }}}$ & $\begin{array}{l}x \mid a l \\
e^{b}\end{array}$ & $\int \phi \Sigma$ & & $\int 0 \sum_{k}^{5}$ & $\Sigma_{k-k+1}$ & $\begin{array}{l}\text { Fission } \\
\text { Source }\end{array}$ & $\begin{array}{l}\text { Total } \\
\text { Intc }\end{array}$ & $\begin{array}{l}\text { Source } \\
\text { Group }\end{array}$ & $\begin{array}{l}\text { Leakage } \\
\text { from Core }\end{array}$ & $\begin{array}{c}\text { Total } \\
\text { Scattered } \\
\text { Source }\end{array}$ \\
\hline 1 & 0001204 & & 0079006 & 0010 & & 000 & & 0013 & & 015 & & 0204 & 02 & & 002843 & \\
\hline 2 & - & & 069404 & 0010 & & 000 & & 0030 & & 032 & 855 & 0344 & & 6625 & 004645 & 0082248 \\
\hline 3 & - & & 0047263 & 0011 & & 000 & & 0040 & & 02 & 760 & 0168 & & 716 & 004403 & 0159162 \\
\hline 4 & - & & 0017899 & 0011 & & 000 & & 0113 & & 02 & 885 & 0180 & & 275 & 009030 & 031275 \\
\hline 5 & - & & 0007356 & 0012 & & 001 & & 0203 & & 014 & 231 & 0090 & & 168 & 007391 & 037168 \\
\hline 6 & - & 0002372 & 0002761 & 0022 & & 002 & & 0157 & & 002 & 1258 & 0014 & & 895 & -000303 & 017495 \\
\hline 7 & - & & 00038117 & 0041 & & 003 & & 0041 & & 000 & 3938 & & & 346 & -00231 & 002346 \\
\hline 8 & - & & 0003818 & 0093 & & 009 & & 0020 & & 856 & $7 \times 10^{-4}$ & & & 3938 & -001788 & 0003938 \\
\hline 9 & - & & 00039286 & 0200 & & 019 & & 0013 & & 265 & $0 \times 10^{-4}$ & & & 08567 & -001296 & 00008567 \\
\hline 10 & & & 0,0038837 & 0292 & & 029 & & 7256 & $\times 10^{-3}$ & 09 & $55 \times 10^{-4}$ & & & 02650 & -000711 & 00002650 \\
\hline 11 & - & & 0011280 & 0614 & & 061 & & 5263 & $10^{-3}$ & 096 & $68 \times 10^{-4}$ & & & 300965 & -0005266 & 00000965 \\
\hline 12 & - & & 0006004 & 0590 & & 058 & & 4480 & $\times 10^{-3}$ & 456 & $0 \times 10^{-5}$ & & & 300967 & -0004434 & 00000967 \\
\hline 13 & & & 0004114 & 0248 & & 024 & & 288 & $\times 10^{-3}$ & 47 & $5 \times 10^{-5}$ & & & 300456 & -000290 & 00000456 \\
\hline 14 & - & & 00042093 & 0448 & & 044 & & 222 & $\times 10^{-3}$ & 20 & $16 \times 10^{-5}$ & & & 300479 & -000220 & 00000479 \\
\hline 15 & - & & 0006660 & 1179 & & 117 & & 287 & $\times 10^{-3}$ & 16 & $64 \times 10^{-5}$ & & & 000209 & -000288 & 00000209 \\
\hline 16 & - & & & 3089 & & 308 & & 9953 & $\times 10^{-3}$ & & & & & 000163 & -0009937 & 00000163 \\
\hline
\end{tabular}

alncludes axial leakage

bNo axial leakage 
TABLE B-II Leakage Neutron Balances for $\mathrm{Al}_{2} \mathrm{O}_{3}$-reflected Reactor

\begin{tabular}{|c|c|c|c|c|c|c|c|c|c|c|}
\hline $\begin{array}{l}\text { Fraction } \\
\text { Leaked from } \\
\text { Boron-free } \\
\text { Core, L }\end{array}$ & $\begin{array}{c}\text { Fraction } \\
\text { Leaked from } \\
\text { Boron Core, } \\
L_{B}\end{array}$ & $\begin{array}{c}\text { Fraction } \\
\text { Entering Boron } \\
\text { Reglon, LBR }\end{array}$ & $\begin{array}{l}\text { Fraction } \\
\text { Absorbed in } \\
\text { Reflector Region, } \\
L_{B}-L_{B R}\end{array}$ & $\begin{array}{l}\text { Fraction } \\
\text { Absorbed } \\
\text { in Boron } \\
\text { Region }\end{array}$ & $\begin{array}{c}\text { Change in } \\
\text { Core Leakage } \\
\text { Fraction, } \\
L-L_{B}\end{array}$ & $\begin{array}{c}\text { Fraction } \\
\text { Leaked from } \\
B+H \text { Core, } \\
L_{B}+H\end{array}$ & $\begin{array}{c}\text { Fraction } \\
\text { Enter Ing } B+H \\
\text { Region, } \\
L_{B}+H\end{array}$ & $\begin{array}{c}\text { Fraction } \\
\text { Absorbed in } \\
\text { Reflector Region } \\
L_{B+H} \quad L R_{B}+H\end{array}$ & $\begin{array}{c}\text { Fraction } \\
\text { Absorbed } \\
\text { in B + H } \\
\text { Region }\end{array}$ & $\begin{array}{c}\text { Change in } \\
\text { Core Leakage } \\
\text { Fractions } \\
L-L_{B}+H\end{array}$ \\
\hline $\begin{array}{l}002768 \\
004532 \\
004741 \\
0010884 \\
009620 \\
0000725 \\
-002243 \\
-001400 \\
-0007655 \\
-0003123 \\
-0001668 \\
-0001049 \\
-0000503 \\
-0000262 \\
-0000192 \\
-0000148 \\
027515\end{array}$ & $\begin{array}{l}002579 \\
004294 \\
004546 \\
010760 \\
009900 \\
0007263 \\
-001551 \\
-0007301 \\
-0002278 \\
-0000437 \\
-883 \times 10^{-5} \\
-149 \times 10^{-5} \\
-151 \times 10^{-6} \\
-265 \times 10^{-7} \\
-435 \times 10^{-8} \\
-430 \times 10^{-9} \\
030242\end{array}$ & $\begin{array}{l}001756 \\
003805 \\
002703 \\
007718 \\
009931 \\
004193 \\
0001498 \\
-0001068 \\
-0000211 \\
497 \times 10^{-5} \\
317 \times 10^{-5} \\
101 \times 10^{-5} \\
203 \times 10^{-5} \\
149 \times 10^{-7} \\
442 \times 10^{-8} \\
556 \times 10^{-9} \\
030137\end{array}$ & $\begin{array}{l}000823 \\
000489 \\
001843 \\
003042 \\
-000031 \\
-003467 \\
-001701 \\
-000623 \\
-000207 \\
-0000487 \\
-120 \times 10^{-4} \\
-250 \times 10^{-5} \\
-354 \times 10^{-6} \\
-414 \times 10^{-7} \\
-877 \times 10^{-8} \\
-986 \times 10^{-9} \\
000104\end{array}$ & $\begin{array}{l}000014 \\
000044 \\
000021 \\
000157 \\
001032 \\
001804 \\
001617 \\
001121 \\
000638 \\
000235 \\
0000995 \\
0000463 \\
0000187 \\
748 \times 10^{-5} \\
433 \times 10^{-5} \\
240 \times 10^{-5} \\
006862\end{array}$ & $\begin{array}{c}000189 \\
000238 \\
000195 \\
000124 \\
-000280 \\
-000653 \\
-000692 \\
-000670 \\
-000538 \\
-000268 \\
-000158 \\
-000104 \\
-0000501 \\
-0000262 \\
0000192 \\
-0000148 \\
-0002727\end{array}$ & $\begin{array}{l}002641 \\
004424 \\
004624 \\
010909 \\
010051 \\
0008206 \\
-001845 \\
-001156 \\
-0005341 \\
0001540 \\
-0000500 \\
-0000150 \\
-267 \times 10^{-5} \\
-503 \times 10^{-6} \\
-111 \times 10^{-6} \\
-143 \times 10^{-7} \\
029712\end{array}$ & $\begin{array}{c}001802 \\
003941 \\
002786 \\
007947 \\
010140 \\
004222 \\
-0003420 \\
-0005569 \\
-0002632 \\
-0000564 \\
-0000131 \\
-208 \times 10^{-5} \\
+609 \times 10^{-6} \\
+208 \times 10^{-6} \\
+558 \times 10^{-7} \\
+117 \times 10^{-7} \\
029606\end{array}$ & $\begin{array}{l}000839 \\
000483 \\
001838 \\
002962 \\
-000089 \\
-003401 \\
-001503 \\
-000599 \\
-000271 \\
-0000976 \\
-0000369 \\
-0000129 \\
328 \times 10^{-5} \\
-711 \times 10^{-6} \\
-167 \times 10^{-6} \\
-260 \times 10^{-7} \\
000107\end{array}$ & $\begin{array}{l}000011 \\
000022 \\
000011 \\
000077 \\
000504 \\
000884 \\
000978 \\
000963 \\
000848 \\
000444 \\
000244 \\
000134 \\
0000563 \\
0000218 \\
0000116 \\
55 \times 10^{-5} \\
005215\end{array}$ & $\begin{array}{l}000127 \\
000108 \\
000117 \\
000025 \\
-000431 \\
-000748 \\
-000398 \\
-000244 \\
-000232 \\
-000158 \\
-000117 \\
-0000898 \\
-0000476 \\
-0000257 \\
-0000191 \\
-0000148 \\
002198\end{array}$ \\
\hline
\end{tabular}

TABLE B-III Leakage Neutron Balances for Carbon-reflected Reactor

\begin{tabular}{|c|c|c|c|c|c|c|c|c|c|c|}
\hline $\begin{array}{l}\text { Fraction } \\
\text { Leaked from } \\
\text { Boron-free } \\
\text { Core, L }\end{array}$ & $\begin{array}{c}\text { Fraction } \\
\text { Leaked from } \\
\text { Boron Core, } \\
L_{B}\end{array}$ & $\begin{array}{l}\text { Fraction } \\
\text { Entering Boron } \\
\text { Region } L_{B R}\end{array}$ & $\begin{array}{c}\text { Fraction } \\
\text { Absorbed in } \\
\text { Reflector Region, } \\
L_{B}-L_{B R}\end{array}$ & $\begin{array}{l}\text { Fraction } \\
\text { Absorbed } \\
\text { in Boron } \\
\text { Region }\end{array}$ & $\begin{array}{c}\text { Change in } \\
\text { Core Leakage } \\
\text { Fraction, } \\
L-L_{B}\end{array}$ & $\begin{array}{c}\text { Fraction } \\
\text { Leaked from } \\
B+H \text { Core, } \\
L_{B}+H\end{array}$ & $\begin{array}{c}\text { Fraction } \\
\text { Entering } \mathbf{B}+\mathrm{H} \\
\text { Region, } \\
L \mathrm{R}_{\mathbf{B}+\mathrm{H}}\end{array}$ & $\begin{array}{c}\text { Fraction } \\
\text { Absorbed in } \\
\text { Reflector Region } \\
L_{B+H} \quad L_{B+H}\end{array}$ & $\begin{array}{l}\text { Fraction } \\
\text { Absorbed } \\
\text { in B + H } \\
\text { Region }\end{array}$ & $\begin{array}{l}\text { Change in } \\
\text { Core Leakage } \\
\text { Fractions, } \\
L \quad L_{B}+H\end{array}$ \\
\hline 002967 & 002597 & 002019 & 000578 & 000009 & 000370 & 002673 & 002083 & 000590 & 000004 & 000294 \\
\hline 005069 & 004527 & 004080 & 000447 & 000041 & 000542 & 004683 & 004242 & 000442 & 000021 & 000386 \\
\hline 005046 & 004671 & 003289 & 001382 & 000021 & 000375 & 004768 & 003394 & 001374 & 000010 & 000278 \\
\hline 011915 & 011528 & 008482 & 003046 & 000139 & 000387 & 011690 & 008725 & 002965 & 000068 & 000225 \\
\hline 010570 & 010633 & 009673 & 000960 & 000825 & -000063 & 010751 & 009850 & 000901 & 000402 & -000181 \\
\hline 0005931 & 001012 & 003471 & 002459 & 001416 & -000419 & 001069 & 003475 & -002406 & 000694 & 000476 \\
\hline-002405 & -001766 & 0004166 & 002183 & 001680 & -000639 & -001937 & 0000121 & 001949 & 000957 & -000468 \\
\hline-001923 & -001086 & 0000191 & -001067 & 001605 & -000837 & -001444 & -0004685 & -000975 & 001172 & -000479 \\
\hline-001342 & -0004589 & 0000182 & -000477 & 001250 & -000883 & -0008142 & -0002867 & -000527 & 001271 & -000528 \\
\hline-0006839 & -0001200 & 0000330 & -000153 & 000621 & -000564 & -0002887 & $-000061 \mathrm{I}$ & -000228 & 000826 & 000395 \\
\hline-0004561 & -0000343 & 0000191 & -0000534 & 000348 & -000422 & -0001167 & $-481 \times 10^{-5}$ & -000112 & 000559 & -000339 \\
\hline-0003558 & $-886 \times 10^{-5}$ & $758 \times 10^{-5}$ & -0000164 & 000218 & -000347 & -0000442 & $698 \times 10^{-5}$ & -0000512 & 000386 & -000312 \\
\hline-0002252 & $-152 \times 10^{-5}$ & $207 \times 10^{-5}$ & $-359 \times 10^{-5}$ & 000122 & -000224 & -0000102 & $673 \times 10^{-5}$ & -0000169 & 000213 & -000215 \\
\hline-0001515 & $-371 \times 10^{-6}$ & $317 \times 10^{-6}$ & $-688 \times 10^{-6}$ & 0000674 & -000151 & $-249 \times 10^{-5}$ & $222 \times 10^{-5}$ & $-471 \times 10^{-5}$ & 000111 & -000149 \\
\hline-0001578 & $-997 \times 10^{-7}$ & $114 \times 10^{-6}$ & $-214 \times 10^{-6}$ & 0000594 & -000158 & $-717 \times 10^{-6}$ & $737 \times 10^{-6}$ & $-145 \times 10^{-5}$ & 0000911 & -000157 \\
\hline-0003384 & $-186 \times 10^{-7}$ & $238 \times 10^{-7}$ & $-424 \times 10^{-7}$ & 0000840 & -000338 & $-154 \times 10^{-6}$ & $166 \times 10^{-6}$ & $-320 \times 10^{-6}$ & 000118 & -000338 \\
\hline 028121 & 031493 & 031492 & 0 & 008506 & -003371 & 030976 & 030976 & 0 & 006903 & -002854 \\
\hline
\end{tabular}

TABLE B-IV Leakage Neutron Balances for Aluminum-reflected Reactor

\begin{tabular}{|c|c|c|c|c|c|c|c|c|c|c|}
\hline $\begin{array}{l}\text { Fraction } \\
\text { Leaked from } \\
\text { Boron-free } \\
\text { Core, } L\end{array}$ & $\begin{array}{c}\text { Fraction } \\
\text { Leaked from } \\
\text { Boron Core, } \\
L_{B}\end{array}$ & $\begin{array}{c}\text { Fraction } \\
\text { Entering Boron } \\
\text { Region, LBR }\end{array}$ & $\begin{array}{c}\text { Fraction } \\
\text { Absorbed in } \\
\text { Reflector Region, } \\
L_{B}-L_{B R}\end{array}$ & $\begin{array}{l}\text { Fraction } \\
\text { Absorbed } \\
\text { In Boron } \\
\text { Region }\end{array}$ & $\begin{array}{l}\text { Change in } \\
\text { Core Leakage } \\
\text { Fraction, } \\
L-L_{B}\end{array}$ & $\begin{array}{c}\text { Fraction } \\
\text { Leaked from } \\
B+H \text { Core, } \\
L_{B+H}\end{array}$ & $\begin{array}{c}\text { Fraction } \\
\text { Enter ing } B+H \\
\text { Region, } \\
L_{B}+H\end{array}$ & $\begin{array}{c}\text { Fraction } \\
\text { Absorbed in } \\
\text { Reflector Region, } \\
L_{B+H} \quad L_{B}+H\end{array}$ & $\begin{array}{c}\text { Fraction } \\
\text { Absorbed } \\
\text { In } B+H \\
\text { Region }\end{array}$ & $\begin{array}{c}\text { Change in } \\
\text { Core Leakage } \\
\text { Fractions } \\
L-L_{B}+H\end{array}$ \\
\hline $\begin{array}{l}002254 \\
003918 \\
004094 \\
010007 \\
009874 \\
002744 \\
-0003324 \\
-0000387 \\
-652 \times 10^{-5} \\
-727 \times 10^{-6} \\
-988 \times 10^{-7} \\
-139 \times 10^{-7} \\
-158 \times 10^{-8} \\
-215 \times 10^{-9} \\
-345 \times 10^{-10} \\
-325 \times 10^{-11} \\
032512\end{array}$ & $\begin{array}{l}002239 \\
003909 \\
004097 \\
010129 \\
010137 \\
002741 \\
-000345 \\
-0000327 \\
-368 \times 10^{-5} \\
-202 \times 10^{-6} \\
-106 \times 10^{-7} \\
-346 \times 10^{-9} \\
-650 \times 10^{-11} \\
-285 \times 10^{-12} \\
-104 \times 10^{-13} \\
-179 \times 10^{-15} \\
032880\end{array}$ & $\begin{array}{l}001721 \\
003528 \\
003532 \\
009303 \\
010763 \\
004034 \\
-0000667 \\
+238 \times 10^{-5} \\
-316 \times 10^{-6} \\
167 \times 10^{-7} \\
298 \times 10^{-8} \\
280 \times 10^{-9} \\
129 \times 10^{-10} \\
285 \times 10^{-12} \\
131 \times 10^{-13} \\
271 \times 10^{-14} \\
032816\end{array}$ & $\begin{array}{l}000518 \\
000381 \\
000565 \\
000826 \\
-000626 \\
-001293 \\
-000268 \\
-0000351 \\
-336 \times 10^{-5} \\
-219 \times 10^{-6} \\
-136 \times 10^{-7} \\
-626 \times 10^{-9} \\
-194 \times 10^{-10} \\
-570 \times 10^{-12} \\
-235 \times 10^{-13} \\
-289 \times 10^{-14} \\
000064\end{array}$ & $\begin{array}{l}000010 \\
000038 \\
000024 \\
000177 \\
000940 \\
000878 \\
000329 \\
0000757 \\
0000117 \\
108 \times 10^{-5} \\
980 \times 10^{-7} \\
888 \times 10^{-8} \\
708 \times 10^{-9} \\
625 \times 10^{-10} \\
715 \times 10^{-11} \\
513 \times 10^{-12} \\
002485\end{array}$ & $\begin{array}{l}000015 \\
000009 \\
-000003 \\
-000122 \\
-000263 \\
+000003 \\
+000002 \\
-000006 \\
-284 \times 10^{-5} \\
-525 \times 10^{-6} \\
-882 \times 10^{-7} \\
-136 \times 10^{-7} \\
-157 \times 10^{-8} \\
-215 \times 10^{-9} \\
-345 \times 10^{-10} \\
-325 \times 10^{-11} \\
-000368\end{array}$ & $\begin{array}{l}002255 \\
003971 \\
004144 \\
010291 \\
010282 \\
002712 \\
-0005421 \\
-0001641 \\
-0000522 \\
-0000102 \\
-269 \times 10^{-5} \\
-703 \times 10^{-5} \\
-117 \times 10^{-6} \\
208 \times 10^{-6} \\
-366 \times 10^{-8} \\
-295 \times 10^{-9} \\
032883\end{array}$ & $\begin{array}{l}001738 \\
003600 \\
003591 \\
009508 \\
010898 \\
003952 \\
-0002959 \\
-0001197 \\
-0000427 \\
-820 \times 10^{-5} \\
-224 \times 10^{-5} \\
-587 \times 10^{-6} \\
-929 \times 10^{-7} \\
-161 \times 10^{-7} \\
-262 \times 10^{-8} \\
-184 \times 10^{-9} \\
032818\end{array}$ & $\begin{array}{l}000517 \\
000371 \\
000553 \\
000783 \\
-000616 \\
-001240 \\
-000246 \\
-000044 \\
-0000085 \\
-20 \times 10^{-5} \\
-45 \times 10^{-6} \\
-116 \times 10^{-6} \\
-24 \times 10^{-6} \\
-47 \times 10^{-7} \\
-104 \times 10^{-8} \\
-111 \times 10^{-9} \\
000066\end{array}$ & $\begin{array}{l}000006 \\
000019 \\
000012 \\
000086 \\
000456 \\
000447 \\
000267 \\
000151 \\
000081 \\
000028 \\
000012 \\
515 \times 10^{-5} \\
163 \times 10^{-5} \\
470 \times 10^{-6} \\
151 \times 10^{-6} \\
311 \times 107 \\
001572\end{array}$ & $\begin{array}{l}-000001 \\
-000053 \\
000050 \\
000284 \\
000408 \\
+000032 \\
+000210 \\
+000125 \\
0000457 \\
95 \times 10^{5} \\
259 \times 10^{-5} \\
689 \times 10^{-6} \\
115 \times 10^{-6} \\
206 \times 10^{-7} \\
363 \times 10^{-8} \\
292 \times 10^{-9} \\
-000371\end{array}$ \\
\hline
\end{tabular}


TABLE B-V Leakage Neutron Balances for Iron-reftected Reactor

\begin{tabular}{|c|c|c|c|c|c|c|c|c|c|c|}
\hline $\begin{array}{l}\text { Fraction } \\
\text { Leaked from } \\
\text { Boron-free } \\
\text { Core, L }\end{array}$ & $\begin{array}{c}\text { Fraction } \\
\text { Leaked from } \\
\text { Boron Core, } \\
L_{B}\end{array}$ & $\begin{array}{c}\text { Fraction } \\
\text { Enterıng Boron } \\
\text { Region, LBR }\end{array}$ & $\begin{array}{c}\text { Fraction } \\
\text { Absorbed in } \\
\text { Reflector Region, } \\
L_{B}-L_{B R}\end{array}$ & $\begin{array}{l}\text { Fraction } \\
\text { Absorbed } \\
\text { In Boron } \\
\text { Region }\end{array}$ & $\begin{array}{c}\text { Change in } \\
\text { Core Leakage } \\
\text { Fraction, } \\
L-L_{B}\end{array}$ & $\begin{array}{c}\text { Fraction } \\
\text { Leaked from } \\
B+H \text { Core, } \\
L_{B}+H\end{array}$ & $\begin{array}{c}\text { Fraction } \\
\text { Entering } B+H \\
\text { Region, } \\
L_{B+H}\end{array}$ & $\begin{array}{c}\text { Fraction } \\
\text { Absorbed in } \\
\text { Reflector Region, } \\
L_{B+H} \quad L_{B}+H\end{array}$ & $\begin{array}{l}\text { Fraction } \\
\text { Absorbed } \\
\text { in B + H } \\
\text { Region }\end{array}$ & $\begin{array}{l}\text { Change in } \\
\text { Core Leakage } \\
\text { Fractions, } \\
L-L_{B}+H\end{array}$ \\
\hline $\begin{array}{l}002351 \\
004643 \\
003948 \\
009307 \\
009315 \\
002272 \\
-0002683 \\
-0002116 \\
-0000729 \\
-0000319 \\
-0000176 \\
-0000105 \\
-435 \times 10^{-5} \\
-154 \times 10^{-5} \\
-502 \times 10^{-6} \\
-535 \times 10^{-7} \\
031219\end{array}$ & $\begin{array}{l}002305 \\
004538 \\
003952 \\
009527 \\
009726 \\
002394 \\
-0002190 \\
-0001250 \\
-0000243 \\
-475 \times 10^{-5} \\
-996 \times 10^{-6} \\
-189 \times 10^{-6} \\
-244 \times 10^{-7} \\
-353 \times 10^{-8} \\
-502 \times 10^{-9} \\
-311 \times 10^{-10} \\
032068\end{array}$ & $\begin{array}{l}001454 \\
003177 \\
003557 \\
009273 \\
010787 \\
003346 \\
0000101 \\
-0000119 \\
+378 \times 10^{-5} \\
212 \times 10^{-5} \\
696 \times 10^{-6} \\
182 \times 10^{-6} \\
303 \times 10^{-7} \\
291 \times 10^{-8} \\
592 \times 10^{-9} \\
390 \times 10^{-10} \\
031598\end{array}$ & $\begin{array}{l}000851 \\
001361 \\
000395 \\
000254 \\
-001061 \\
-000952 \\
-000229 \\
-000113 \\
-0000281 \\
-687 \times 10^{-5} \\
-169 \times 10^{-5} \\
-371 \times 10^{-6} \\
-547 \times 10^{-7} \\
-644 \times 10^{-8} \\
-109 \times 10^{-8} \\
-701 \times 10^{-10} \\
000469\end{array}$ & $\begin{array}{l}000008 \\
000030 \\
000032 \\
000234 \\
001157 \\
001130 \\
000518 \\
000254 \\
0000979 \\
0000351 \\
0000157 \\
767 \times 10^{-5} \\
284 \times 10^{-5} \\
887 \times 10^{-6} \\
272 \times 10^{-6} \\
283 \times 10^{-7} \\
003524\end{array}$ & $\begin{array}{l}000046 \\
000105 \\
-000004 \\
-000220 \\
-000411 \\
-000122 \\
-0000493 \\
-0000866 \\
-0999486 \\
-0000272 \\
-0000166 \\
-0000103 \\
-433 \times 10^{-5} \\
-154 \times 10^{-5} \\
-502 \times 10^{-6} \\
-535 \times 10^{-7} \\
-000850\end{array}$ & $\begin{array}{l}002333 \\
004614 \\
004007 \\
009741 \\
009897 \\
002329 \\
-0005151 \\
-0003501 \\
-0001122 \\
-0000333 \\
-0000107 \\
-317 \times 10^{-5} \\
-623 \times 10^{-6} \\
-119 \times 10^{-6} \\
-230 \times 10^{-7} \\
-182 \times 10^{-8} \\
031896\end{array}$ & $\begin{array}{l}001475 \\
003265 \\
003622 \\
009526 \\
010956 \\
003236 \\
-0003683 \\
-0002281 \\
-0000633 \\
-663 \times 10^{-5} \\
-849 \times 10^{-7} \\
+569 \times 10^{-6} \\
252 \times 10^{-6} \\
478 \times 10^{-7} \\
893 \times 10^{-8} \\
709 \times 10^{-9} \\
031415\end{array}$ & $\begin{array}{l}000858 \\
001349 \\
000385 \\
000215 \\
-001059 \\
-000907 \\
-000147 \\
-000122 \\
-0000489 \\
-0000267 \\
-0000106 \\
-374 \times 10^{-5} \\
-875 \times 10^{-6} \\
-167 \times 10^{-6} \\
-319 \times 10^{-7} \\
-253 \times 10^{-8} \\
000480\end{array}$ & $\begin{array}{l}000004 \\
000016 \\
000019 \\
000124 \\
000578 \\
000585 \\
000443 \\
000396 \\
000310 \\
000159 \\
0000847 \\
0000437 \\
0000161 \\
514 \times 10^{-5} \\
184 \times 10^{-5} \\
343 \times 10^{-6} \\
002786\end{array}$ & $\begin{array}{l}000018 \\
000029 \\
-000059 \\
-000434 \\
-000582 \\
-000057 \\
+0002468 \\
0001385 \\
0000393 \\
14 \times 10^{-5} \\
-69 \times 10^{-5} \\
-74 \times 10^{-5} \\
-373 \times 10^{-5} \\
-142 \times 10^{-5} \\
479 \times 10^{-6} \\
-417 \times 10^{-7} \\
-000678\end{array}$ \\
\hline
\end{tabular}

TABLE B-VI Leakage Neutron Balances for Nickel-reflected Reactor

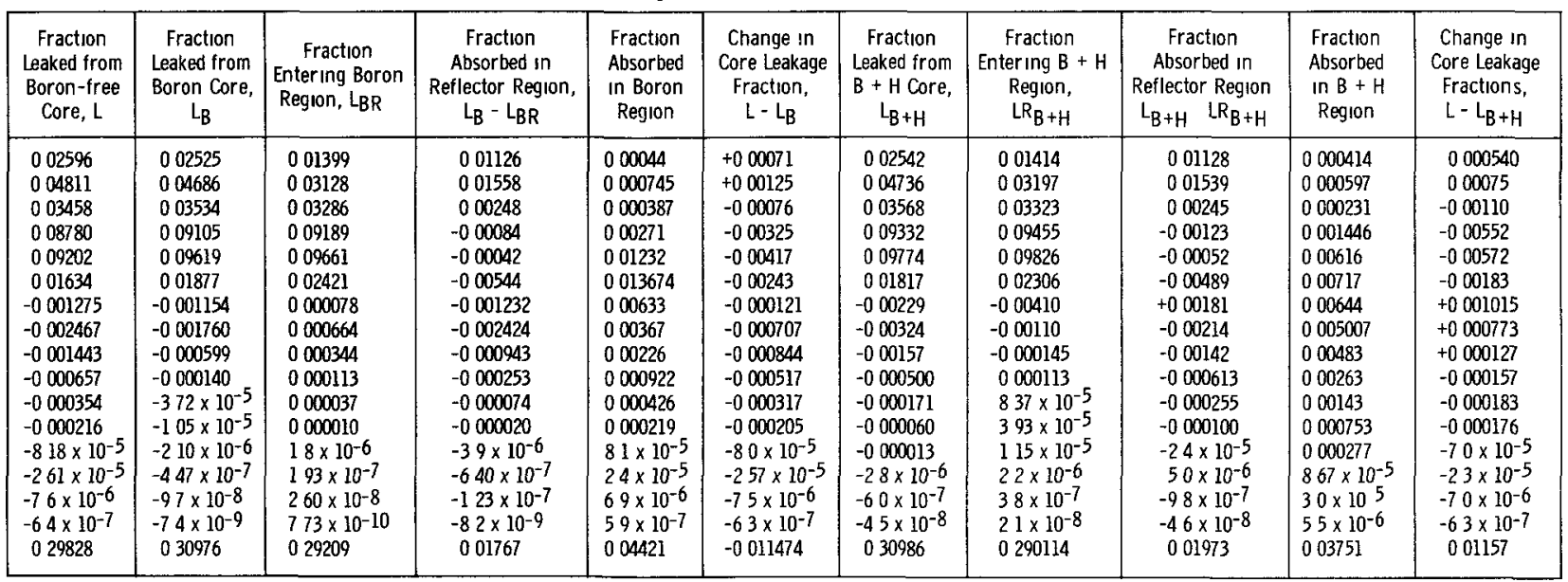




\section{Input Specifications}

\begin{tabular}{|c|c|c|}
\hline Card No. & Format & Input Description \\
\hline 1000 & F 12.5 & Problem number. \\
\hline 2000 & $12 \mathrm{~A} 6$ & Description of problem. \\
\hline \multirow[t]{5}{*}{3000} & $4 I 6$ & Input options, $N, M, I C$, and IX. \\
\hline & & $\begin{array}{l}\mathrm{N}=\text { cross-section option. Used if problems employ- } \\
\text { ing the same cross sections are run consecutively. } \\
\quad \mathrm{N}>0 ; \text { Readcross sections. } \\
\quad \mathrm{N} \leq 0 ; \text { Do not read cross sections. }\end{array}$ \\
\hline & & $\begin{aligned} M= & \text { consecutive problem option. } \\
& M \leq 0 ; \text { Final problem in series. } \\
& M>0 ; \text { More problems following. }\end{aligned}$ \\
\hline & & $\begin{aligned} & I C= \text { In-leakage options. } \\
& \text { IC } \leq 0 ; \text { In-leakage will be equal to out-leakage of } \\
& \text { previous problem. } \\
& \\
& \text { IC }=1 ; \text { In-leakage will be set equal to zero for } \\
& \text { all groups. } \\
& \\
& \text { IC }=2 ; \text { In-leakage will be read as input data. }\end{aligned}$ \\
\hline & & $\begin{aligned} \text { IX }= & \text { Leakage cross-section option. } \\
& \text { IX } \neq 0 ; \text { Print out leakage cross section that is, } \\
& \text { Leakage out } / \text { Flux integral. } \\
& \text { IX }=0 ; \text { Donot print leakage cross section. }\end{aligned}$ \\
\hline 4000 & $6 \mathrm{E} 12.5$ & $\begin{array}{l}\Sigma_{\mathrm{REM}(\mathrm{j})} \text { The total group-dependent removal cross } \\
\text { section defined as } \Sigma_{\mathrm{REM}}=\Sigma_{\mathrm{TRANSFER}}+\Sigma_{\mathrm{F}}+\Sigma_{\mathrm{C}} .\end{array}$ \\
\hline 7000 & $6 \mathrm{E} 12.5$ & $\chi_{(\mathrm{j})} \quad$ Fission neutron spectrum. \\
\hline 8000 & $6 \mathrm{E} 12.5$ & $\begin{array}{l}\sum_{j \rightarrow k} \text { Group-dependent transfer (slowing-down) } \\
\text { cross section. The transfer matrix from each group } \\
\text { is entered on a separate card. }\end{array}$ \\
\hline 9000 & $6 \mathrm{E} 12.5$ & $\int \phi \quad$ Region-integrated flux. \\
\hline 10000 & $6 \mathrm{E} 12.5$ & In-leakage. Entered if $I C=2$. \\
\hline 11000 & F12.5 & Normalization factor for fission source. \\
\hline
\end{tabular}


C Neutron balance code

DIMENSIONFLUX(16), FISS(1),SIGRE(16), SIGSC (16.5), PISP(16), 1SIGCA(16), SCAT (16), TOPRE (17), TOTCA(17), TOTSC(17), FISOR(17), 2SCATFR $(16,5), \operatorname{SCA} T O(16,21), S C A T T O(17), T O T S O R(17)$, SLEAK (17), 3PROB (1), XSECY (16), DISC(12), SLEAKI(1) , SIGTK(16), SIGJJ (16)

26 READ $5, P R O B,(D I S C(K), K=1,12)$

PRINT 1

PRINT2,PROB, (DISC $(K), K=1,12)$

READ $3, N, M, I C, I X$

PRINT $85, N, M, I C, I X$

IF $(N) 27,27,28$

28 CONTINUE

70 READ $4,(S I G R F(K), K=1,16)$

72 READ $4,\{F \mid S P(K), K=1,16)$

DO $29 K=1.16$

$29 \operatorname{READ} 4,(\operatorname{SIGSC}(K, j), J=1,5$,

27 READ $4,($ FLUX $(K), K=1,16)$

IF (IC-1)16,80,43

16 DO $7 K=1,16$

7 SLEAKI $(K)=S L E A K(K)$

GO TO 42

80 DO $81 \quad K=1,16$

81 SLEAKI $(K)=0.0$

GO TO 42

43 READ $4,($ SLEAKI $(K), K=1,16)$

42 READ 6,FISS

DO $30 K=1.16$

$30 \operatorname{SCAT}(K)=0.0$

DO $12 K=1,16$

DO $12 \mathrm{~J}=1,5$

SCAT $(K)=\operatorname{SCAT}(K)+\operatorname{SIGSC}(K, J)$

$S I G C A(K)=S I G R E(K)-S C A T(K)$

TOTRE $(K)=S$ IGRE $(K) * F L U X(K)$

$\operatorname{TOTCA}(K)=\operatorname{SIGCA}(K) * F L U X(K)$

TOTSC $(K)=S C A T(K) * F L U X(K)$

$\operatorname{SCATFR}(K, J)=\operatorname{SIGSC}(K, J) \oplus F L U X(K)$

$F I S O R(K)=F I S P(K) \otimes F I S S$

$L=K+J$

$12 \operatorname{SCATO}(K, L)=S C A T F R(K, J)$

90 PRINT 45

PRINT 46

DO $4 K=1.16$

44 PRINT $9, K, F L U X(K), S I G R E(K), F I S P(K), S L E A K I(K), S I G C A(K)$

RRINT 8

PRINT 10

DO $11 K=1,16$

11 PRINT $9, K,(S I G S C(K, J), J \equiv 1,5)$

PRINT 33, FISS

DO $31 L=2,16$

31 SCATTO $(L)=0.0$

DO $13 L=2,16$

DO $13 K=1,16$

13 SCATTO $L I=S C A T T O(L)+S C A T O(K, L)$

SCATTO(1) $=0.0$

$\operatorname{SLEAK}(17)=0.0$

SCATTO $(17)=0,0$

TOTRE (17) $=0.0$

$\operatorname{TOTCA}(17)=0.0$

TOTSC $(17)=0,0$

FISOR (17) $\approx 0.0$

SLEAKI $(17)=0,0$ 


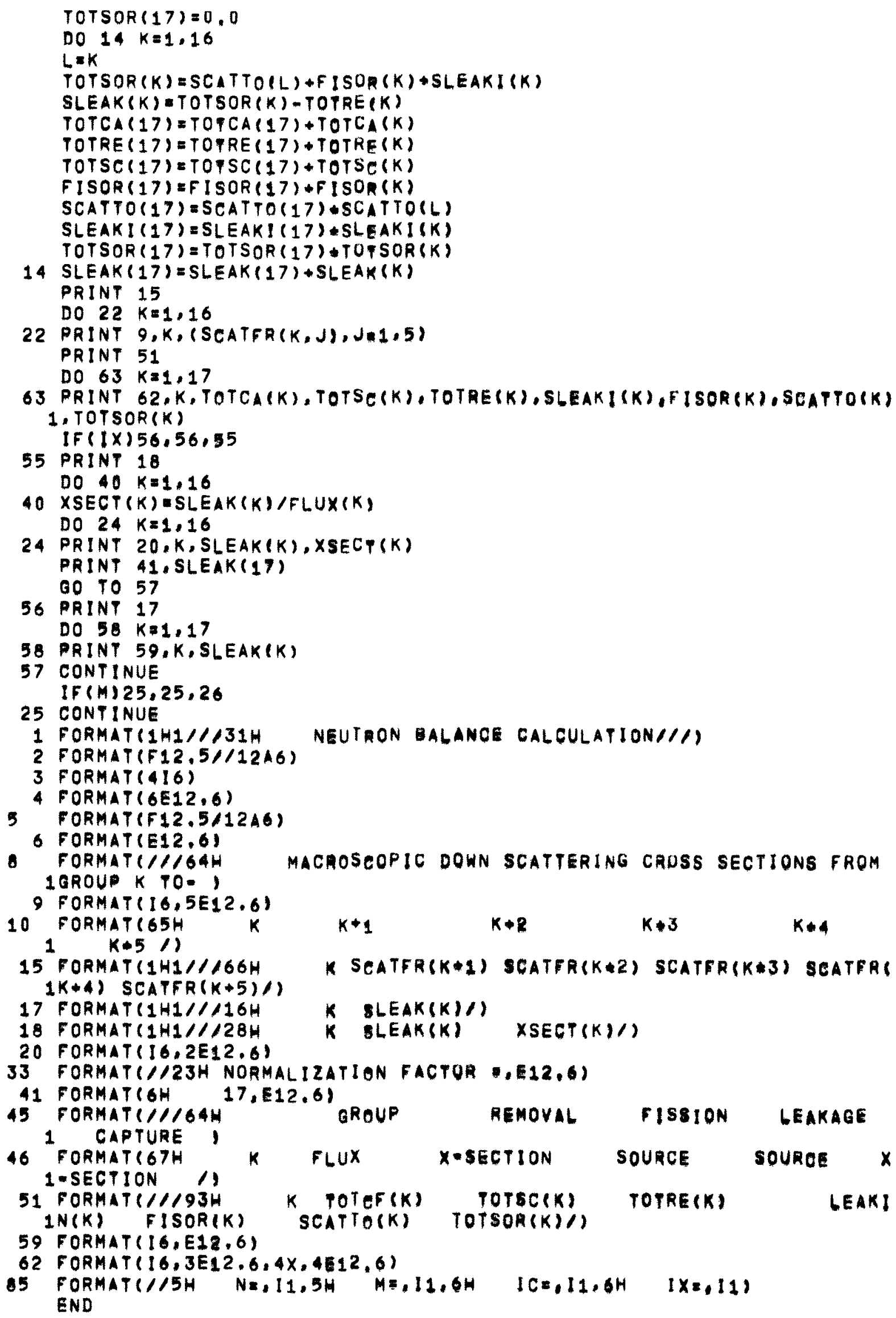


APPENDIX C

A FORTRAN Code for Optimizing Control-vane Thickness Written for the CDC-160A Computer

The determination of an optimum control-vane thickness by the controlvane curtain technique described in Section II requires a large number of fairly similar calculations by transport or diffusion theory. The method is thus expensive both in terms of time and computer utilization. The computations cannot be speeded up by reducing the number of mesh points or loosen= ing the convergence criterion, since the quantity being determined is obtained as the difference of two separate converged eigenvalue computations. The convergence criteria, therefore, must become even more stringent as the problems become more similar.

This type of computational difficulty, in which the desired result is but a part of the output of a large and complex code, is a familiar one. An ideal way to circumvent it would be to calculate the desired result directly; however, this usually requires a special code. An alternative solution is to isolate that part of the output from a complex problem which directly deter. mines the desired quantity. Subsequently the data can be applied to cases which are similar to the base problem. The requirement of very stringent convergence for similar problems is then removed and the relevant aspects of the problem being calculated become clearer. Such a method was adopted for the code presented in this Appendix.

As noted in Section II, it was determined that a computable quantity which is very nearly proportional to the control effect of a control vane is the "weighted control function." The weighted control function or WCF is defined as the number of neutrons captured in a control vane weighted by the adjoint flux existing in the vane:

$$
\mathrm{WCF}=\sum_{j=1}^{\mathrm{m}} \phi_{j} \phi_{j}^{+} \Sigma_{\text {Cap } j}
$$

The control span is proportional to the difference in the integrals of WCF. The integration is over the control vane while it is first in the IN and then the OUT position:

$$
\text { control span } \propto \int_{\text {Vane IN }}^{W C F} d v-\int_{\text {Vane OUT }}^{W C F} d v .
$$

The code presented in this Appendix calculates an optimum vane thickness with respect to the above difference. The code requires both real and adjoint fluxes as input. It can compute the optimum only over a limited 
range of vane thicknesses which do not depart too far from the vane thickness of the base problem used to provide the initial $\phi$ and $\phi^{+}$values. The code was therefore used tofill in the gaps of vane thicknesses obtained by a few (usually three) sets of calculations which calculated the control span of several different vane thicknesses by the "poison curtain" technique.

The sequence of the calculations performed by the code is as follows (see Fig. C-1):

1. From initial real and adjoint flux values the distribution of the WCF over the control vane is determined.

2. The distribution is approximated by a least-squares fit to a third-degree polynomial.

3. The obtained polynomial is used in calculating the integral of the WCF over the control vane. In this aspect the optimization code is superior to the initial curtain-type calculation since the actual volume of the control vane is used. (In the "curtain" calculation the poison material of the vane is spread over a ring concentric with the core.)

4. The procedure is repeated for the vane in the OUT position, and the difference in the integrated WCF is obtained.

5. The thickness of the control vane is changed by a small amount.

6. The WCF at the edge of the new control vane is extrapolated from existing data and a new least-squares fit to the extrapolated WCF distribution is obtained.

7. The calculation is repeated. The iterative procedure is ter minated when the difference of the integrated WCF has reached a peak or when the thickness of the vane exceeds half the control-drum radius.

The weak point of the code is in the extrapolation of the WCF distribution to new vane thicknesses. It was found that the extrapolation loses credibility when the vane thickness being calculated departs from the initial vane thickness by $50 \%$. Even with this limitation, the code was very useful in the survey calculations and significantly reduced the time during which the big computers were employed. An important additional benefit is that the parameters contributing to the control span are dealt with directly in the code and consequently the calculator becomes thoroughly familiar with them. It is possible that the code might find use in the future and it is therefore presented in some detail. In the subsequent pages the flow sheet of the code, its input specifications and the FORTRAN writeup are given. 
START

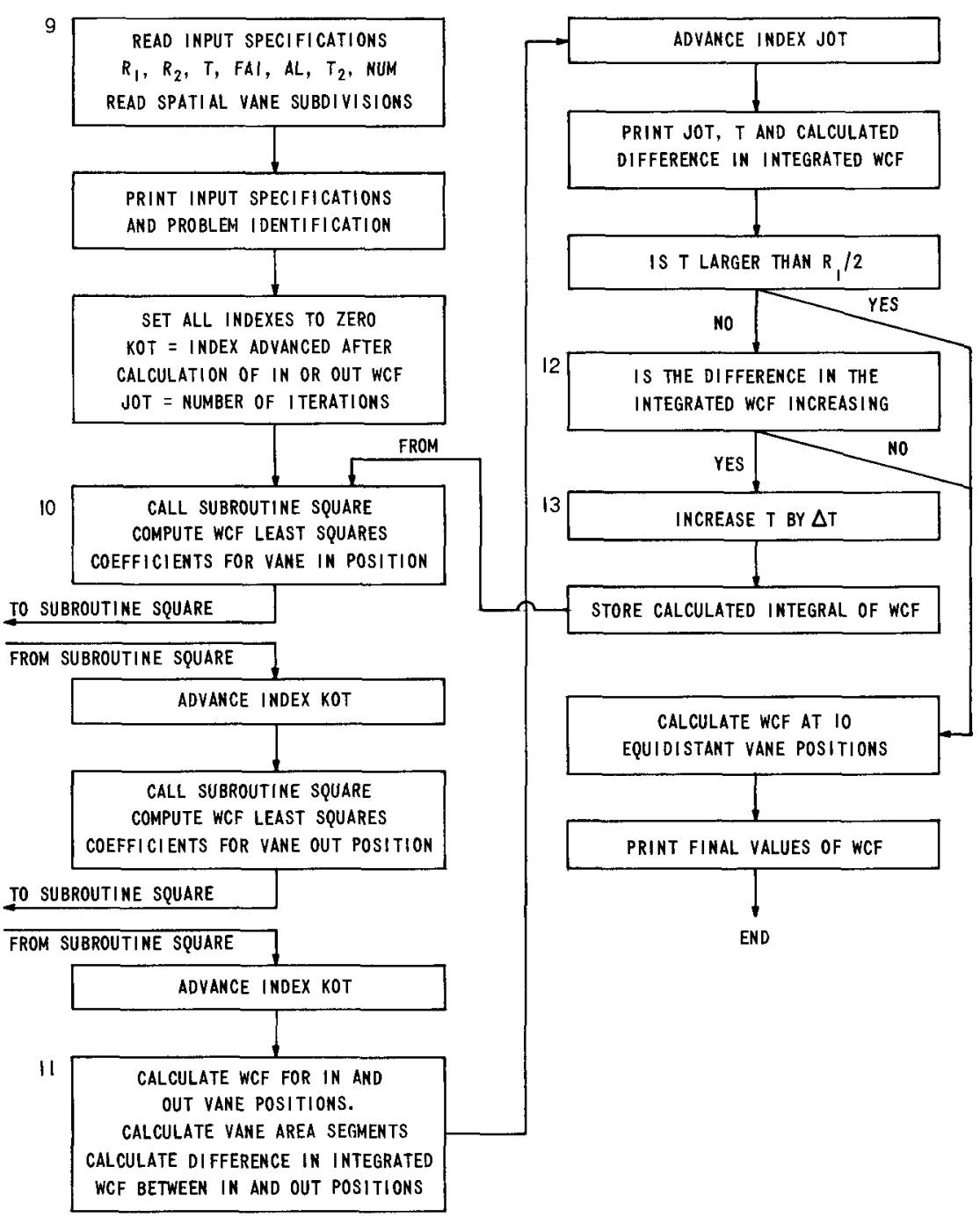

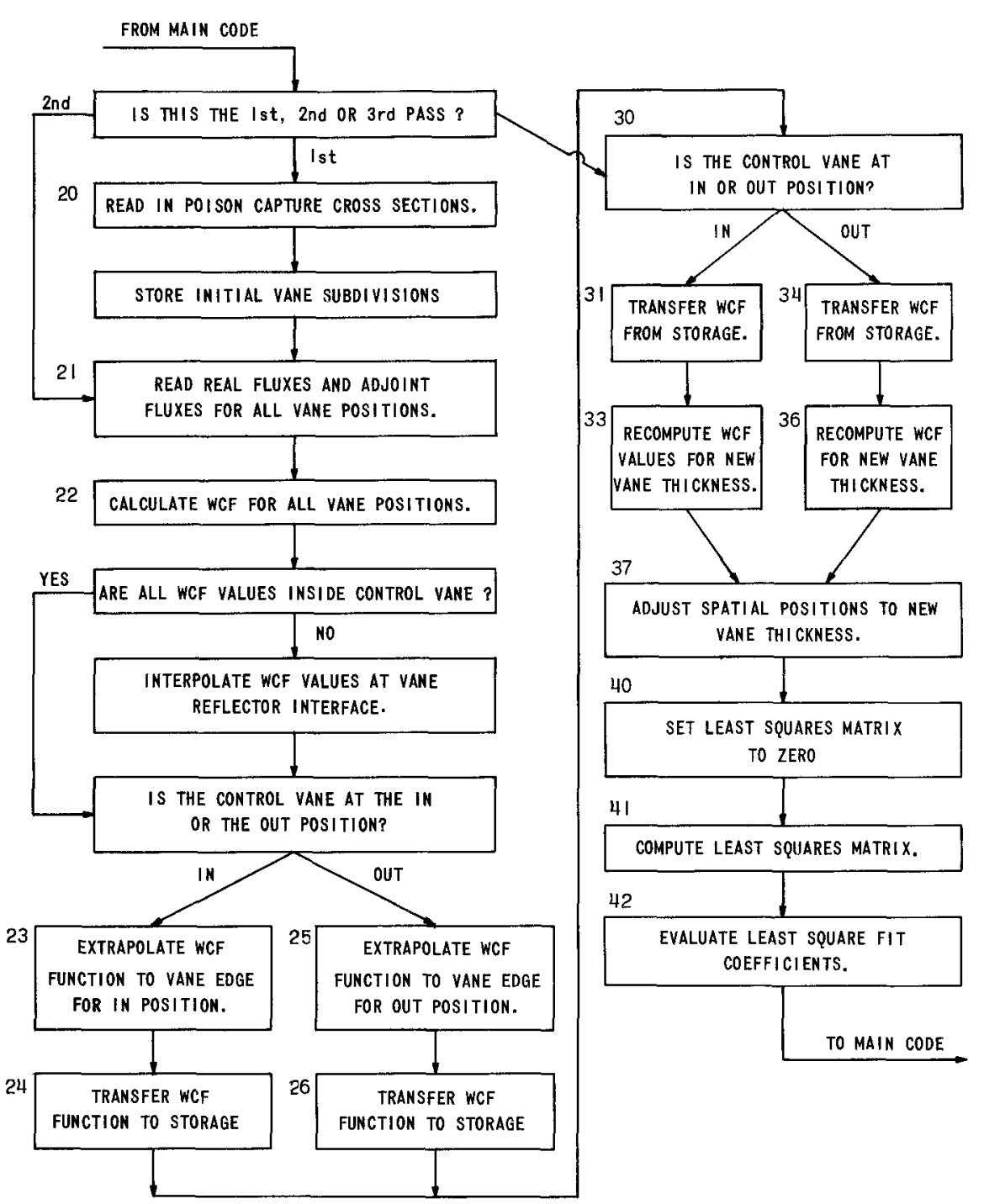

Fig. C-1. Diagram of Vane-optimization Code 
Input Specifications

\begin{tabular}{|c|c|c|}
\hline Card No. & Format & Input Description \\
\hline \multirow[t]{9}{*}{100} & $6 \mathrm{E} 10.4, \mathrm{I} 6$ & $\begin{array}{l}\text { Geometry specifications and input options, } R_{1}, R_{2} \text {, } \\
\text { T, FAI, AL, } T_{2} \text {, NUM. }\end{array}$ \\
\hline & & $\mathrm{R}_{1}=$ Control-drum radius. \\
\hline & & $R_{2}=$ Distance of control drum from core centerline. \\
\hline & & $\mathrm{T}=$ Initial thickness of control vane. \\
\hline & & FAI $=$ Angle (in radians) spanned by control vane. \\
\hline & & $\begin{aligned} \mathrm{AL}= & \text { Option concerning real and adjoint fluxes } \\
& \text { supplied to code. }\end{aligned}$ \\
\hline & & $\begin{array}{c}\mathrm{AL}=0 \text {; fluxes inside the control vane only: } \\
\mathrm{AL}>0 \text {; first and last flux values read are } \\
\text { outside the control vane. }\end{array}$ \\
\hline & & $\begin{aligned} \mathrm{T}_{2}= & \text { Distance of control drum from core-reflector } \\
& \text { interface. }\end{aligned}$ \\
\hline & & $\begin{aligned} \text { NUM }= & \text { Number of segments into which the control } \\
& \text { section is divided for purposes of numerical } \\
& \text { integration. }\end{aligned}$ \\
\hline 200 & $6 \mathrm{E} 12.5$ & $\begin{array}{l}\text { Spatial points for which real and adjoint flux values } \\
\text { are read. The outer edge of the vane is taken as } \\
\text { reference position. }\end{array}$ \\
\hline 300 & $6 \mathrm{E} 12.5$ & $\begin{array}{l}\text { Capture cross section of control-vane poison. } \\
\text { Macroscopic cross section or cross section per } \\
\text { absorber atom can be used. }\end{array}$ \\
\hline 400 & $6 \mathrm{E} 12.5$ & $\begin{array}{l}\text { Real and adjoint fluxes for all spatial positions. } \\
\text { First real and adjoint fluxes for the control-drum } \\
\text { IN condition, then for the control-drum OUT } \\
\text { condition are read. }\end{array}$ \\
\hline
\end{tabular}


- chntrol vane ihtcknes optimizaton

c

THE CALCULA ION OF SIGXCAPTURE\#FLUX ADJOINT FLUX, INTEGRATED OVEF

A CODE FOR COMPUTING AN OPTIMUM CONTROL VANE THICKNES BASED ON

C THE ACTUAL VANE IRFA AND MAXIMISATION OF THE DIFFERENCE OF THIS

C FUNCTION BETWEEN THE IN AND OUT POSITIONS OF THE VANE.

COMMON KOT, T,R1,R2, ALFA1, ALFA2,R

DIMENSION PIN(10), DOUP(10),R(12)

PRINT 21

9

READ 2K, R1, R2,T,PAT, ALFA1, ALFA2, NUM

READ $29,(R(1), 1=1,6)$

PRINT 22, R1,R2, NUM

PRINT 23

PRINT 24

KOT $=0$

JoT $=0.0$

OWCFT $=0.0$

10 CALL SOUARE $(A 0,11, A 2, A 3)$

KOT $=$ KOT +1

CALL SOUARE $(B 0,81,82,83)$

KOT $=$ KOT +1

$A N U M=N U M$

DELT $=T / A N U M$

WCFT $=0.0$

DO $11 \quad I=1$, NUM

AI $=1$

$X \equiv$ DELT*AI

PRIN $=A Q+A 1 * X+A 2 *(X * 2) * A 3 *(X * 3)$

PROUT $=80+B 1 * X * B 2 *(X * 2) * B 3 *(X * * 3)$

$A R E A=T E L T * F A 1 *(R 1-X+.5 * D E L T)$

WCF = ARFA (PRIN-PROUT)

11 WCFT $=W C F T+W C F$

JOT $=$ JOT +1

PRINT 25, JOF, T, WCFT

IF (2.T-R1) $12,12,14$

12

IF (OWCFT-WCF 1$) 13,13,14$

$13 T=T+$ DELT

OWCFT = WCFT

GO TO 10

14

DO $15 \mathrm{I}=1,10$

$A I=1$

$U=(T / 10) * A$.

PIN(I) $=A D+A I * U+A 2 *(U * * 2) * A 3 *(U * * 3)^{\circ}$

POUT $(1)=B O+B 1 * U+B 2 *(U * 2) * B 3 *(U * 3)$

15

CONTINUE

PRINT 27

PRINT 28, (PIN(I), POUT(I), I =1,10)

GO Iก 9

FORMATI42HI OPTIMITATION OF CONTROL VANE THICKNES,

22 FORMAT $/ 44 \mathrm{H}$ DRUM RADIUS $=E 12,5,36 \mathrm{H}$

$C E R=F 12.5,22 \mathrm{H}$

VANE MESH POINTS

DRUM DISTANCE FROM CORE CEN"

FORMAT $(/ / / 42 H$

FORMAT $146 \mathrm{H}$ ITTERATION NUMBER

FORMAT $(110 X,(2,4 X$, DE12.5)

FORMAT $(6 E 10.4 .16)$

FORMAT (//47H IMPORTANCE FUNCT IN VANE

FORMAT (5X,F12.5,10X,E12.5)

FORMAT (6E12, S)

ENก

SUBROUTINE SRUARE $(\times 1, \times 2, \times 3, \times 4)$

COMMON KOT, T',R1, R2, ALFA1, ALFA2, R

DIMENSION F (16), PA $(16), S I G(16), H(18), R(12), B(4,5), A(4,5)$

IF $(K 0 T-1) 20,21,3 n$ 


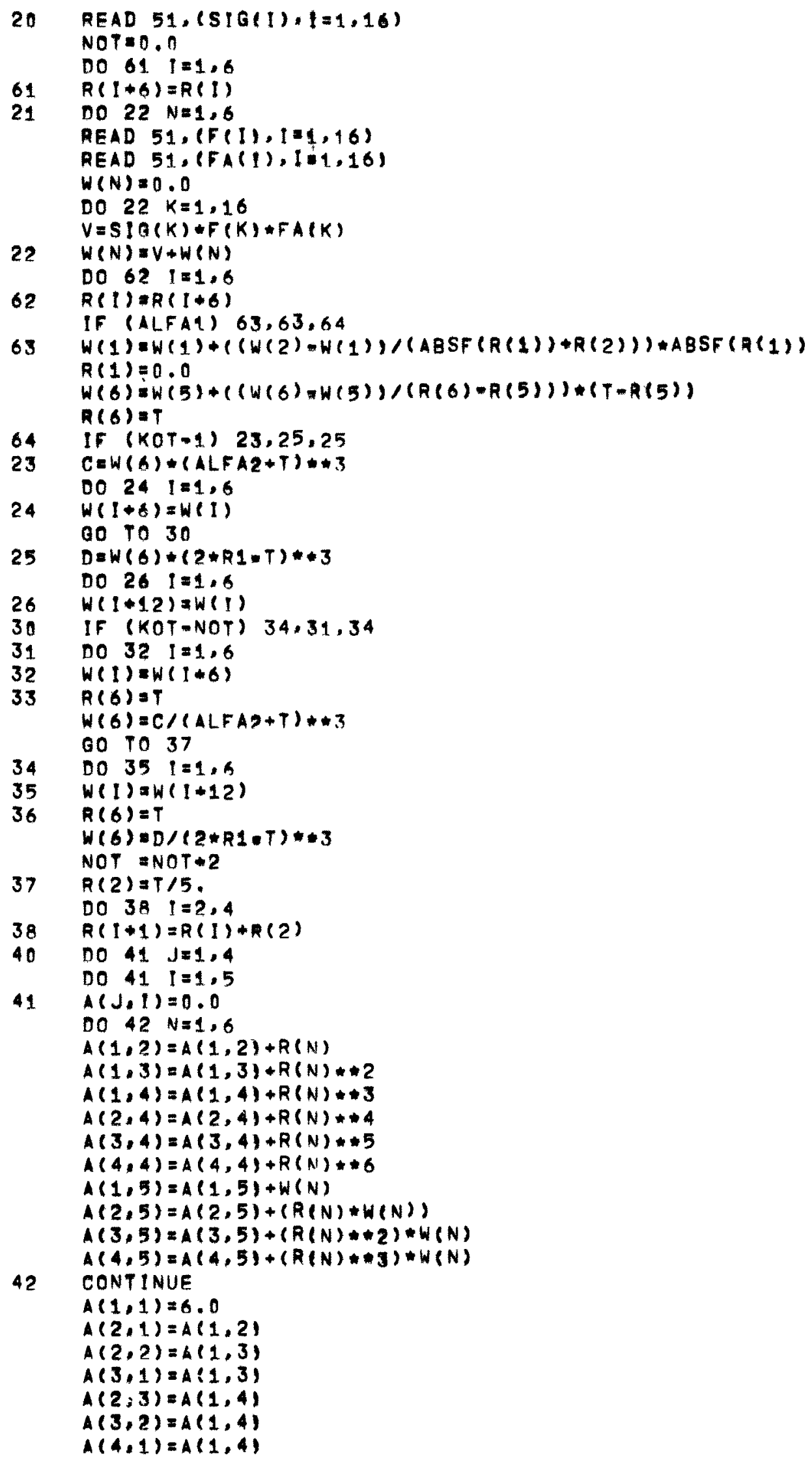




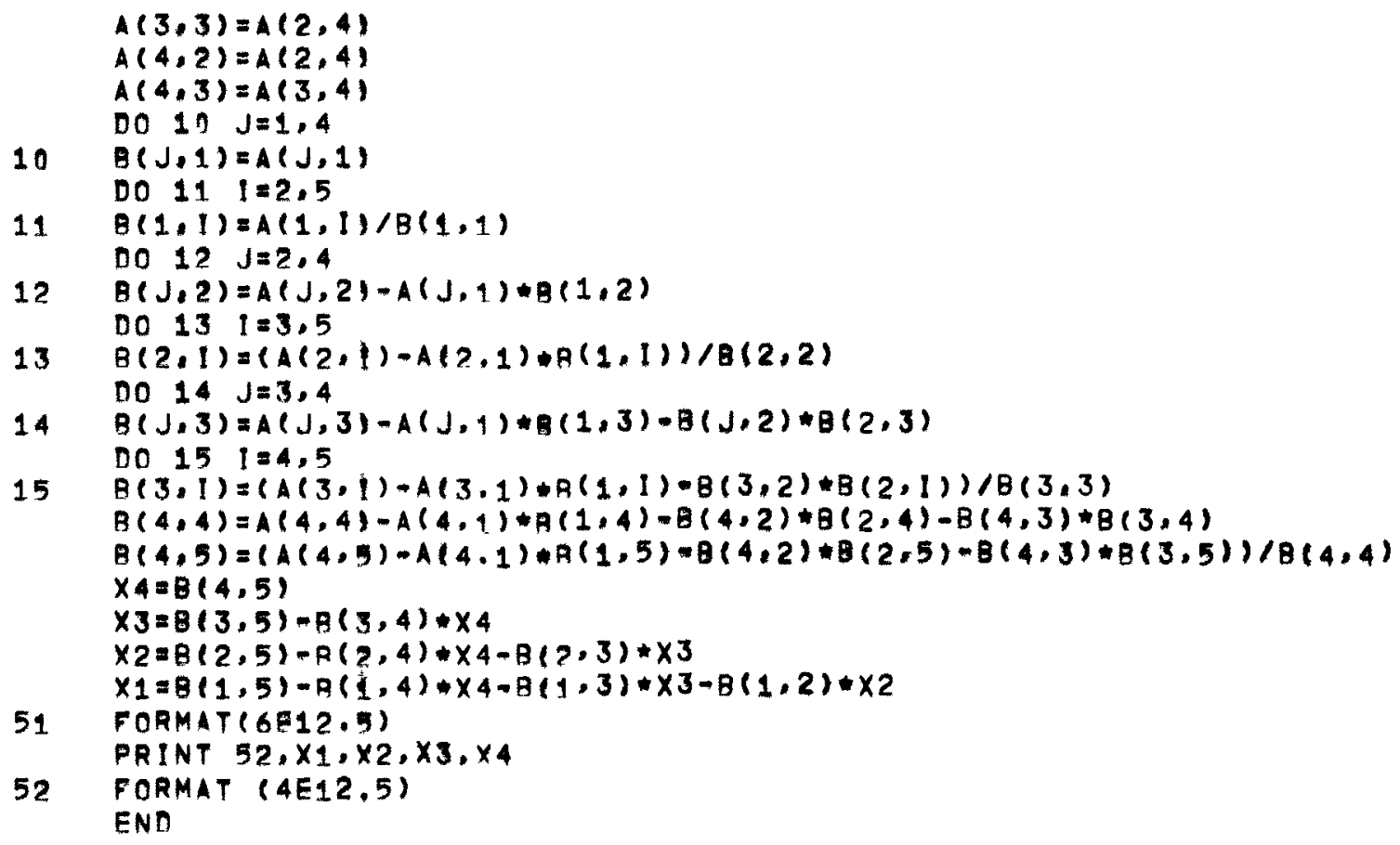




\section{APPENDIX D}

\section{An Analytical Determination of Optimum Control-vane Thickness}

An analytical determination of an optimum vane thickness for an unself-shielded control vane is presented. The control-vane thickness is optimized with respect to the distance over which the poison is transported from an idealized core boundary.

In the present derivation, an increase in vane thickness is considered to have two effects. The first is an increase in the poison volume, the second a reduction in the average distance over which the poison is transferred between the IN and OUT positions of the control drums. At a certain distance the product of the poison volume and the distance over which the poison is transferred becomes maximum. The control-vane thickness corresponding to this poison volume and maximum distance of poison transfer is the object of this calculation.

The parameters of the derivation are defined by Fig. D-1.

$$
\begin{aligned}
& {\left[\begin{array}{l}
\text { Average distance } \\
\text { of control poison } \\
\text { at drums IN position }
\end{array}\right]=\bar{R}_{I N}=\frac{\int_{0}^{\phi}\left[R_{2}-\cos \theta\left(R_{1}-1 / 2 T\right)\right]\left[T\left(R_{1}-1 / 2 T\right] d \theta\right.}{\int_{0}^{\phi} T\left(R_{1}-1 / 2 T\right) d \theta}} \\
& =R_{2}-\frac{\left(R_{1}-1 / 2 T\right)}{\phi} \sin \phi \\
& {\left[\begin{array}{l}
\text { Average distance of } \\
\text { control poison at } \\
\text { drums OUT position }
\end{array}\right]=\bar{R}_{\text {OUT }}=\frac{\int_{0}^{\phi}\left[R_{2}+\cos \theta\left(R_{1}-1 / 2 T\right)\right]\left[T\left(R_{1}-1 / 2 T\right)\right] d \theta}{\int_{0}^{\phi} T\left(R_{1}-1 / 2 T\right) d \theta}} \\
& =R_{2}+\frac{\left(R_{1}-1 / 2 T\right)}{\phi} \sin \phi \\
& \text { Poison volume }=A=2 \int_{0}^{\phi} T\left(R_{1}-1 / 2 T\right) d \theta=2 T \phi\left(R_{1}-1 / 2 T\right) \\
& \overline{\mathrm{R}}_{\text {OUT }}-\overline{\mathrm{R}}_{\mathrm{IN}}=\frac{2}{\phi}\left(\mathrm{R}_{1}-1 / 2 \mathrm{~T}\right) \sin \phi \\
& {\left[A x\left(\bar{R}_{\text {OUT }}-\bar{R}_{I N}\right)\right]=P_{(T)}=4 T \sin \phi\left(R_{1}-1 / 2 T\right)^{2}}
\end{aligned}
$$




$$
\begin{gathered}
\frac{d P(T)}{d T}=4 \sin \phi\left[\left(R_{1}-1 / 2 T\right)^{2}-T\left(R_{1}-1 / 2 T\right)\right]=4 \sin \phi\left[R_{1}^{2}-2 R_{1} T+3 / 4 T^{2}\right] \\
\Leftrightarrow \frac{d P(T)}{d T}=0 \quad 3 T^{2}-8 R_{1} T+4 R_{1}^{2}=0 \\
T=\frac{8 R_{1} \pm \sqrt{64 R_{1}^{2}-48 R_{1}^{2}}}{6}=\frac{4 R_{1} \pm 2 R_{1}}{3}
\end{gathered}
$$

therefore

$$
\text { Optimum } \mathrm{T}=\frac{2}{3} \mathrm{R}_{1} \text {. }
$$

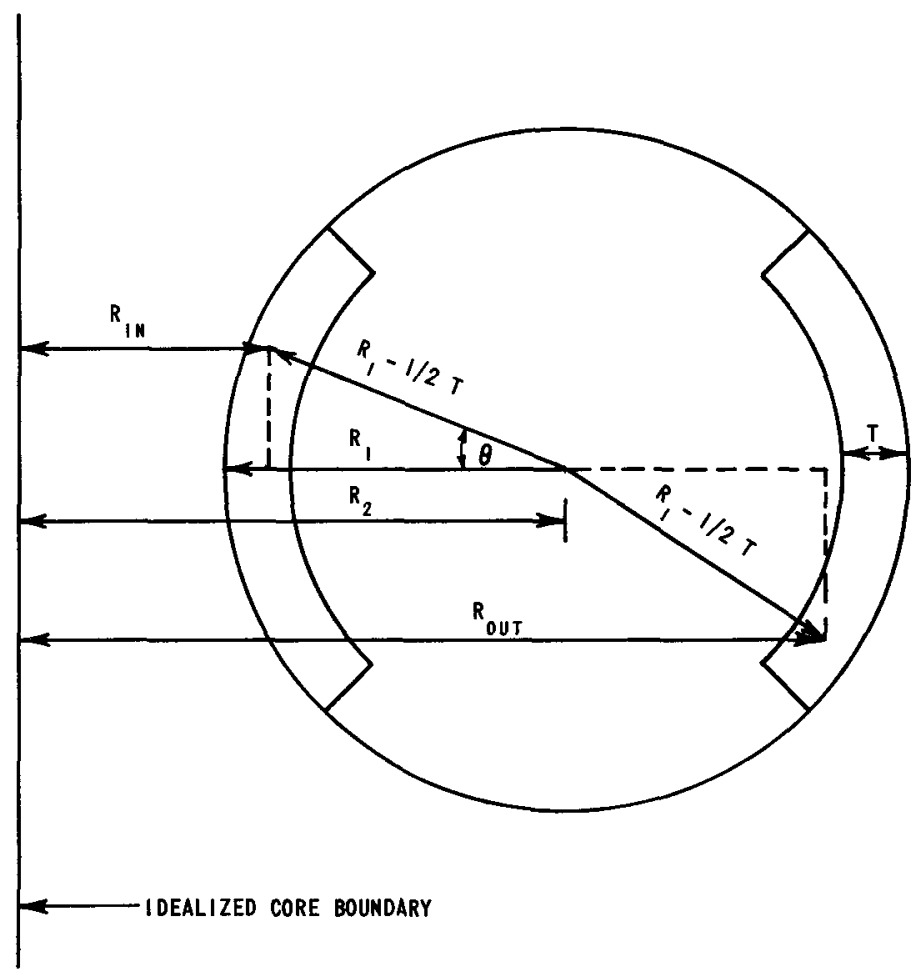

Fig. D-1. Schematic Representation of Control Vane and Idealized Core Boundary 


\section{REFERENCES}

1. K. Almenas, Study of Reflector-based Control of Fast Nuclear Rocket Reactors, Trans. Am. Nucl. Soc. 8(1), 165-166 (June 1965) Summary.

2. W. G. Knapp et al., Physics Measurements of Modified Tungsten-based Aluminum-reflected Fast Reactors, Trans. Am. Nucl. Soc. $\underline{8}(1), 241$ (June 1965) Summary.

3. R. C. Doerner, W. G. Knapp, and K. Almenas, Physics Measurements in Tungsten-based Aluminum-reflected Fast Reactors, Trans. Am. Nuc1. Soc. $7(2), 236$ (Nov 1964) Summary.

4. K. Almenas, R. C. Doerner, and W. G. Knapp, Properties of Al Reflectors of Fast Critical Assemblies, ibid., 304.

5. M. N. Nikolaw et al., Investigation of Neutron Flux Peaking in MuZtiplication Regions Caused by Supplementary Reflectors Made of Different Materials, Proceedings of IAEA Symposium on Exponential and Critical Experiments (Amsterdam 1963) $1,261$.

6. V. I. Golubov et al., The Influence of Supplementary Reflectors of Various Materials on the Total Number of Neutron Captures in a MC Blanket, At. Energ. 15, 327 (1963).

7. M. N. Nikolaw et al., Propagation of Neutrons in a Nickel Shield of a Fast Reactor, Proceedings of IAEA Conference on the Physics of Fast and Intermediate Reactors (Vienna 1962) 1 , 403.

8. R. C. Doerner, W. G. Knapp, K. K. Almenas, C. Cohn, R. A. Karam, W. Y. Kato, and W. B. Loewenstein, Experimental Physics Studies in Tungsten-based Fast Reactors, ANL-7110, Reactor Physics Division Annual Report, July 1, 1964 to June 30, 1965 (Dec 1965), pp. 215-221.

9. K. K. Almenas, Study of Reflector-based Control of Fast Nuclear Rocket Reactors, ibid, pp. 224-227.

10. A. V. Campise, Accuracy of the Sn Code in CelZ Calculations, NSE I, 104-110 (1960).

11. G. E. Hansen and W. H. Roach, Six and Sixteen Group Cross Sections for Fast and Intermediate Critical Assemblies, LAMS-2543.

12. W. Loewenstein and J. White, Parametric Survey of Homogeneous Unmoderated Rocket Reactors, Reactor Physics Division Annual Report, July 1 , 1963 to June 30, 1964, ANL-7010 (Jan 1965), pp. 123-127.

13. R. Kaiser and W. B. Loewenstein, Natural Tungsten Cross Sections for Fast and Intermediate Neutron Spectra, Reactor Physics Division Annual Report, July 1, 1963 to June 30, 1964, ANL-7010 (Jan 1965), pp. 129-131.

14. K. Almenas, Verification of Tungsten Cross Sections, ibia, pp. 131-134. 
15. D. C. Stupegia, M. Schmidt, and A. Madson, Fast Neutron Copture in Rhenium, [to be published in J. Nucl. Engr. (Reactor Science and Technology)].

16. W. G. Davey, A Comparison of Experimental and Calculated Promptneutron Lifetimes and Central Reactivity Coefficients in ZPR-III Assemblies and Their Relationship to Other Reactor Parameters, ANL-6682 (June 1963).

17. H. Hummel and A. Rago, An Accurate Treatment of Resonance Scattering in Light Elements in Fast Reactors, Proceedings of IAEA Seminar on Physics of Fast and Intermediate Reactors (Vienna 1962) 1, 231.

18. K. Almenas, The Neutronics of Reactor Control with Reflector Materials, Reactor Physics Division Annual Report, July 1, 1963 to June 30, 1964, ANL-7010 (Jan 1965), pp. 134-137.

19. D. Meneghetti, Recent Advances and Problems in Theoretical Analyses of ZPR-III Fast Critical Assembiies, Proceedings of IAEA Seminar on Physics of Fast and Intermediate Reactors (Vienna 1962) 1, 458. 